RODRIGo MARTINS ABREU

\title{
Avaliação dos desfechos virológicos e de adesão ao tratamento antiviral em pacientes portadores de hepatite B crônica
}

Tese apresentada à Faculdade de Medicina da Universidade de São Paulo para obtenção do título de Doutor em Ciências

Programa de Ciências em Gastroenterologia Orientadora: Profa. Dra. Suzane Kioko Ono Coorientador: Prof. Dr. Raymond Felix Schinazi

São Paulo 
Dados Internacionais de Catalogação na Publicação (CIP)

Preparada pela Biblioteca da

Faculdade de Medicina da Universidade de São Paulo

Creprodução autorizada pelo autor

\begin{abstract}
Abreu, Rodrigo Martins
Avaliação dos desfechos virológicos e de adesão ao tratamento antiviral em pacientes portadores de hepatite B crônica / Rodrigo Martins Abreu -- São Paulo, 2017.

Tese(doutorado)--Faculdade de Medicina da Universidade de São Paulo. Programa de Ciências em Gastroenterologia.

Orientadora: Suzane Kioko Ono.

Coorientador: Raymond Felix Schinazi.
\end{abstract}

Descritores: 1.Hepatite B 2.Farmacorresistência viral 3.Farmacocinética 4.Adesão à medicação 5.Antivirais

USP/FM/DBD-168/17 
Aos meus pais, Waldir e Luzia, grandes exemplos em minha vida. 


\section{AGRADECIMENTOS}

Há cerca de oito anos, eu cheguei a São Paulo para iniciar a pós-graduação na Divisão de Farmácia do Hospital das Clínicas da USP. Naquele período, tive o privilégio de conhecer a Profa. Dra. Suzane Kioko Ono e, a partir daí, um longo caminho de estudos e grandes ensinamentos foi percorrido, durante o mestrado e doutorado. 'Muito obrigado, professora, por acreditar desde o início nesse projeto de adesão em hepatite B e me orientar na carreira científica e profissional'.

Nessa cidade com tantas oportunidades, tive a honra de conviver com pessoas que foram essenciais para o meu desenvolvimento profissional e pessoal. Nesse sentido, gostaria de agradecer:

Ao Prof. Dr. Flair José Carrilho, pelo incentivo à pesquisa científica que tanto valoriza, obrigado por acreditar em nosso projeto, viabilizando a concessão de uma bolsa de estudos e apoio na participação de tantos eventos científicos.

Ao Prof. Dr. Raymond Schinazi, que aceitou coorientar essa pesquisa e recebeu-me em seu laboratório na Emory University por seis meses, em Atlanta - EUA. Foi uma honra trabalhar com ele durante esse período e fazer parte do seu grupo. Em especial, gostaria de agradecer à Profa. Dra. Leda Bassit, por seus ensinamentos e orientações, imprescindíveis para a realização desse trabalho.

À Dra. Lilia Ganova-Raeva e ao Dr. Yury Khudyakov (Centers for Disease Control and Prevention - EUA), agradeço pela valiosa ajuda em biologia molecular e apoio ao projeto. 
Aos amigos farmacêuticos da Divisão de Farmácia do Instituto Central do HCFMUSP, agradeço por todo o apoio, carinho e ensinamentos. Em especial, à Dra. Vanusa Barbosa, Dra. Márcia Marin e Dra. Andrea Sforsin, por apoiarem, desde o início, esse projeto e gentilmente autorizarem o meu afastamento para o estágio de doutorado sanduiche nos Estados Unidos. Muito obrigado pela confiança e pelo estímulo à pesquisa.

Aos farmacêuticos envolvidos no Grupo de Hepatite B, Priscilla Rocha, Ariane Minari, Mayara Dias, Júlia Pires e, especialmente, à Patrícia Alarcon, obrigado pela colaboração no atendimento aos pacientes, fundamental na coordenação das atividades desse ambulatório. Agradeço também aos residentes e aprimorandos da Divisão de Farmácia, especialmente, à Talita Rocha e Mislene Bispo. Esse trabalho não seria possível sem a colaboração dessas pessoas.

Ao Programa de Hepatites Virais da Secretaria de Saúde do Estado de São Paulo, em especial à Dra. Claudia Binelli, por nos apoiar na confecção da cartilha "Juntos contra a Hepatite B", essencial nas intervenções junto aos pacientes.

Aos médicos da Unidade 2MG 0404, especialmente Dr. Luis Claudio Mendes e seus residentes, por auxiliarem na condução do trabalho.

Ao Departamento de Gastroenterologia: Claudia Arruda, Renato Madrid, Fátima Gomes, Nalva Moraes, Fabiana Bispo e Vilma Libério, agradeço pela ajuda e pela atenção.

Aos membros da banca do exame de qualificação: Prof. Dr. Edson Abdala, Profa. Dra. Eliana Battaggia Gutierrez e Prof. Dr. Eduardo Lani Volpe da Silveira, agradeço pela leitura criteriosa, com valiosos ensinamentos e correções. 
À Dra. Aline Siqueira Ferreira, obrigado pela amizade, ajuda estatística e entusiasmo com esse trabalho.

Aos amigos que fiz no grupo da Dra. Suzane, durante todos esses anos, em que o projeto foi desenvolvido: Helena Paschoale, Ana Maria Souza, Paulo Nasser, Camila Ferreira, Fernanda Campos, Júlia Pires, Natália Ribeiro, Mariana Nabeshima, Bianca Sanctis, Raeldes Barros, Denise Ferreira, Chris Omosako, Karen Miyamura, Rosana Braga, Victor Vaisberg, Felipe Pereira e Vera Kim, meu respeito e reconhecimento pelo auxílio dispensado nas várias fases desse trabalho.

Aos amigos, Francis Manzoni, Camila Monteiro, Josiane Caneschi e Henrique Santos, que ajudaram na revisão desse trabalho. Obrigado por todo o apoio e amizade.

Meu especial agradecimento ao Conselho Nacional de Desenvolvimento Científico e Tecnológico (CNPq) (processo 201812/2014-2), Alves de Queiroz Family Fund for Research, mServices e Raymond F. Schinazi and Family Foundation pelo auxílio financeiro, sem os quais esse trabalho não seria possível.

Aos pacientes, principal motivação desta pesquisa. 
"A doença é o lado escuro da vida, uma cidadania mais onerosa. Todos que nascemos temos essa dupla cidadania, no reino da saúde e no reino da doença. Embora todos gostaríamos de usar só o bom passaporte, mais cedo ou mais tarde, cada um de nós é obrigado, pelo menos por um tempo, a se identificar como cidadãos daquele outro lugar."

Susan Sontag, (1933-2004). 


\section{NORMALIZAÇÃO ADOTADA}

Esta tese está de acordo com as seguintes normas, em vigor no momento desta publicação:

Referências: adaptado de International Committee of Medical Journals Editors (Vancouver).

Universidade de São Paulo. Faculdade de Medicina. Divisão de Biblioteca e Documentação. Guia de apresentação de dissertações, teses e monografias. Elaborado por Anneliese Carneiro da Cunha, Maria Julia de A. L. Freddi, Maria F. Crestana, Marinalva de Souza Aragão, Suely Campos Cardoso, Valéria Vilhena. 3a ed. São Paulo: Divisão de Biblioteca e Documentação; 2011.

Abreviaturas dos títulos dos periódicos de acordo com List of Journals Indexed in Index Medicus. 


\section{Sumário}

Lista de abreviaturas, símbolos e siglas

Lista de figuras

Lista de tabelas

Resumo

Summary

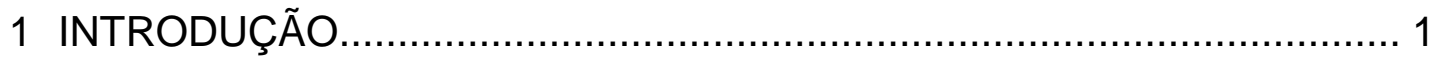

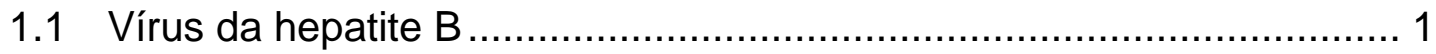

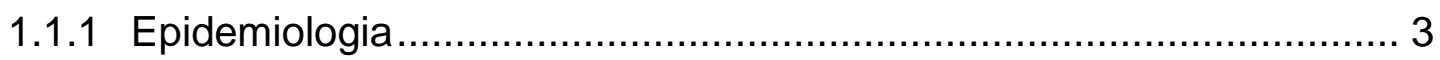

1.1.2 Infecção pelo HBV no Brasil ................................................... 5

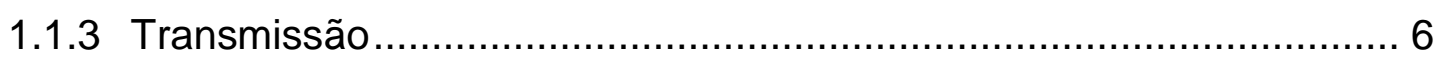

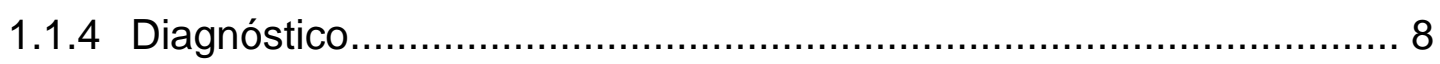

1.1 .5 Arsenal terapêutico ......................................................... 10

1.1 .6 Resistência antiviral ............................................................ 12

1.2 Adesão ao tratamento ............................................................. 14

1.2.1 A adesão ao tratamento na hepatite B crônica.............................. 16

2 OBJETIVOS.............................................................................. 19

2.1 Objetivo Geral.............................................................. 19

2.2 Objetivos Específicos .......................................................... 19

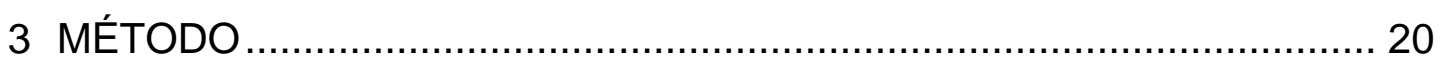

3.1 Delineamento do estudo....................................................... 20

3.2 Caracterização do serviço .................................................. 22

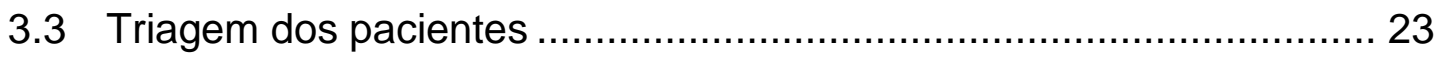

3.4 Seleção da população em estudo ............................................ 23

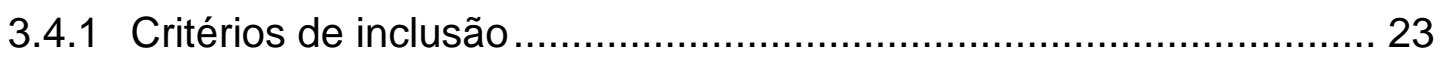

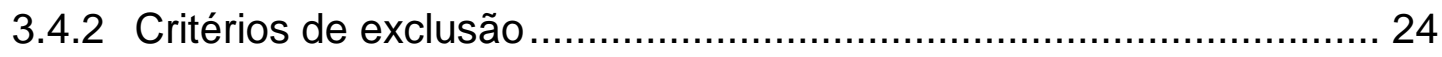

3.4.3 Diagnóstico primário...................................................... 24

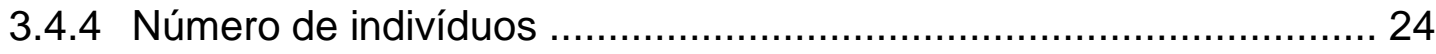

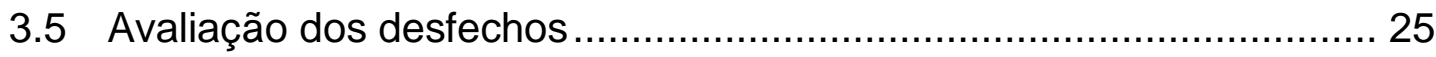

3.6 Avaliação de adesão ao tratamento antiviral por métodos indiretos.... 25

3.7 Avaliação de adesão ao tratamento antiviral por método direto .......... 27

3.7.1 Pacientes e amostras ....................................................... 27 
3.7.2 Quantificação plasmática do antiviral

3.8 Genotipagem do HBV e pesquisa de variantes de resistência antiviral28

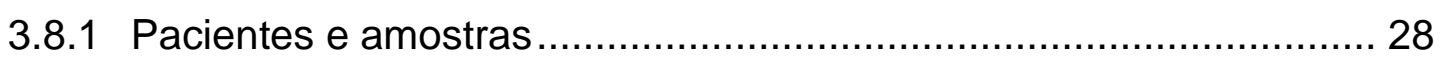

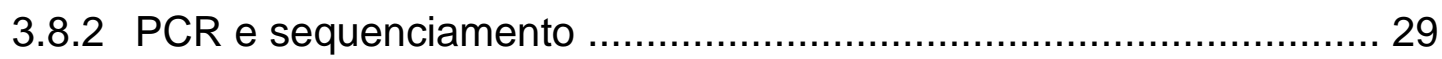

3.9 Procedimento de coleta........................................................... 30

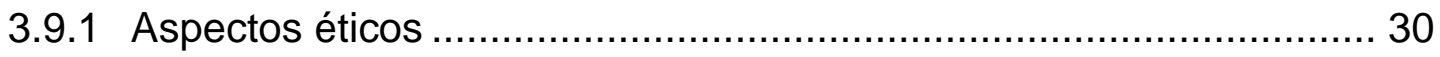

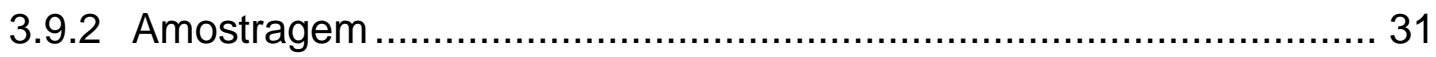

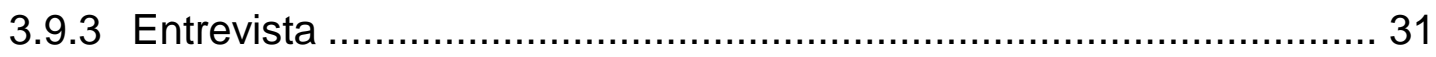

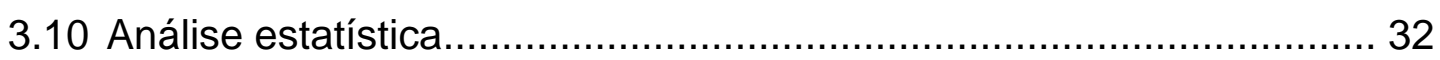

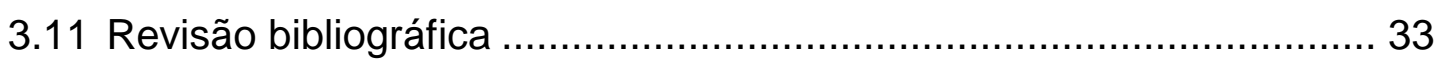

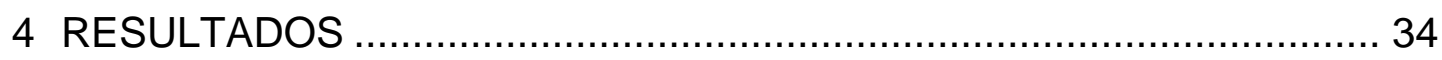

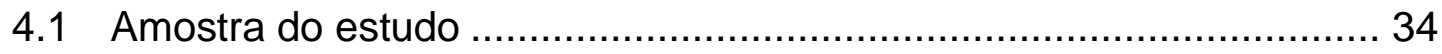

4.2 Caracterização da amostra do estudo ............................................. 37

4.3 Desfecho primário ................................................................ 42

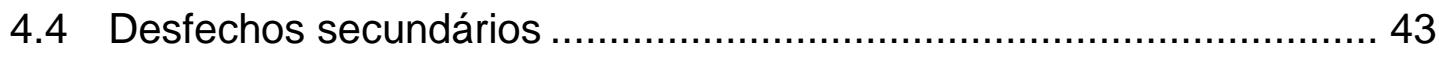

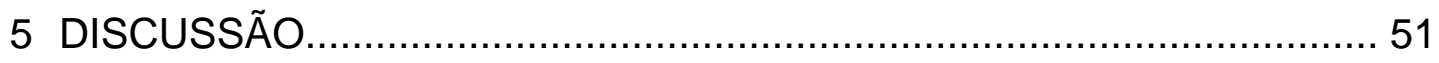

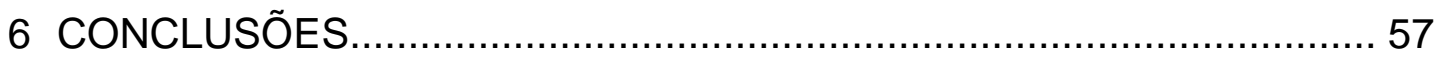

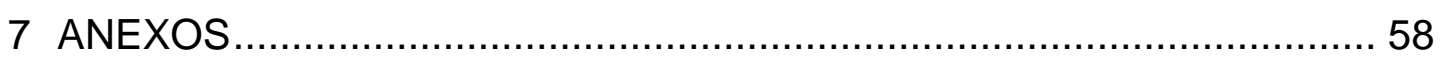

7.1 Anexo A - Cartilha "Juntos contra a Hepatite B" .............................. 58

7.2 Anexo B - CEAT-HBV - "Questionário para avaliação da adesão ao tratamento antiviral em pacientes portadores de hepatite B crônica" .......... 59

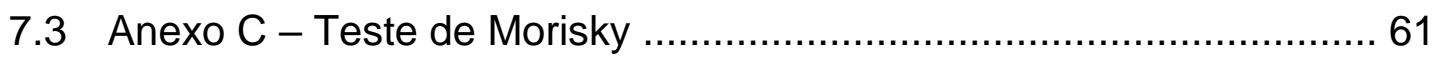

7.4 Anexo D - Protocolo de Nested PCR para amplificação do HBV-DNA62

7.5 Anexo E - Aprovação do protocolo de pesquisa ................................. 63

7.6 Anexo F - Termo de Consentimento Livre e Esclarecido...................... 64

7.7 Anexo G - Aprovação do protocolo de pesquisa com finalidade de

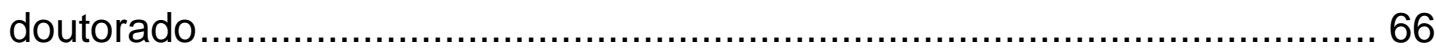

7.8 Anexo $\mathrm{H}$ - Aprovação dos documentos relacionados ao doutorado sanduíche

7.9 Anexo I - Quantificação plasmática dos antivirais por CL-MS/MS ...... 69

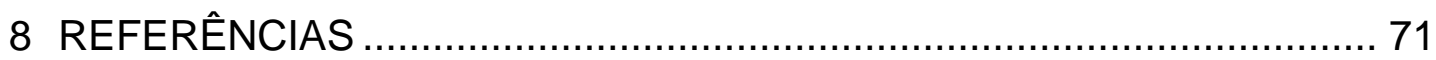




\section{LISTA DE ABREVIATURAS, SÍMBOLOS E SIGLAS}

\begin{tabular}{|c|c|}
\hline$\%$ & por cento \\
\hline$>$ & maior que \\
\hline$\geq$ & maior que ou igual a \\
\hline$<$ & menor \\
\hline- & negativo \\
\hline+ & positivo \\
\hline$=$ & igual a \\
\hline \pm & mais ou menos \\
\hline 2MG40 & Grupo do Fígado \\
\hline 2MG 0404 & nome da Unidade \\
\hline A2MG & Ambulatório do Serviço de Gastroenterologia \\
\hline $\mathrm{AgHBc}$ & antígeno core do HBV \\
\hline $\mathrm{AgHBe}$ & antígeno e do HBV \\
\hline $\mathrm{AgHBs}$ & antígeno de superfície do HBV \\
\hline AIDS & Síndrome da Imunodeficiência Adquirida \\
\hline ALT & alanina aminotransferase \\
\hline anti-HBc & anticorpos contra o antígeno core do HBV \\
\hline anti-HBe & anticorpos contra o antígeno e do HBV \\
\hline anti-HBs & anticorpos contra o antígeno de superfície do HBV \\
\hline AST & aspartato aminotransferase \\
\hline CAPPesq & $\begin{array}{l}\text { Comissão de Ética para Análise de Projetos de Pesquisa } \\
\text { do HCFMUSP }\end{array}$ \\
\hline CEAT-VIH & $\begin{array}{l}\text { do espanhol, Cuestionario para la Evaluación de la } \\
\text { Adhesión al Tratamiento Antiretroviral }\end{array}$ \\
\hline CEAT-HBV & $\begin{array}{l}\text { Questionário para avaliação da adesão ao tratamento } \\
\text { antiviral em pacientes portadores de hepatite } B \text { crônica } \\
\text { (versão do CEAT-VIH, validado para hepatite B crônica) }\end{array}$ \\
\hline $\mathrm{CHC}$ & carcinoma hepatocelular \\
\hline CL-MS/MS & $\begin{array}{l}\text { cromatografia líquida acoplada a espectrômetro de massa } \\
\text { em tandem }\end{array}$ \\
\hline DeCS & Descritores em Ciências da Saúde \\
\hline DNA & ácido desoxirribonucléico \\
\hline Dr. & Doutor \\
\hline
\end{tabular}




$\begin{array}{ll}\text { Dra. } & \text { Doutora } \\ \text { EUA } & \text { Estados Unidos } \\ \text { FDA } & \text { do inglês, Food and Drug Administration } \\ \text { HBx } & \text { proteína X do HBV } \\ \text { HC } & \text { Hospital das Clínicas } \\ \text { HCFMUSP } & \text { Hospital das Clínicas da Faculdade de Medicina da } \\ & \text { Universidade de São Paulo } \\ \text { HBV } & \text { vírus da hepatite B } \\ \text { HBV-DNA } & \text { carga viral de HBV } \\ \text { HCV } & \text { vírus da hepatite C } \\ \text { HIV } & \text { vírus da imunodeficiência humana } \\ \text { ITT } & \text { do inglês, intention-to-treat } \\ \text { MeSH } & \text { do inglês, Medical Subject Headings } \\ \text { mL } & \text { mililitro } \\ \mathrm{n} & \text { número de observações na série } \\ \text { no } & \text { número } \\ \text { OMS } & \text { Organização Mundial da Saúde } \\ p & \text { probabilidade calculada / aproximada } \\ \text { PCR } & \text { reação em cadeia da polimerase } \\ \text { Prof. } & \text { Professor } \\ \text { Profa. } & \text { Professora } \\ \text { Q1 - Q3 } & \text { intervalo interquartil } \\ \mathrm{r} & \text { coeficiente de correlação de Spearman } \\ \text { RT } & \text { do inglês, reverse transcriptase (transcriptase reversa) } \\ \text { SPSS } & \text { do inglês, Statistical Package for the Social Sciences } \\ \text { SUS } & \text { Sistema Único de Saúde } \\ \text { TCLE } & \text { Termo de Consentimento Livre e Esclarecido } \\ \text { UI } & \text { unidade internacional } \\ & \end{array}$




\section{LISTA DE FIGURAS}

Figura 1. Vírus da hepatite B 1

Figura 2. Distribuição geográfica dos genótipos e subgenótipos do HBV...... 2

Figura 3. Estimativa de soroprevalência do AgHBs positivo no mundo ......... 3

Figura 4. Prevalência do AgHBs em diferentes regiões geográficas ............ 4

Figura 5. Taxa de detecção dos casos de hepatite B (por 100.000 habitantes), segundo faixa etária e sexo

Figura 6. Taxa de detecção dos casos de hepatite B (por 100.000 habitantes), segundo região de residência por ano de notificação

Figura 7. Distribuição percentual dos casos de hepatite $B$, segundo provável fonte/mecanismo de infecção, por ano de notificação 8

Figura 8. História natural e avaliação dos pacientes com infecção crônica pelo HBV

Figura 9. Representação esquemática das variantes do HBV e resistência antiviral

Figura 10. Representação esquemática do desenho do estudo 21

Figura 11. Curva padrão de calibração para os quatro analitos (3TC, Tenofovir, Adefovir e Entecavir). 28

Figura 12. Seleção da Amostra do Estudo 35

Figura 13. Representação esquemática das três avaliações de adesão ao tratamento e pacientes excluídos ao longo dos 4 anos de seguimento ....... 36 Figura 14. Análise dinâmica dos desfechos virológicos e de adesão ao tratamento na população per-protocol. As cores apresentam os desfechos em ordem progressiva: vermelho (pior), amarelo (intermediário) e verde (melhor). 
Figura 15. Análise dinâmica dos desfechos virológicos e de adesão ao tratamento na população ITT. As cores apresentam os desfechos em ordem progressiva: vermelho (pior), amarelo (intermediário) e verde (melhor). .... 46 Figura 16. Distribuição dos pacientes quanto as mudanças de antivirais ao longo do tempo. (A) Esquema terapêutico na primeira avaliação de adesão. HCFMUSP, dezembro de 2010 a agosto de 2011 ( $n=183$ ) (B) Esquema terapêutico na segunda avaliação de adesão. HCFMUSP, novembro de 2013 a maio de $2014(n=143)$. (C) Esquema terapêutico na terceira avaliação de adesão. HCFMUSP, julho de 2014 a março de 2015 $(n=135)$

Figura 17. Derivação da população com falha de tratamento no início do estudo 48

Figura 18. Representação esquemática das amostras de soro/plasma dos pacientes com HBV. Aproximadamente 800 pares de base da região da polimerase do HBV-DNA foram amplificados por Nested PCR e podem ser visualizados por eletroforese em gel de agarose $2 \%$. HCFMUSP, dezembro de 2010 a agosto de $2011(n=54)$.

Figura 19. Variantes de resistência antiviral analisadas pelo software DeepChek- HBV/HDV v1.4. (A) Frequência das variantes de resistência antiviral de acordo com os genótipos do HBV $(n=54)$ (B) Frequência das variantes de resistência antiviral de acordo com o esquema terapêutico $(n=$ 183). *3TC $150 \mathrm{mg}^{(66)}$. 50 


\section{LISTA DE TABELAS}

Tabela 1. Padrões sorológicos da infecção crônica pelo HBV ...................... 9

Tabela 2. Principais drogas anti-HBV aprovadas.................................. 11

Tabela 3. Características demográficas e socioeconômicas dos pacientes no início do estudo. HCFMUSP, dezembro de 2010 a agosto de 2011 $(n=183)$ 39

Tabela 4. História médica relacionada à hepatite $B$ crônica no início do estudo. HCFMUSP, dezembro de 2010 a agosto de 2011 ( $n=183$ )...... 40

Tabela 5. Informações relacionadas ao tratamento da hepatite B crônica no início do estudo. HCFMUSP, dezembro de 2010 a agosto de 2011 $(n=183)$

Tabela 6. Distribuição dos pacientes quanto ao tempo de tratamento com antivirais, em meses. HCFMUSP, dezembro de 2010 a agosto de 2011 $(n=183)$

Tabela 7. Frequência de adesão em função dos desfechos virológicos e de adesão ao tratamento pelo CEAT-HBV e Teste de Morisky, ao longo dos 4 anos de seguimento.

Tabela 8. Frequência de migração entre os grupos distribuídos por desfechos virológicos e de adesão ao tratamento antiviral ao longo do tempo, de acordo com a população per-protocol. HCFMUSP, dezembro de 2010 a março de 2015 45

Tabela 9. Frequência de migração entre os grupos distribuídos por desfechos virológicos e de adesão ao tratamento antiviral ao longo do tempo, de acordo com a população por ITT. HCFMUSP, dezembro de 2010 a março de 2015 


\section{RESUMO}

Abreu RM. Avaliação dos desfechos virológicos e de adesão ao tratamento antiviral em pacientes portadores de hepatite B crônica [Tese]. São Paulo: Faculdade de Medicina, Universidade de São Paulo; 2017.

Introdução: A adesão ao tratamento da hepatite B crônica na vida real tem sido pouco estudada em todo o mundo. Neste estudo, foram avaliados os desfechos virológicos e de adesão ao tratamento antiviral de longo prazo em pacientes monoinfectados com hepatite B crônica. Métodos: Trata-se de um estudo prospectivo de coorte com pacientes portadores de hepatite B crônica $(n=183)$, tratados com adefovir, entecavir, lamivudina e / ou tenofovir, realizado em um centro de referência terciário brasileiro. A adesão ao tratamento foi avaliada por um questionário validado, denominado CEAT-HBV, em três momentos (2010/2011, $2013 / 2014$ e 2014/2015). As variantes de resistência às drogas para hepatite $B$ e a farmacocinética de um único ponto foram determinadas por sequenciamento e cromatografia líquida com espectrômetro de massa em tandem, respectivamente. Resultados: CEAT-HBV identificou 79/183 (43\%) pacientes em não-adesão ao tratamento antiviral e entre esses, 53/79 (67\%) tinham maior frequência de HBV DNA positiva. Porém, 38\% (70/183) tiveram carga viral positiva sugerindo não resposta ao tratamento. As mais frequentes variantes de resistência aos antivirais foram M204I/V (78\%), L180M (59\%), L80I (15\%), V173L (7\%) e Q215H (6\%). As principais causas associadas com a ausência de resposta ao tratamento antiviral foram variantes de resistência às drogas (39\%), variantes de resistência às drogas e não adesão (23\%), não adesão (13\%), duração de tratamento insuficiente (10\%), e indeterminada (16\%). A farmacocinética de dose única indicou 48\% (31/65) de não adesão ao antiviral. Dois anos depois da primeira avaliação, o CEAT-HBV indicou que 101/143 (71\%) pacientes estavam em adesão ao tratamento, baseado na análise da população per-protocol. Entretanto, 21\% (40/183) dos pacientes não puderam ser avaliados e foram excluídos. As principais razões para exclusão foram óbito (20/183), 11 dos 20 óbitos causados pelo carcinoma hepatocelular, perda de seguimento (16/183) e outras (4/183). Todos os participantes receberam nesse momento uma cartilha para orientação do tratamento. A terceira avaliação do CEAT-HBV (2014/2015) mostrou que 112/135 (83\%) pacientes estavam em adesão ao tratamento (população per-protocol) e 8/143 (6\%) foram excluídos. Desfechos de longo prazo mostraram que a taxa de adesão baseado no CEAT-HBV continua a aumentar após 4 anos $(p<0,001)$. Conclusões: Nossos dados realçam a importância do monitoramento da avaliação de adesão à terapia para hepatite $B$ crônica. Desfechos de adesão de longo prazo podem ser dinâmicos e é possível aumentar a taxa de migração para o grupo com adesão/HBV DNA negativa.

Descritores: Hepatite B; Farmacorresistência Viral; Farmacocinética; Adesão à Medicação; Antivirais. 


\section{SUMMARY}

Abreu RM. Evaluation of virological and adherence outcomes regarding antiviral treatment in chronic hepatitis B patients [Thesis]. São Paulo: "Faculdade de Medicina, Universidade de São Paulo"; 2017.

Background: Chronic hepatitis $B(\mathrm{CHB})$ real-life treatment adherence has been poorly studied worldwide. In this study, it was evaluated long term virological and adherence outcomes regarding antiviral treatment in monoinfected $\mathrm{CHB}$ patients. Methods: A prospective cohort study with CHB patients $(n=183)$ treated with adefovir, entecavir, lamivudine and / or tenofovir was performed in a Brazilian reference tertiary center. Treatment adherence was evaluated by a validate questionnaire named CEAT-HBV within three year-periods (2010/2011, 2013/2014 and 2014/2015). HBV drug resistance variants and single-dose pharmacokinetics were determined by sequencing and LC-MS/MS, respectively. Results: CEAT-HBV identified $79 / 183(43 \%)$ patients with non-adherence to antiviral treatment and among them, 53/79 (67\%) were more frequently viral load positive. However, 38\% (70/183) had positive viral loads suggesting treatment non-response. Most frequent antiviral resistance variants were M204I/V (78\%), L180M (59\%), L80I (15\%), V173L $(7 \%)$ and $\mathrm{Q} 215 \mathrm{H}(6 \%)$. The main causes associated with nonresponse to antiviral treatment were drug resistance variants (39\%), drug resistance variants and nonadherence together $(23 \%)$, non-adherence $(13 \%)$, insufficient treatment duration $(10 \%)$, and undetermined (16\%). Single-dose pharmacokinetics indicated $48 \%$ (31/65) antiviral non-adherence. Two years after the first assessment, the CEATHBV indicated that 101/143 (71\%) patients were adhered treatment, on basis of an analysis of the per-protocol population. However, $21 \%$ (40/183) of the patients could not be evaluated and were excluded. The main reasons for exclusion were death (20/183), 11 out 20 deaths due to hepatocellular carcinoma, loss to follow up (16/183) and others (4/183). HBV booklet was used for medical education. The third CEAT-HBV assessment (2014/2015) showed that 112/135 (83\%) patients were on treatment adherence (per-protocol population) and 8/143 (6\%) were excluded. Longterm evaluation showed that adherence rate based on CEAT-HBV continue to increase after 4-years $(p<0.001)$. Conclusions: Our data highlights the importance of CHB therapy adherence assessment monitoring. Long-term adherence outcomes may be dynamic and it is possible to increase the migration rate to adherence/HBV DNA negative group.

Descriptors: Hepatitis B; Drug Resistance, Viral; Pharmacokinetics; Medication Adherence; Antiviral Agents. 


\section{INTRODUÇÃO}

\subsection{Vírus da hepatite B}

O vírus da hepatite B (HBV) (Figura 1), descoberto em 1965 por Baruch Blumberg, é um DNA vírus pertencente à família Hepadnaviridae, apresentando no seu genoma um DNA circular e parcialmente duplicado de aproximadamente 3.200 pares de bases $^{(1-4)}$.

O genoma viral apresenta 4 fases de leitura aberta: superfície (S), core $(\mathrm{C})$, polimerase $(\mathrm{P})$ e $\mathrm{X}$. A região $\mathrm{S}$ codifica proteínas de superfície do envelope e é composta pelas regiões pré-S1 (grande), pré-S2 (média) e S (pequena). $\mathrm{O}$ gene $\mathrm{C}$ e região pré-C codificam a proteína core, o antígeno $\mathrm{C}$ do vírus da hepatite $\mathrm{B}(\mathrm{AgHBc})$, que é encontrado no tecido hepático e excepcionalmente no soro. A região pré-core codifica a proteína $\mathrm{AgHBe}$, presente no soro de pacientes com replicação do HBV. O gene $\mathrm{P}$ codifica a polimerase, importante para a replicação do HBV e alvo de antivirais. O gene $X$ codifica o HBx, que parece estar envolvido nos processos de carcinogênese, através de transativação de promotores celulares e virais ${ }^{(2,5,}$ 6).

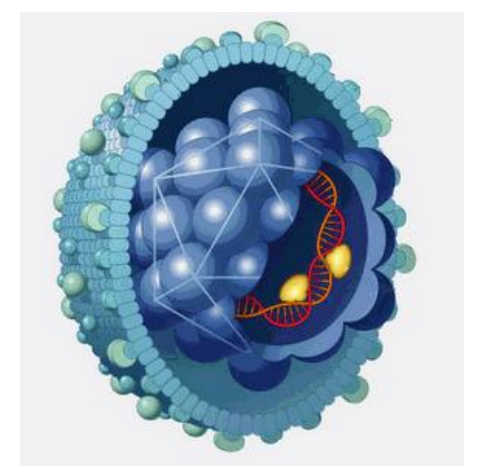

FONTE: Perkins, 2002(7)

Figura 1. Vírus da hepatite $B$

O HBV pode ser classificado em dez genótipos (A-J), que podem ser subdivididos em mais de 40 subgenótipos ${ }^{(8)}$. A distribuição geográfica dos 
genótipos é mostrada na figura 2. Os genótipos B e C são mais frequentes no leste da Ásia, onde a taxa de cronicidade da infecção na idade adulta é menor que $1 \%$. O genótipo $A$ tem sido transmitido sexualmente em todo 0 mundo, com taxas de cronicidade da infecção entre 5 e $10 \%(9,10)$.

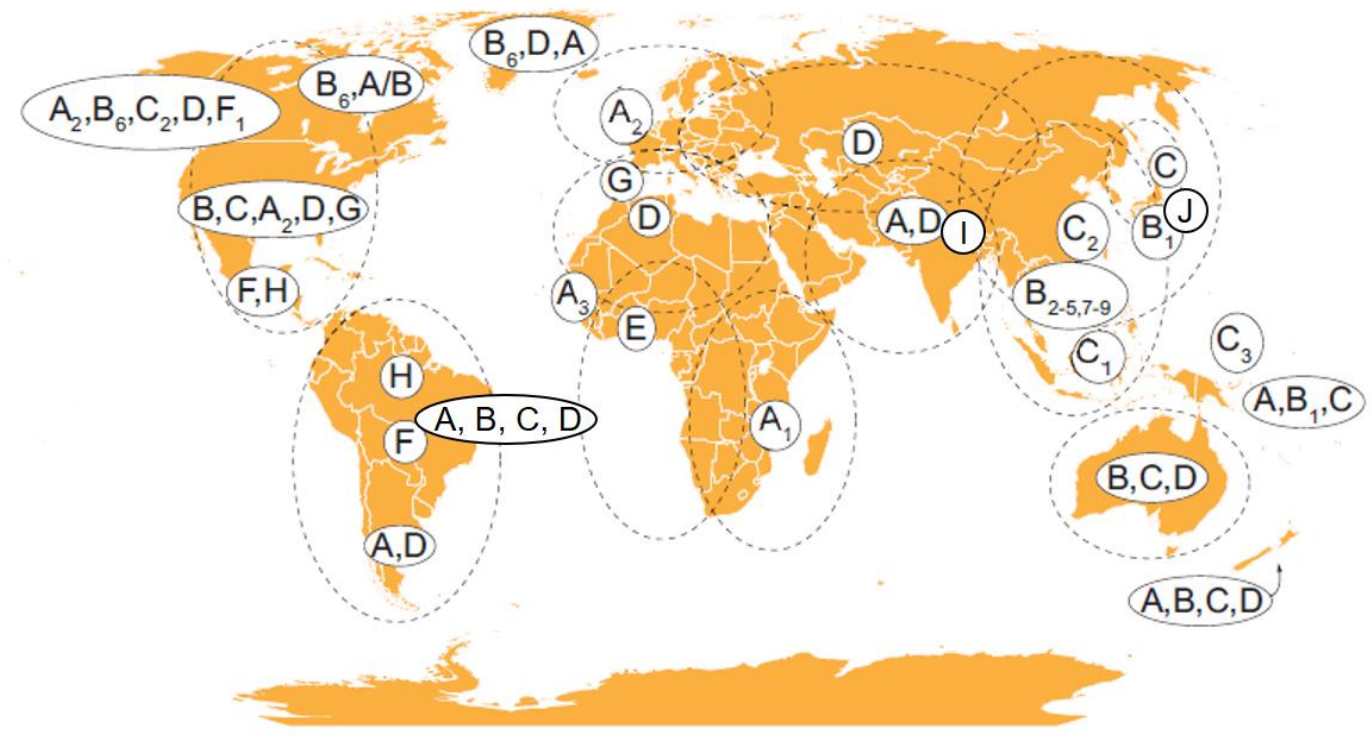

FONTE: Adaptado de Locarnini, et al., 2015(8,11)

Figura 2. Distribuição geográfica dos genótipos e subgenótipos do HBV.

Os genótipos podem influenciar o curso da doença e originar diferenças biológicas específicas, assim como ajudar no monitoramento da eficácia do tratamento padrão através da classificação da rota, patogênese do vírus, gravidade da doença, taxa de soroconversão do antígeno e do vírus da hepatite $\mathrm{B}(\mathrm{AgHBe})$ e desenvolvimento de resistência à terapia antiviral(12-16).

A presença de carga viral de DNA do HBV no soro é a melhor indicação de replicação viral ativa, sendo detectada por técnicas sensíveis como a reação em cadeia da polimerase (PCR). A quantificação da carga viral de HBV é útil para predizer a resposta à terapia antiviral(2). 


\subsubsection{Epidemiologia}

A infecção crônica pelo HBV é um dos mais importantes problemas de saúde pública(17-19), levando a complicações de longo prazo como a cirrose $(30 \%)$ e mortes por carcinoma hepatocelular $(\mathrm{CHC})(45 \%)^{(8)}$. Estima-se que aproximadamente um quarto ( 2 de 7,5 bilhões) da população mundial apresente evidências sorológicas para o HBV, 240 milhões de pessoas estejam infectadas e 786 mil óbitos anuais ocorram pela doença ${ }^{(8,20)}$. Apesar de existir vacina segura e eficaz contra o vírus da hepatite $B$ desde o início da década de 80 , a hepatite crônica causada por esse agente está longe de ser eliminada(2,19, 21-23).

A prevalência da infecção pelo HBV na população tem sido estimada por meio da notificação de casos pelos sistemas oficiais de vigilância epidemiológica, pelo rastreamento sorológico realizado nos bancos de sangue ou, eventualmente, em inquéritos epidemiológicos regionais com finalidade de pesquisa $(24,25)$.

A epidemiologia global da infecção pelo HBV tem sido descrita, tradicionalmente, de acordo com três categorias de endemicidade (alta, intermediária e baixa), dependendo da proporção da população que é soropositiva para o antígeno s do HBV (AgHBs) (Figura 3).

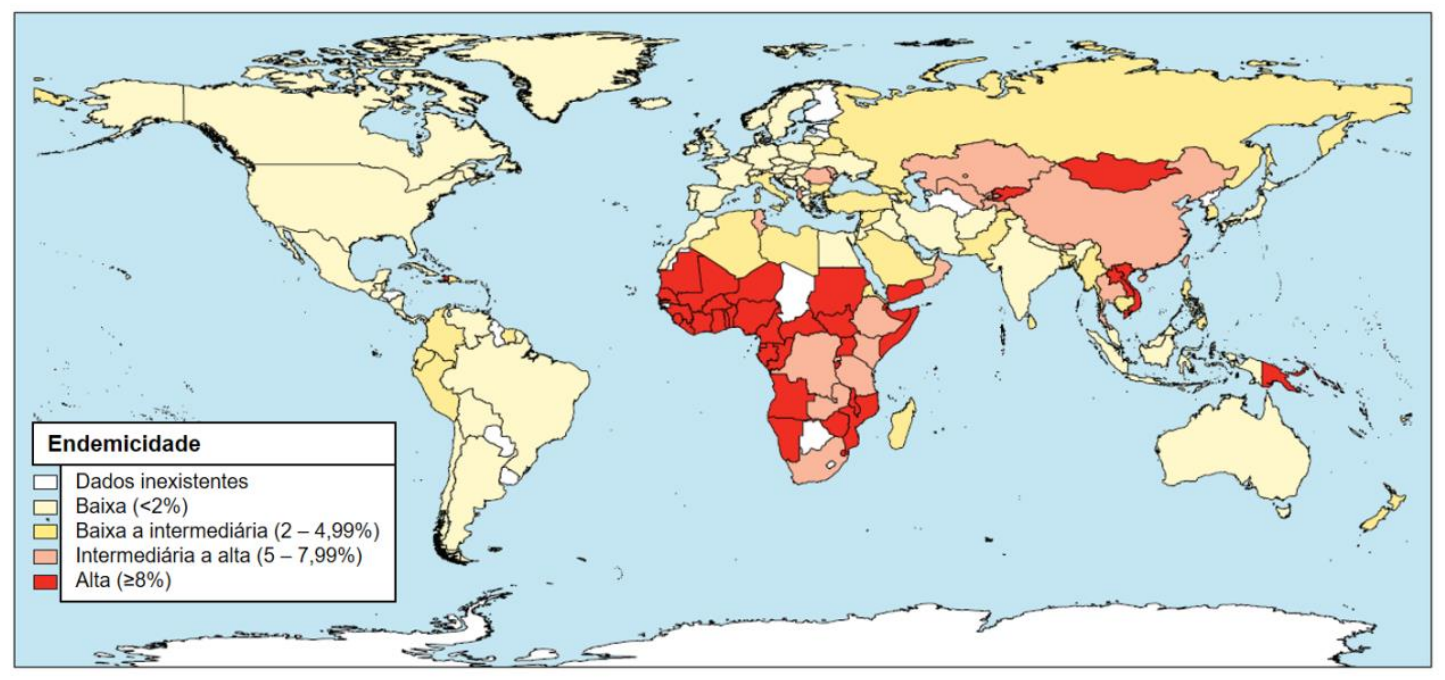

FONTE: Adaptado de Schweitzer, et al., 2015(26)

Figura 3. Estimativa de soroprevalência do AgHBs positivo no mundo 
Países com alta endemicidade são aqueles onde a soroprevalência do AgHBs é maior ou igual a 8\%, com endemicidade intermediária são aqueles entre 2 a $8 \%$ e de baixa endemicidade os com soroprevalência menor que $2 \%{ }^{(19,23)}$. A figura 4 nos mostra a prevalência do AgHBs em diferentes regiões geográficas ${ }^{(27)}$.

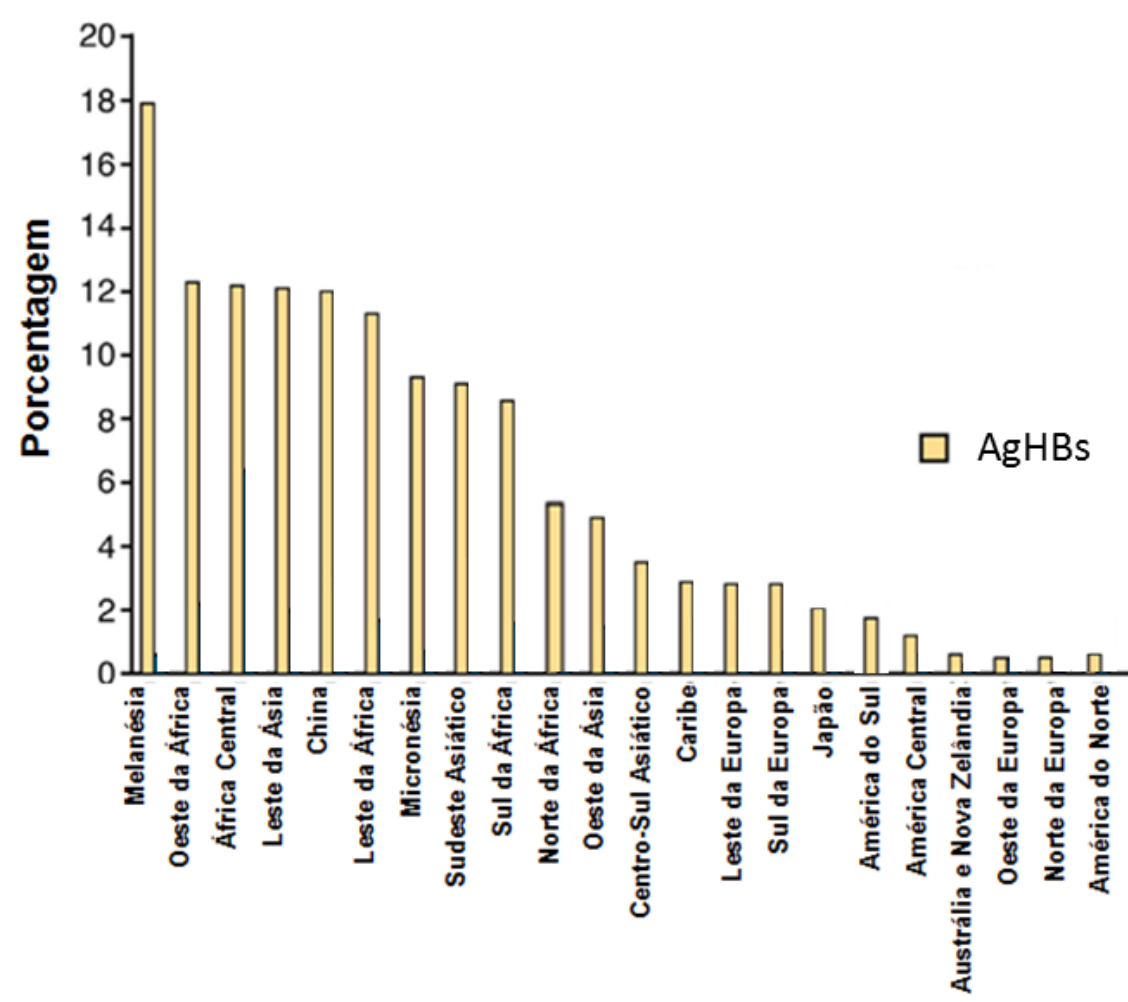

FONTE: Adaptado de El-Serag, 2012 (27)

Figura 4. Prevalência do AgHBs em diferentes regiões geográficas

Porém, a infecção oculta do HBV pode tornar esse cenário ainda mais delicado. A prevalência da infecção oculta do HBV pode ser afetada por vários fatores, dentre os quais a própria prevalência do HBV, a população estudada e a sensibilidade do método diagnóstico utilizado ${ }^{(28)}$. Por exemplo, a incidência de infecção oculta de HBV pode variar de 0-15\% em indivíduos com anti-HBc positivo e a taxa dessa infecção foi reportada entre 0-89\% em pacientes que vivem com HIV(29, 30). Ainda, a infecção oculta do HBV pode chegar a $36 \%$ em pacientes em hemodiálise ${ }^{(31)}$. 


\subsubsection{Infecção pelo HBV no Brasil}

No Brasil, os exames de triagem realizados em bancos de sangue são responsáveis pela maioria dos dados obtidos. O primeiro estudo multicêntrico para estimar a prevalência de hepatite $B$ no Brasil, realizado em duas regiões brasileiras (Nordeste e Centro-Oeste), com 7.881 indivíduos, evidenciou a presença do AgHBs positivo em menos de $1 \%$ dessa população, representando um total estimado de 30.000 indivíduos portadores de infecção crônica pelo HBV(32).

Do ponto de vista epidemiológico, a prevalência da infecção pelo HBV é dinâmica, com fortes influências de condições socioeconômicas, hábitos de vida, movimentos migratórios e grau de exposição ao risco(33).

De acordo com dados do Ministério da Saúde do Brasil (2012), estimase que a cada ano, 14.000 novos casos de infecção por HBV são notificados e 500 pessoas morram devido à doença, o que representa 120.343 casos acumulados no país entre 1999 e 2011 . Ainda, o número de casos aumenta em pessoas com mais de 24 anos (Figura 5) e a região Sul tem a maior incidência, seguida pela região Norte (Figura 6) ${ }^{(34)}$.

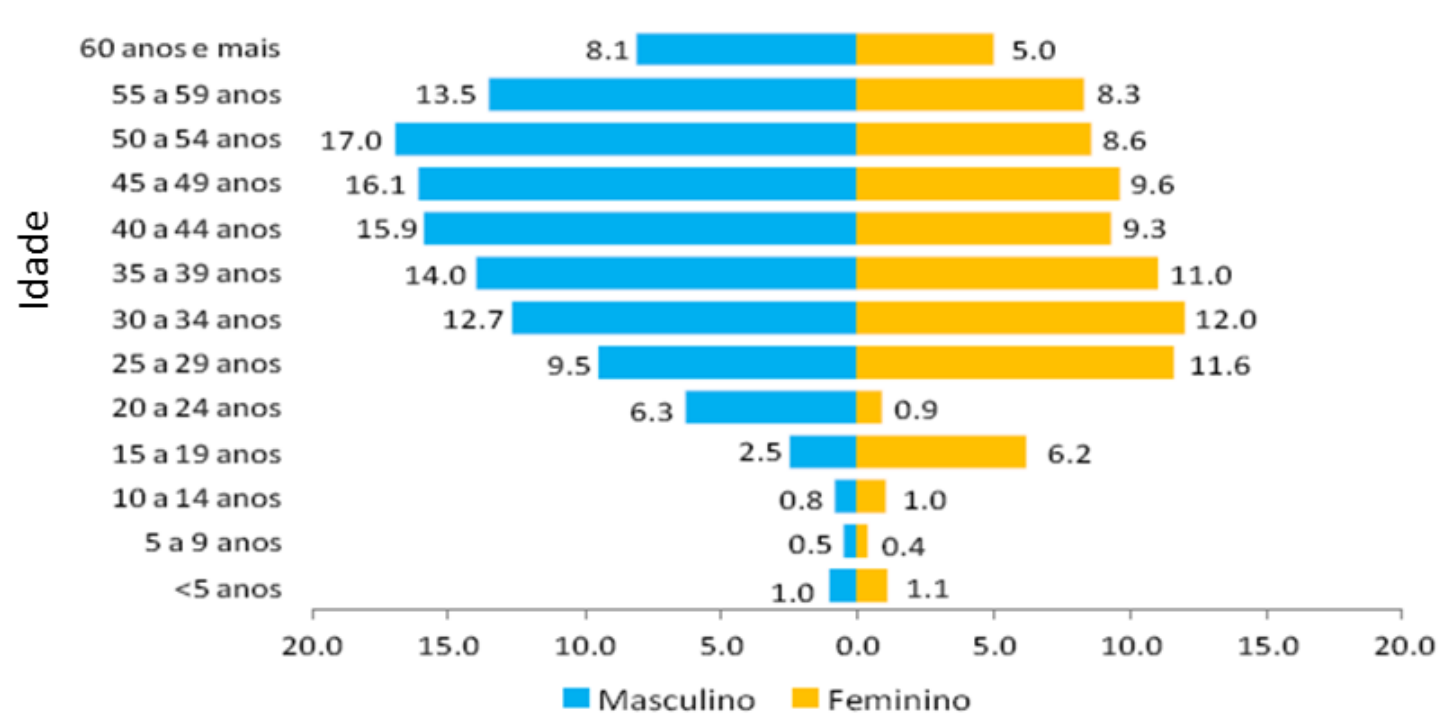

FONTE: Brasil, 2012(34)

Figura 5. Taxa de detecção dos casos de hepatite B (por 100.000 habitantes), segundo faixa etária e sexo 


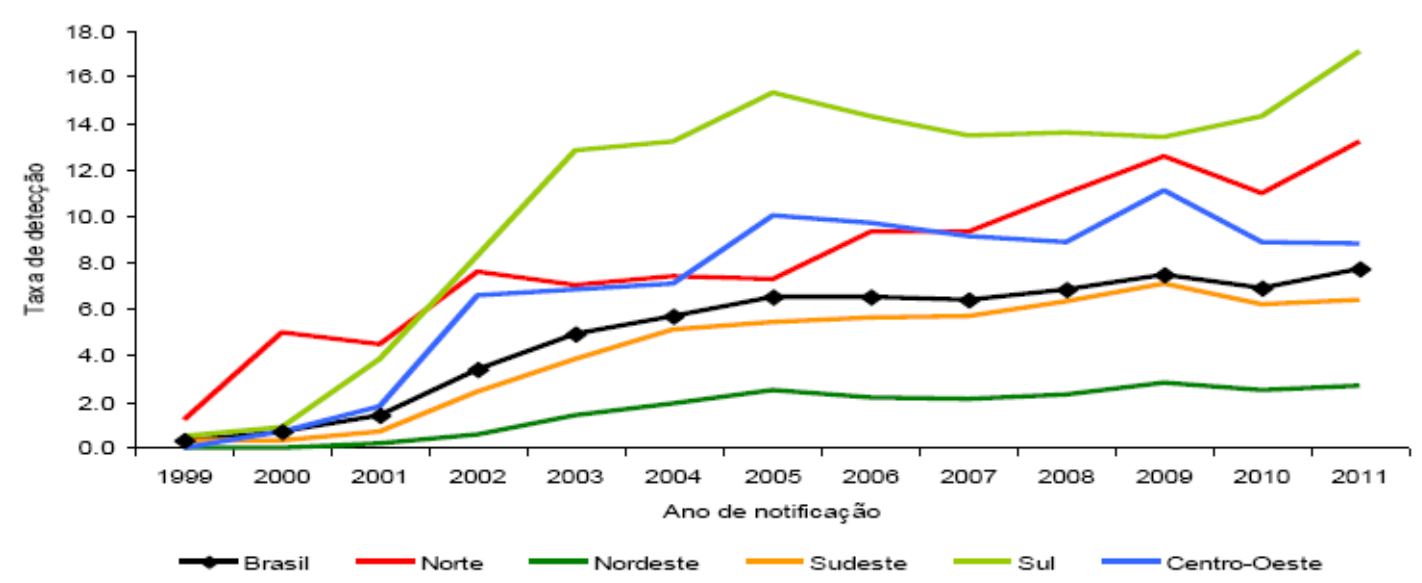

FONTE: Brasil, 2012(34)

Figura 6. Taxa de detecção dos casos de hepatite B (por 100.000 habitantes), segundo região de residência por ano de notificação

\subsubsection{Transmissão}

A hepatite $\mathrm{B}$, historicamente conhecida como a doença transmitida através do sangue contaminado, tinha no doador de sangue importante fonte de infecção. Com o aperfeiçoamento dos métodos de deteç̧ão do AgHBs, foi possível selecionar os doadores de forma mais rigorosa, diminuindo assim a probabilidade de um indivíduo contrair infecção por transfusão sanguínea ${ }^{(19)}$.

O período de incubação do HBV varia de 42 a 180 dias, sendo que o AgHBs aparece inicialmente de 42 a 56 dias após a infecção. O HBV é aproximadamente 100 vezes mais infeccioso que 0 vírus da imunodeficiência humana (HIV) e 10 vezes mais que o vírus da hepatite $\mathrm{C}$ $(\mathrm{HCV})^{(35,36)}$.

O HBV é transmitido principalmente através de exposição percutânea ou de mucosas aos fluidos corpóreos ou a sangue contaminado, sendo de grande importância pelo seu potencial de provocar hepatite crônica. As maiores concentrações de vírus são verificadas no sangue e secreções serosas, diminuindo consideravelmente no sêmen, fluido vaginal e saliva. Sabe-se que o HBV é estável no meio ambiente e pode permanecer viável por cerca de sete dias, sem perder sua infectividade. De modo geral, o vírus 
se dissemina através de contato com sangue ou outros fluidos orgânicos contaminados, assumindo padrões de transmissão bastante variáveis ${ }^{(2,33,37)}$.

Por outro lado, a saliva pode ser veículo de transmissão em caso de mordidas, porém não foram documentados casos de transmissão por beijo ou outros tipos de exposição à saliva. Além disso, o risco de infecção é baixo através de outros fluidos corporais, incluindo lágrimas, suor, urina, fezes, leite materno, líquor e líquido sinovial, que apesar de poder apresentar o AgHBs, a ausência do vírion intacto é a razão pelo qual a transmissão da doença não tem sido associada(33, 38).

As principais formas de contágio são transmissão perinatal, relações sexuais, transfusão de sangue ou derivados, uso de drogas intravenosas, transplante de órgãos ou tecidos, e lesões de pele ou acidentes com agulhas, principalmente entre profissionais da área da saúde. Situações mais raras caracterizadas por exposição percutânea, tais como tatuagens, piercing, acupuntura e acidentes com outros objetos cortantes também são documentados como fatores de risco para a transmissão( $19,33,39,40)$.

Em áreas de alta endemicidade, a transmissão vertical é a grande responsável pela disseminação da doença. Porém, nos países de baixa e média prevalência de infecção pelo HBV, o contato sexual é a causa principal de infecção(41-43). No Brasil, de acordo com dados recentes de notificações, a principal forma de infecção é a via sexual (Figura 7) ${ }^{(34)}$.

Estudos demonstraram a forte influência racial na transmissão do HBV em regiões de baixa endemicidade, sendo a infecção por HBV superior entre crianças de origem asiática quando comparada com as de origem ocidental, o que sugere forte transmissão vertical em orientais e caracteriza os membros dessas famílias como um grupo de alto risco, tornando necessário imunoprofilaxia(44, 45). 


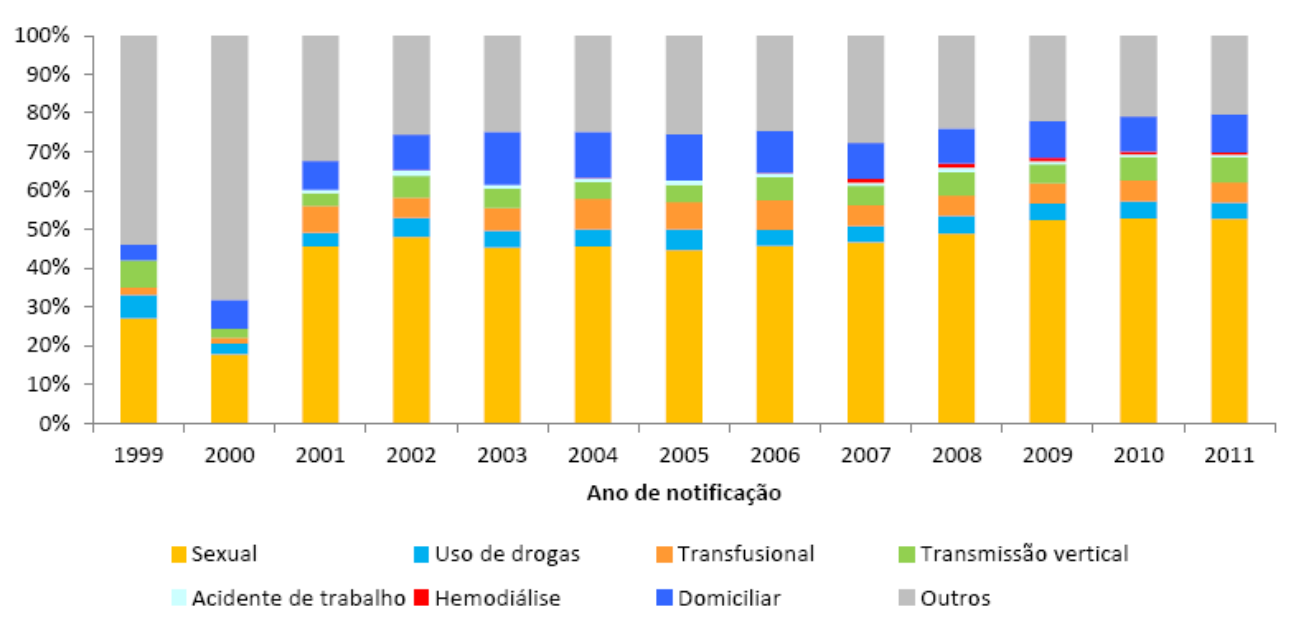

FONTE: Brasil, 2012(34)

Figura 7. Distribuição percentual dos casos de hepatite $B$, segundo provável fonte/mecanismo de infecção, por ano de notificação

\subsubsection{Diagnóstico}

A hepatite B crônica é a doença necroinflamatória do fígado, causada por infecção persistente do HBV, sendo caracterizada pelo antígeno s do vírus da hepatite $\mathrm{B}$ (AgHBs) positivo por mais de 6 meses. Ainda, pode ocorrer à elevação persistente da concentração sérica da alanina aminotransferase (ALT), carga viral do DNA do HBV maior do que 2.000 $\mathrm{Ul} / \mathrm{mL}$ (AgHBe negativo) e maior do que $20.000 \mathrm{Ul} / \mathrm{mL}$ (AgHBe positivo), e doença hepática ativa evidenciada em biópsia(46, 47).

O HBV possui tropismo pela célula hepática e se liga a receptores presentes na superfície celular. Esse vírus estabelece a infecção crônica por evitar o sistema imunológico do hospedeiro. O HBV não tem um nível de citotoxicidade eficiente, sendo a resposta imune do hospedeiro a hepatócitos infectados pelo vírus que leva ao desenvolvimento da hepatite. As células T (CD8+ específicas contra HBV) contribuem significativamente para a eliminação do HBV e o desenvolvimento da hepatite ${ }^{(48)}$.

A figura 8 representa as fases clínicas da doença e demonstra 0 espectro variado e variável, oscilando entre estado de portador, com baixa viremia, e hepatite crônica, que pode evoluir para cirrose, insuficiência hepática e carcinoma hepatocelular ${ }^{(18,49)}$. 


\begin{tabular}{|c|c|c|c|c|}
\hline & \multicolumn{2}{|c|}{ AgHBe positivo } & \multicolumn{2}{|c|}{ AgHBe negativo } \\
\hline & $\begin{array}{l}\text { Infecção } \\
\text { crônica }\end{array}$ & $\begin{array}{l}\text { Hepatite } \\
\text { crônica }\end{array}$ & $\begin{array}{l}\text { Infecção } \\
\text { crônica }\end{array}$ & $\begin{array}{c}\text { Hepatite } \\
\text { crônica }\end{array}$ \\
\hline AgHBs & Alto & $\begin{array}{c}\text { Alto / } \\
\text { Intermediário }\end{array}$ & Baixo & Intermediário \\
\hline $\mathrm{AgHBe}$ & Positivo & Positivo & Negativo & Negativo \\
\hline $\begin{array}{c}\text { HBV-DNA } \\
\text { ALT }\end{array}$ & $\begin{array}{c}>10^{7} \mathrm{UI} / \mathrm{mL} \\
\text { Normal }\end{array}$ & $\begin{array}{c}10^{4}-10^{7} \mathrm{UI} / \mathrm{mL} \\
\text { Elevada }\end{array}$ & $\begin{array}{c}<2.000 \mathrm{UI} / \mathrm{mL} \\
\text { Normal }\end{array}$ & $\begin{array}{c}>2.000 \mathrm{UI} / \mathrm{mL} \\
\text { Elevada }\end{array}$ \\
\hline $\begin{array}{l}\text { Doença } \\
\text { hepática }\end{array}$ & $\begin{array}{l}\text { Ausente / } \\
\text { mínima }\end{array}$ & $\begin{array}{l}\text { Moderada / } \\
\text { Grave }\end{array}$ & Ausente & $\begin{array}{l}\text { Moderada / } \\
\text { Grave }\end{array}$ \\
\hline $\begin{array}{c}\text { Terminologia } \\
\text { antiga }\end{array}$ & Imunotolerante & Imunoreativa & Portador inativo & Hepatite crônica \\
\hline
\end{tabular}

Figura 8. História natural e avaliação dos pacientes com infecção crônica pelo HBV

O diagnóstico laboratorial é feito através da detecção dos marcadores sorológicos e da dosagem das aminotransferases ${ }^{(35)}$.

Na Tabela 1 estão listados os diversos padrões sorológicos da infecção crônica pelo HBV. Como podemos observar, o padrão sorológico da infecção pelo HBV mutante é idêntico ao do portador inativo do HBV, daí a necessidade da quantificação da carga viral(51). A soroconversão do AgHBs é comumente entendido como uma cura funcional da infecção pelo HBV, mesmo quando ocorre persistência do DNA circular fechado covalentemente $(\operatorname{cccDNA})^{(48)}$.

Tabela 1. Padrões sorológicos da infecção crônica pelo HBV

\begin{tabular}{|c|c|c|c|c|c|c|}
\hline Marcadores & AgHBs & $\mathrm{AgHBe}$ & Anti-HBe & Anti-HBc total & Anti-HBs & HBV-DNA \\
\hline $\begin{array}{c}\text { Infecção } \\
\text { crônica HBV }\end{array}$ & + & $+/-$ & $+/-$ & + & - & + \\
\hline $\begin{array}{c}\text { Infecção } \\
\text { oculta HBV }\end{array}$ & - & - & - & + & - & + \\
\hline $\begin{array}{l}\text { Portador } \\
\text { inativo HBV }\end{array}$ & + & - & + & + & - & $+/-$ \\
\hline $\begin{array}{l}\text { Pré-core } \\
\text { mutante }\end{array}$ & + & - & + & + & - & + \\
\hline $\begin{array}{l}\text { Infecção } \\
\text { passada }\end{array}$ & - & - & - & $+/-$ & + & - \\
\hline
\end{tabular}

FONTE: Adaptado de Fonseca, 2007(51)

Legenda: + = reagente; - = não reagente; HBV-DNA = carga viral do HBV. 


\subsubsection{Arsenal terapêutico}

As opções de tratamento atualmente disponíveis são insuficientes para curar completamente o $\mathrm{HBV}$ e eliminar o $\operatorname{cccDNA}{ }^{(48)}$. Entretanto, sete agentes terapêuticos encontram-se aprovados para uso na hepatite $B$ crônica na maioria dos países do mundo: adefovir, entecavir, lamivudina, telbivudina, tenofovir, interferon-alfa e interferon peguilado(52-59). A tabela 2 mostra os principais análogos de nucleos(t)ídeos aprovados.

Todos esses agentes são capazes de suprimir a replicação do HBV, porém a resposta sustentada não é frequente, ocorrendo em menos de $20 \%$ dos pacientes tratados. A maioria dependerá de tratamento por tempo indefinido, permanecendo com a carga viral do HBV suprimida apenas durante o tratamento com o medicamento antiviral(22, 60-64).

No Brasil, a partir de 2002, vigorou o "Protocolo Clínico e Diretrizes Terapêuticas Hepatite Viral Crônica B", que contemplava o uso de lamivudina e interferon-alfa para o tratamento da hepatite B crônica ${ }^{(65)}$. No entanto, em 2010, o Ministério da Saúde divulgou o "Protocolo clínico e diretrizes terapêuticas para o tratamento da hepatite viral crônica B e coinfecções" em formato impresso, com o intuito de regulamentar o uso de antivirais e atualizar o arsenal terapêutico de acordo com as diretrizes internacionais. Nesse protocolo, a lamivudina e o interferon-alfa foram mantidos, e foram incluídos os seguintes fármacos: adefovir, entecavir, tenofovir e interferon peguilado; para o tratamento da hepatite viral crônica $B$ e as coinfecções deste com o vírus Delta, o HIV e o HCV(66).

Em 2017, em função dos novos avanços da medicina na assistência à hepatite B, o Ministério da Saúde publicou o "Protocolo clínico e diretrizes terapêuticas para hepatite B e coinfecções" que opta por não recomendar os medicamentos inteferon-alfa e adefovir. Além disso, amplia-se a participação de entecavir e tenofovir; e recomenda-se a substituição da lamivudina, devido à fraca barreira genética e fácil desenvolvimento de resistência, preferencialmente por tenofovir ${ }^{(67)}$. 
Tabela 2. Principais drogas anti-HBV aprovadas.

\begin{tabular}{|c|c|c|c|c|c|}
\hline Droga & $\begin{array}{l}\text { Estrutura } \\
\text { química }\end{array}$ & $\begin{array}{c}\text { Nome } \\
\text { Comercial }\end{array}$ & $\begin{array}{l}\text { Mecanismo de } \\
\text { ação }\end{array}$ & $\begin{array}{c}\text { Industria } \\
\text { Farmacêutica }\end{array}$ & $\begin{array}{c}\text { Ano de } \\
\text { aprovação } \\
\text { no FDA }\end{array}$ \\
\hline Lamivudina & & $\begin{array}{l}\text { Zeffix, } \\
\text { Heptovir, } \\
\text { Epivir, e } \\
\text { Epivir-HBV }\end{array}$ & $\begin{array}{c}\text { Análogo de } \\
\text { nucleosídeo / } \\
\text { Inibidor da RT }\end{array}$ & $\begin{array}{c}\text { GlaxoSmith } \\
\text { Kline }\end{array}$ & $\begin{array}{c}1998 \text { (para } \\
\text { adultos) e } \\
2000 \text { (para } \\
\text { crianças) no } \\
\text { EUA }\end{array}$ \\
\hline Adefovir & & $\begin{array}{l}\text { Preveon e } \\
\text { Hepsera }\end{array}$ & $\begin{array}{c}\text { Análogo de } \\
\text { nucleotídeo / } \\
\text { Inibidor da RT }\end{array}$ & Gilead & 2002 (EUA) \\
\hline Entecavir & & Baraclude & $\begin{array}{c}\text { Análogo de } \\
\text { nucleosídeo / } \\
\text { Inibidor da RT }\end{array}$ & $\begin{array}{c}\text { Bristol Meyers } \\
\text { Squibb }\end{array}$ & 2005 (EUA) \\
\hline Telbivudina & & $\begin{array}{l}\text { Sebivo } \\
\text { (Europa) e } \\
\text { Tyzeka } \\
\text { (EUA) }\end{array}$ & $\begin{array}{c}\text { Análogo de } \\
\text { nucleosídeo / } \\
\text { Inibidor da RT }\end{array}$ & $\begin{array}{l}\text { Idenix, } \\
\text { Novartis }\end{array}$ & 2006 (EUA) \\
\hline Clevudina & & $\begin{array}{l}\text { Levovir e } \\
\text { Revovir }\end{array}$ & $\begin{array}{l}\text { Análogo de } \\
\text { nucleosídeo / } \\
\text { Inibidor da RT }\end{array}$ & $\begin{array}{c}\text { Bukwang } \\
\text { Pharm }\end{array}$ & $\begin{array}{c}2006 \\
\text { (Korea) }\end{array}$ \\
\hline Tenofovir & & Viread & $\begin{array}{l}\text { Análogo de } \\
\text { nucleotídeo / } \\
\text { Inibidor da RT }\end{array}$ & Gilead & 2008 (EUA) \\
\hline
\end{tabular}

FONTE: Adaptado de Kim, et al., 2010(68)

Legenda: $\mathrm{RT}=$ transcriptase reversa.

Os objetivos principais do tratamento são reduzir a progressão da lesão hepática e erradicar o HBV, com o intuito de minimizar os riscos de evolução para cirrose com necessidades de transplante e desenvolvimento do carcinoma hepatocelular. Como o HBV replica através de transcrição reversa, o uso de inibidores da enzima transcriptase reversa, como a 
lamivudina, passou a ser uma ótima opção. Porém, o desenvolvimento de resistência antiviral tornou-se um obstáculo nos tratamentos por longos períodos, sendo necessário o desenvolvimento de estratégias (como terapia combinada) para melhorar a resposta ao tratamento ${ }^{(69-72)}$.

Existem inúmeras evidências de que os objetivos principais do tratamento possam ser alcançados por meio da supressão da carga viral do HBV, a qual deve ser mantida o mais baixo possível, idealmente abaixo do limite de detecção da técnica de PCR (50 a 400 cópias $/ \mathrm{mL}$ ). Pacientes com carga viral plasmática de HBV indetectável costumam apresentar melhora clínica, normalização das aminotransferases (ALT, AST) e regressão da fibrose hepática.

O desenvolvimento da vacina e o tratamento antiviral têm gerado esperança para a eliminação e erradicação da infecção por HBV. A vacinação mostrou-se eficaz, desde o início, para evitar a infecção, além de ser uma maneira eficiente de controlar a propagação do vírus em crianças nascidas de mães portadoras. Dessa forma, a vacinação infantil universal será a chave para a erradicação da hepatite $B$, e isso requer o compromisso de todos os países ${ }^{(73)}$.

Contudo, a identificação de novos alvos e drogas curativas têm sido um grande desafio para a comunidade científica. Abordagens terapêuticas alternativas com alvo direta ou indiretamente no cccDNA estão sendo desenvolvidas; e várias moléculas estão sendo testadas, algumas já em estudos clínicos de fase 2 e 3. Por fim, acredita-se que a combinação de antivirais direcionados a replicação do HBV e fármacos que restauram ou aumentam a resposta imune do hospedeiro podem levar a cura funcional e talvez absoluta dentro de uma década ${ }^{(74)}$.

\subsubsection{Resistência antiviral}

Atualmente, não existem modelos animais simples para testes de eficácia de drogas antivirais. As drogas são testadas na fase não clínica, em ensaios in vitro, para determinar a eficiência e o perfil de resistência. Nestes 
ensaios, os hepatócitos são infectados com variantes de HBV selvagens ou mutantes, e os efeitos dos análogos de núcleos(t)ídeos são determinados através da medição da replicação do HBV ou de sua citotoxicidade. Os ensaios são realizados para determinar os efeitos de várias mutações na resistência aos análogos de nucleos(t)ídeos. A polimerase viral de variantes selvagens ou mutantes do HBV são expressos a partir de plasmídeos e testados para iniciação e alongamento do DNA viral(75-77). As principais mutações dos inibidores da transcriptase reversa do HBV estão apresentadas na figura 9 .

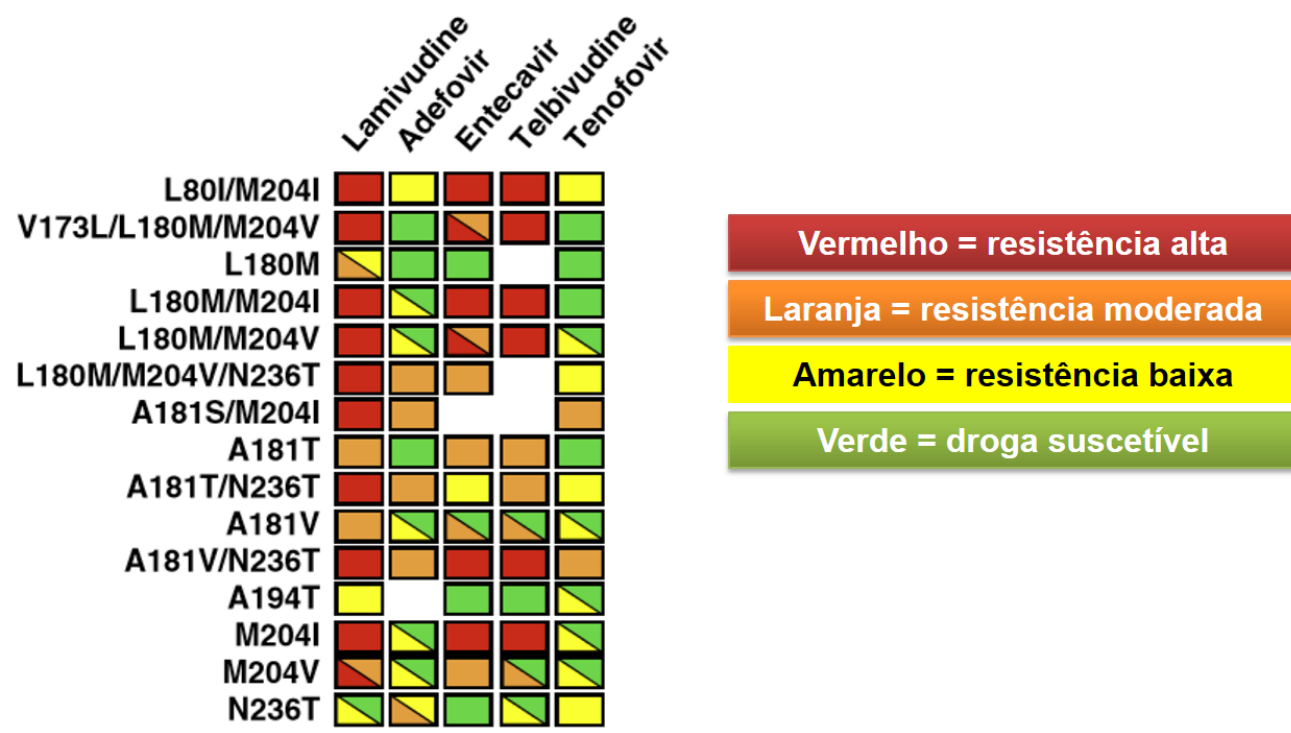

FONTE: Adaptado de Menéndez-Arias, et al., 2014(78)

Figura 9. Representação esquemática das variantes do HBV e resistência antiviral

A determinação da taxa de desenvolvimento de resistência a partir de experiência clínica varia consideravelmente dependendo dos agentes antivirais. Para a lamivudina e a telbivudina, as taxas de resistência são de $30 \%$ e $15 \%$ ao ano, respectivamente. Quando utilizados em monoterapia, o entecavir e adefovir têm barreiras mais elevadas de resistência, com taxas inferiores a $2 \%$ após dois anos. Os dados de resistência ao tenofovir ainda não foram reportados. Após cinco anos de tratamento, as taxas de resistência são de cerca de $70 \%$ para a lamivudina, 28\% para adefovir, menos de $1 \%$ para o entecavir, e $0 \%$ para tenofovir e interferon ${ }^{(75,77)}$. 


\subsection{Adesão ao tratamento}

A baixa adesão ao tratamento de doenças crônicas é um problema mundial. Estima-se que cerca de $50 \%$ dos pacientes portadores de doenças crônicas, nos países desenvolvidos, não seguem seus tratamentos de maneira recomendada, com resultados ainda piores nos países em desenvolvimento ${ }^{(79)}$. Estudos recentes sugerem que a melhora da adesão diminui a mortalidade, consultas de emergência e internações, reduz custos médicos e promove o bem-estar dos pacientes ${ }^{(80,81)}$.

O termo compliance, do inglês, proposto por Haynes (1979), remete a responsabilidade por tomar os medicamentos, resultante de uma relação médico-paciente não dialogada, de um único sentido. Dessa forma, o poder se encontra com o médico, que deve assumir a responsabilidade de ditar o tratamento, cabendo ao paciente apenas cumprir a recomendação proposta(82).

A Organização Mundial da Saúde (OMS) critica esse tratamento autoritário na relação médico-paciente, argumentando que nas sociedades modernas, o paciente assume progressivamente um papel mais ativo no seu tratamento, pautado no questionamento às ordens médicas e na postura dialogada por parte do profissional de saúde ${ }^{(79)}$.

Dessa forma, a OMS recomenda o uso do termo adherence, que define o quanto o comportamento de um paciente na tomada de medicamentos corresponde com as recomendações médicas. Assim, o termo adherence diferencia-se de compliance ao colocar o paciente como parte do processo de cuidar de sua saúde, isto é, estar de acordo com as propostas terapêuticas dos profissionais de saúde ${ }^{(79,83)}$.

O termo adherence, do inglês, tem sido traduzido na língua portuguesa para aderência ou adesão. O termo aderência parece mais adequado quando se trata de qualificar a condição do indivíduo como agente passivo ao processo, ao passo que o termo adesão traduz o sentido como postura ativa, que coloca o paciente como corresponsável ao seu tratamento. Nesse 
sentido, o termo adesão está mais próximo do conceito proposto pela $\mathrm{OMS}^{(84)}$.

Diversos métodos podem ser utilizados para estimar a adesão dos pacientes a medicamentos. Esses métodos podem ser utilizados separadamente ou em associação, e incluem revisão de prontuários médicos, auto-relato dos pacientes, relato dos familiares, contagem de comprimidos residuais, análises de dispensação de medicamentos, marcadores biológicos no soro ou na urina, ensaios para quantificar os medicamentos ou seus metabólitos e resultados terapêuticos ${ }^{(79)}$.

Esses métodos são classificados como diretos ou indiretos, sendo os diretos, a observação da tomada de medicamentos e o monitoramento biológico do medicamento ou seus metabólitos. Os indiretos compreendem relato do profissional (impressão médica), registros farmacêuticos, contagem manual de comprimidos, monitoramento eletrônico de doses, desfecho clínico favorável e métodos de relato dos pacientes mediante questionários estruturados e escalas visuais( ${ }^{(82)}$.

Vários métodos têm sido estudados para medir a adesão, mas nenhum pode ser considerado o padrão ouro para todos os tipos de pesquisa em

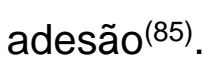

Com relação aos métodos diretos, observa-se que além do custo elevado, o monitoramento biológico do medicamento ou seus metabólitos apresenta disponibilidade restrita, o que dificulta o emprego em estudos ambulatoriais com grandes amostras e múltiplas drogas ${ }^{(82)}$.

Dessa forma, os questionários estruturados, obtidos por entrevista ou autopreenchimento, são as opções mais usadas por sua facilidade operacional e baixo custo. Assim, os questionários que estimam comportamento ou impressões do paciente frente ao tratamento classificam os pacientes quanto à adesão ou não(86).

Diversos instrumentos de avaliação da adesão estão disponíveis, sendo alguns gerais para várias doenças como o Teste de Morisky e a Questão de Haynes $(86,87)$. Em etapa anterior deste estudo, foi adaptado e validado um questionário específico para a hepatite $B$ crônica, denominado 
"Questionário para avaliação da adesão ao tratamento antiviral em pacientes portadores de hepatite B crônica" (CEAT-HBV) ${ }^{(88,89)}$. Esse questionário foi validado a partir do "Cuestionario para la Evaluación de la Adhesión al Tratamiento Antiretroviral' (CEAT-VIH), adaptado e validado para o português, é um questionário aplicável a pacientes adultos que vivem com HIV(90-93). Ainda, estudos mostraram a utilidade desse instrumento no Brasil e em outros países como Colômbia, Espanha, Peru, Portugal e México ${ }^{(91-95)}$.

\subsubsection{A adesão ao tratamento na hepatite $B$ crônica}

A descontinuação do tratamento antiviral geralmente leva à perda de controle viral e desenvolvimento de variantes de resistência antiviral(52, 96, 97). O desenvolvimento de resistência a qualquer uma das drogas hoje utilizadas no tratamento da hepatite $B$ crônica pode ser detectada através da elevação dos níveis séricos da carga viral de HBV, acompanhado de elevação da ALT, perda da melhora histológica inicial e, em alguns casos, de quadro clínico grave de icterícia e descompensação hepática ${ }^{(98-100)}$.

Dentre os fatores que levam a resistência, podemos citar as mutações, a baixa barreira genética de algumas drogas e a perda de adesão ao tratamento farmacológico. A presença de mutações na polimerase do HBV origina a resistência genotípica, que pode ser comprovada através do sequenciamento direto dos produtos da reação do $\mathrm{PCR}^{(98-102)}$.

Vários autores já apontam a adesão à terapia antiviral como a chave para o sucesso terapêutico, diminuindo a resistência às drogas, a carga viral plasmática de HBV e, com isso, os custos com o tratamento(102-106). A adesão ao tratamento antiviral para HBV mostrou correlação com a resposta clínica e o resultado do tratamento ${ }^{(106)}$. Com isso, o monitoramento da adesão é uma ação estratégica para evitar a falha do tratamento(88, 105-107).

Como a maioria dos pacientes não alcança a resposta sustentada, o tratamento deve ser mantido por muitos anos, havendo risco de seleção de cepas virais resistentes a uma ou mais drogas, reduzindo as opções terapêuticas. Para prevenir esse desfecho, a melhor maneira é empregar 
antivirais com alta potência e elevada barreira genética, além de seguir algumas regras como evitar tratamentos desnecessários, trocar o esquema terapêutico sempre que não houver resposta virológica inicial, evitar drogas com perfil de resistência cruzada e, principalmente, evitar a monoterapia sequencial, pois tem grande risco de provocar resistência(66, 105, 108-110).

Além disso, o paciente deve assumir responsabilidade como parte do processo de cuidar de sua saúde, através da adesão ao tratamento farmacológico proposto pelo médico, uma vez que a não adesão pode contribuir como causa do desenvolvimento de resistência antiviral, e consequentemente, aumento da carga viral de $\operatorname{HBV}(79,103,105)$.

Nos últimos anos, começaram a surgir os primeiros trabalhos de avaliação da adesão para esse grupo de pacientes. Chotiyaputta e colaboradores (2012) estudaram a adesão ao tratamento com análogos de núcleos(t)ídeos em pacientes portadores de hepatite $\mathrm{B}$ crônica. Eles evidenciaram $74,1 \%$ de pacientes com adesão de $100 \%$ nos 30 dias anteriores à pesquisa. Constataram também que a adesão foi maior nos homens idosos com maior renda mensal(106).

O estudo de Sogni e colaboradores (2012), realizado na França, incluiu pacientes que realizavam tratamento para hepatite $B$ crônica durante pelo menos três meses e estudaram a adesão através da análise de auto-relatos. Com isso, foram observados $61 \%, 32 \%$ e $7 \%$ dos pacientes classificados em com adesão, adesão moderada e não adesão, respectivamente. Sendo assim, esses pesquisadores demonstraram que a educação terapêutica e uma avaliação sistemática da adesão usando auto-relatos devem ser promovidas para garantir a eficácia de tratamento a longo prazo, na prática

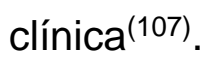

Sabe-se que não é uma tarefa fácil o paciente apresentar-se com adesão ao tratamento medicamentoso, uma vez que a falta de informação sobre a doença e/ou medicamento, esquema terapêutico, baixa escolaridade e surgimento de reações adversas comprometem o sucesso da terapêutica nas mais variadas doenças como hipertensão arterial, diabetes, hepatites virais crônicas, HIV, entre outras ${ }^{(79)}$. 
Porém, quando estudamos a não adesão em pacientes diabéticos e hipertensos, por exemplo, a falha terapêutica é manifestada mais rapidamente, através de alterações da glicemia e pressão arterial, respectivamente. Com isso, torna-se mais fácil estabilizar o paciente, uma vez que os medicamentos não induzem resistência, além de apresentar um arsenal terapêutico bastante complexo ${ }^{(79,111)}$.

Quando nos reportamos a doenças crônicas tratadas com antivirais, como as hepatites virais crônicas e o HIV, devemos enfatizar a importância da adesão ao tratamento para que os fármacos atuem de forma eficaz. Por outro lado, a não adesão é muitas vezes detectada tardiamente, quando o paciente já apresenta resistência antiviral, o que se torna um grave problema devido ao número de drogas disponíveis ser limitado. Ainda, a não adesão ao antiviral não acarreta uma repercussão clínica imediata, o que dificulta o entendimento do paciente sobre a importância da tomada do medicamento.

Uma revisão sistemática da adesão ao tratamento de hepatite $B$ sugere que a não adesão pode ser fenômeno menos frequente, mas há um risco aumentado de falha virológica em doentes com adesão ao antiviral prejudicada ${ }^{(112)}$.

A comunicação efetiva com o paciente através de programas de educação médica continuada parece ter papel estratégico para promover a melhora da adesão continuamente ${ }^{(113)}$. Dessa forma, o monitoramento da adesão a longo prazo é um dos fatores cruciais para evitar o desenvolvimento de resistência antiviral e garantir sucesso terapêutico por maior tempo ${ }^{(93,104)}$. 


\section{OBJETIVOS}

\subsection{Objetivo Geral}

Avaliar os desfechos virológicos e de adesão ao tratamento antiviral a longo prazo em pacientes portadores de hepatite B crônica.

\subsection{Objetivos Específicos}

Avaliar a frequência de migração entre os grupos distribuídos por desfechos virológicos e de adesão ao tratamento antiviral.

Avaliar os preditores de falha de tratamento no início do estudo. 


\section{MÉTODO}

\subsection{Delineamento do estudo}

Trata-se de um estudo de coorte prospectivo, tendo como populaçãoalvo os pacientes com diagnóstico de hepatite B crônica atendidos no Ambulatório do Serviço de Gastroenterologia (A2MG), Especialidade (Grupo do Fígado - 2MG40), Unidade (2MG 0404) do Instituto Central do Hospital das Clínicas da Faculdade de Medicina da Universidade de São Paulo (HCFMUSP), um centro terciário de referência para hepatites virais.

Os pacientes com consultas agendadas nessa Unidade passaram por uma triagem prévia para identificação daqueles que estavam em tratamento antiviral no momento da consulta médica. Em seguida, eles foram convidados a participar do estudo.

Foram realizadas três visitas por paciente, sendo realizada na primeira visita os seguintes procedimentos: obtenção do Termo de Consentimento Livre e Esclarecido (TCLE) e aplicação de um questionário, incluindo os instrumentos de avaliação de adesão antiviral. Foram coletadas informações sociodemográficas, relacionadas à doença e a percepção do paciente em relação ao seu tratamento medicamentoso. Os dados relativos ao perfil clínico dos pacientes foram compilados diretamente do prontuário. Além disso, todos os sujeitos de pesquisa foram divididos em função dos desfechos virológicos e de adesão ao tratamento antiviral (por avaliação pelo CEAT-HBV) ${ }^{(88)}$, de acordo com os grupos:

- Adesão e carga viral HBV-DNA negativa;

- Adesão e carga viral HBV-DNA positiva;

- Não Adesão e carga viral HBV-DNA negativa;

- Não Adesão e carga viral HBV-DNA positiva;

$\mathrm{Na}$ segunda visita, foram novamente aplicados os instrumentos de avaliação de adesão, descritos em detalhes posteriormente, e foi realizada 
uma orientação sobre a tomada de medicamentos antivirais, com o uso da Cartilha "Juntos contra a Hepatite B", como material de apoio para comunicação de adesão ao tratamento na hepatite B crônica (Anexo A).

Na terceira visita, foram aplicados novamente os mesmos instrumentos de avaliação de adesão e orientação com a Cartilha. A figura 10 representa de forma esquemática o desenho do estudo.

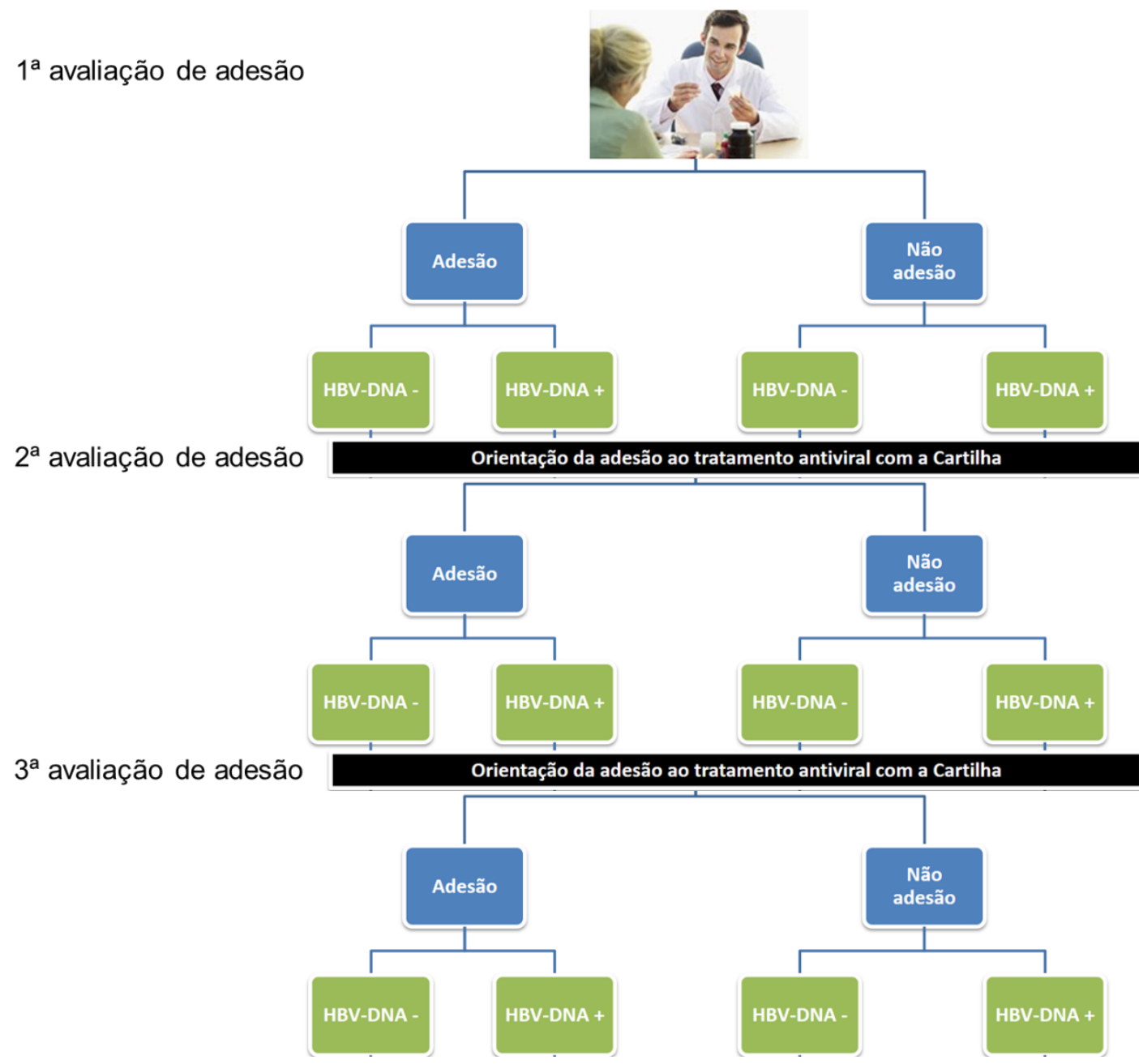

Figura 10. Representação esquemática do desenho do estudo

O período de recrutamento foi de dezembro de 2010 a junho de 2011 , sendo sete meses de triagem na Unidade (2MG 0404). Como o tempo máximo que uma prescrição médica atendida na Farmácia Ambulatorial do HCFMUSP é de seis meses, foi possível realizar a triagem com todos os pacientes em acompanhamento nesse ambulatório. 
Os pacientes que não comparecessem à consulta médica na data agendada seriam excluídos da avaliação de adesão. Porém, foram realizados contatos telefônicos para remarcá-los nesse ambulatório, com o intuito de verificar se os mesmos preenchiam aos critérios de inclusão e nenhum de exclusão. Portanto, para os pacientes já triados até junho de 2011, o período de inclusão de pacientes foi estendido por mais dois meses (até agosto de 2011).

\subsection{Caracterização do serviço}

A investigação foi realizada no HCFMUSP, um hospital universitário de nível terciário de São Paulo, no Estado de São Paulo. Esse hospital é integrado ao Sistema Único de Saúde (SUS) e atende pacientes de alta complexidade, sendo referência internacional.

A Unidade (2MG 0404) do Ambulatório do Serviço de Gastroenterologia é referência para o tratamento da hepatite B crônica, com a realização de aproximadamente 1.500 atendimentos em 2011, sendo em média 30 pacientes agendados por semana.

Os pacientes portadores de hepatite B crônica têm direito ao fornecimento gratuito de medicamentos de alto custo previstos no "Protocolo Clínico e Diretrizes Terapêuticas para o Tratamento da Hepatite Viral Crônica B e Coinfecções", publicado pelo Ministério da Saúde em formato eletrônico (2009), e no ano seguinte impresso(66).

Considerando a necessidade de aprimorar os instrumentos e estratégias que asseguram e ampliam o acesso da população aos serviços de saúde, foi atualizada a política de acesso aos medicamentos em estreita relação com os princípios da Constituição e da organização do SUS. Sendo assim, a Portaria oㅡ 2.981, de 26 de novembro de 2009, regulamenta e aprova, no âmbito do SUS, o Componente Especializado da Assistência Farmacêutica como parte da Política Nacional de Assistência Farmacêutica, integrante do Bloco de Financiamento da Assistência Farmacêutica. A partir desta data, são autorizados como Componente Especializado da Assistência 
Farmacêutica para tratamento da hepatite B crônica os seguintes medicamentos: adefovir, entecavir, lamivudina, tenofovir, interferon-alfa e interferon peguilado ${ }^{(66,114)}$.

\subsection{Triagem dos pacientes}

Para a triagem dos pacientes, foi gerado o relatório com o nome dos agendados, semanalmente, antes das consultas médicas realizadas na Unidade (2MG 0404). O atendimento médico dessa Unidade acontecia sempre às quintas-feiras, no turno da manhã, mesmo horário em que os pacientes eram convidados a participar da pesquisa.

A partir do relatório de agendamento, os pacientes foram divididos em dois grupos: os que já tinham registro de retirada de algum medicamento para tratamento da hepatite $B$ crônica na Farmácia Ambulatorial do HCFMUSP, que era um critério de seleção, e aqueles que nunca retiraram nenhum medicamento antiviral para essa doença.

Os pacientes em uso de interferon-alfa ou interferon peguilado foram excluídos desse estudo porque esse tratamento é realizado por tempo limitado e o número de efeitos colaterais é superior às drogas antivirais. Ainda, trata-se de um número de paciente muito pequeno, para o qual a não adesão não resultaria diretamente no desenvolvimento de resistência antiviral, visto que esses medicamentos são classificados como imunomoduladores.

\subsection{Seleção da população em estudo}

\subsubsection{Critérios de inclusão}

Os seguintes critérios de inclusão deveriam ser atendidos no momento da triagem para a participação no estudo:

I. Pacientes de ambos os sexos, com idade $\geq 18$ anos.

II. Pacientes com diagnóstico de infecção crônica pelo vírus da hepatite B. 
III. Pacientes em tratamento, por pelo menos três meses, com um ou mais dos seguintes antivirais: adefovir (ADV) $10 \mathrm{mg} / \mathrm{dia}$, entecavir (ETV) 0,5 - $1 \mathrm{mg} / \mathrm{dia}$, lamivudina (3TC) $150 \mathrm{mg} / \mathrm{dia}$, e/ou tenofovir (TDF) $150 \mathrm{mg} / \mathrm{dia}$.

IV. Disposição e capacidade em responder as perguntas do questionário.

V. Pacientes que concordam em participar do estudo e fornecem o consentimento livre e esclarecido, com a compreensão de que o paciente possui o direito de se retirar do estudo a qualquer momento.

\subsubsection{Critérios de exclusão}

Os seguintes critérios excluíam os pacientes da amostra do estudo:

I. Soroconversão do AgHBs levando ao término do tratamento antiviral (antes do início do estudo).

II. Graves distúrbios psiquiátricos, neurológicos e cognitivos associados.

III. Coinfecção com hepatite $\mathrm{C}$ e hepatite $\mathrm{D}$.

IV. Coinfecção pelo vírus da imunodeficiência humana (HIV) ou doença relacionada à Síndrome da Imunodeficiência Adquirida (AIDS).

\subsubsection{Diagnóstico primário}

Pacientes que apresentavam infecção crônica pelo vírus da hepatite $B$ (definida por AgHBs positivo por mais de seis meses), em tratamento há pelo menos três meses com um ou mais dos seguintes antivirais: adefovir, entecavir, lamivudina, e/ou tenofovir.

\subsubsection{Número de indivíduos}

Foram incluídos todos os pacientes da Unidade (2MG 0404), recrutados no período de dezembro de 2010 a agosto de 2011, do Ambulatório do Serviço de Gastroenterologia que apresentavam infecção 
crônica pelo vírus da hepatite $\mathrm{B}$, que atendiam aos critérios de inclusão e nenhum de exclusão.

\subsection{Avaliação dos desfechos}

Os desfechos primários foram as frequências de resposta virológica e adesão ao tratamento após 4 anos de seguimento. Os desfechos secundários incluíram a frequência de migração entre os grupos distribuídos por desfechos virológicos e de adesão ao tratamento antiviral ao longo do tempo; e os preditores de falha de tratamento da hepatite $B$ crônica no início do estudo.

Após a inclusão de pacientes no estudo, a quantificação plasmática do antiviral e a pesquisa de variantes de resistência às drogas foram avaliadas para a compreensão dos fatores associados a falha de tratamento no início do estudo, em sujeitos de pesquisa com amostras positivas de HBV-DNA.

\subsection{Avaliação de adesão ao tratamento antiviral por métodos indiretos}

A avaliação da adesão ao tratamento antiviral foi realizada em três períodos: Dezembro (2010) / Agosto (2011), Novembro (2013) / Maio (2014) e Julho (2014) / Março (2015).

Foi utilizada a versão em português de um questionário validado denominado "Questionário para avaliação da adesão ao tratamento antiviral em pacientes portadores de hepatite B crônica" (CEAT-HBV) ${ }^{(88,89)}$, que é um instrumento composto por vinte perguntas as quais avaliam o grau de adesão ao tratamento antiviral (Anexo B).

O CEAT-HBV compreende 20 itens e foi subdividido em dois domínios. O primeiro domínio contempla perguntas que questionam o grau de cumprimento ao tratamento antiviral, e é composto de cinco perguntas (1-4 e 12), e o segundo está relacionado a barreiras para a não adesão, compreendendo as demais quinze perguntas do questionário (5-11 e 13-20) $(88,89)$. 
A quantificação das respostas foi realizada mediante a escala Likert de cinco pontos, exceto nos itens 5, 19 e 20 do questionário, e maior pontuação indica maior grau de adesão ao tratamento ${ }^{(88,89)}$.

$\mathrm{Na}$ questão 5, a pontuação varia de zero a dois pontos, sendo caracterizado de zero quem não sabe o nome e dose do antiviral utilizado no momento, um ponto quando o paciente sabe apenas uma das informações e dois pontos quando a resposta é completa. Nas questões 19 e 20, a pontuação varia de zero a um ponto por pergunta, sendo que respostas negativas na questão 19 e afirmativas na questão 20 recebem pontuações. O escore mínimo é de 17 e o máximo, 89 pontos. O CEAT-HBV apresenta um ponto de corte (< 80 pontos) no escore global do questionário, que indica pacientes em não adesão ao tratamento antiviral e está correlacionado a HBV-DNA detectável(88, 89).

Foi utilizado também um questionário amplamente utilizado para identificar o grau de adesão ao tratamento medicamentoso prescrito, denominado Teste de Morisky(86). Este teste avalia o comportamento do paciente em relação ao uso diário do medicamento, com base nas respostas a quatro perguntas, relacionadas ao horário, esquecimento, percepção de ausência de sintomas da doença e ausência de efeitos colaterais (Anexo $C$ ).

As respostas às perguntas do teste foram pontuadas, atribuindo-se um ponto a cada resposta afirmativa. Assim, o resultado do teste pode ser expresso em uma escala entre zero e quatro pontos. Dessa forma, uma resposta afirmativa a qualquer uma dessas perguntas classifica o indivíduo em não adesão(86).

A resposta virológica foi considerada um desfecho de adesão e foi avaliada através do monitoramento qualitativo do HBV-DNA no plasma/soro dos pacientes. Resultados de HBV-DNA indetectáveis foram considerados um método indireto de avaliação da adesão ao tratamento devido à forte ligação entre taxa de adesão e resposta virológica(103). A quantificação do HBV-DNA foi realizada através de PCR em tempo real, utilizando o COBAS TaqMan HBV test (Roche Molecular Systems, Inc., Branchburg, NJ, Estados Unidos). O limite de detecção do HBV-DNA estava entre 12 e 110.000 .000 
UI/mL. Quando o sujeito de pesquisa estava com HBV-DNA positivo na primeira avaliação de adesão, foram realizadas a confirmação de adesão por método direto, através da quantificação sorológica/plasmática do antiviral; e a pesquisa de variantes de resistência às drogas para hepatite $B$.

\subsection{Avaliação de adesão ao tratamento antiviral por método direto}

\subsubsection{Pacientes e amostras}

As amostras de soro ou plasma obtidas dos pacientes foram oriundas do Biorrepositório de material biológico humano do Departamento de Gastroenterologia da Faculdade de Medicina da Universidade de São Paulo. Foram selecionadas as amostras de soro ou plasma do mesmo período de recrutamento e primeira avaliação de adesão ao tratamento. As amostras foram enviadas para o Laboratory of Biochemical Pharmacology do Departamento de Pediatria da Emory University, localizado em Atlanta, Geórgia, Estados Unidos.

\subsubsection{Quantificação plasmática do antiviral}

Foram utilizados $50 \mu \mathrm{L}$ de soro/plasma (amostras de 3TC em monoterapia) e $200 \mu \mathrm{L}$ de plasma/soro (amostras com outros esquemas terapêuticos) para extração com $1 \mathrm{~mL}$ de metanol 100\% e $10 \mathrm{ng} / \mathrm{mL}$ de emtricitabina (amostras de 3TC em monoterapia); ou $10 \mathrm{ng} / \mathrm{mL}$ de emtricitabina e $1 \mathrm{ng} / \mathrm{mL}$ de aciclovir (amostras com outros esquemas terapêuticos). O sobrenadante de cada extração era coletado, rotaevaporado, e reconstituído com $300 \mu \mathrm{L}$ de ácido fórmico 0,1\%.

Posteriormente, as amostras foram analisadas por cromatografia líquida acoplada a espectrômetro de massa em tandem (LC-MS/MS). Um sistema de HPLC Dionex Ultimate 3000 (Thermo Scientific, Waltham, MA) acoplado com um espectrômetro de massas do tipo triplo quadrupolo $A B$ SCIEX API 5000 (AB SCIEX, Framingham, MA), com uma ionização por eletronebulização operado em modo positivo, foi usado para a análise de 
LC-MS/MS. Analyst software versão 1.5 .2 foi usado para operar o espectrômetro de massas e para a análise dos dados.

As curvas de calibração foram geradas a partir de padrões de 3TC, ADV, TDF e ETV, por diluições em série em amostras de doadores livres de drogas, utilizando o mesmo método de extração descrito anteriormente (Figura 11)(115). A faixa linear foi: Lamivudina (3TC), 1 - $800 \mathrm{ng} / \mathrm{mL}$; Tenofovir (TDF), 0,05 - $400 \mathrm{ng} / \mathrm{mL}$; Adefovir (ADV), 0,25 - $400 \mathrm{ng} / \mathrm{mL}$; Entecavir (ETV) $0,01-20 \mathrm{ng} / \mathrm{mL}$.
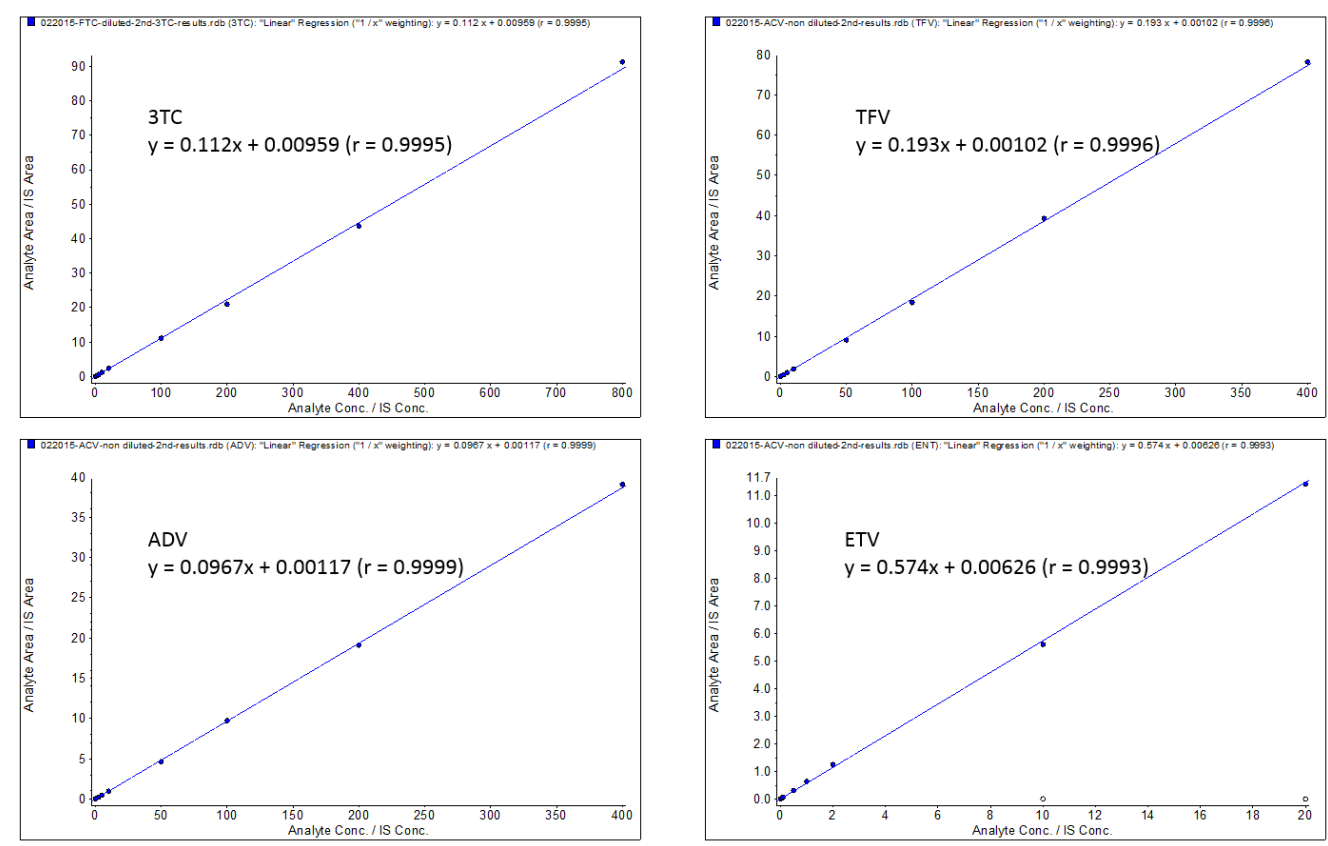

Figura 11. Curva padrão de calibração para os quatro analitos (3TC, Tenofovir, Adefovir e Entecavir).

\subsection{Genotipagem do HBV e pesquisa de variantes de resistência antiviral}

\subsubsection{Pacientes e amostras}

As amostras de soro ou plasma obtidas dos pacientes foram oriundas do mesmo banco de amostras acima citado e enviadas também para o Laboratory of Biochemical Pharmacology, no Estados Unidos. 
Os pacientes com HBV-DNA positiva, que entraram no estudo, foram selecionados para a realização do sequenciamento convencional para identificação do genótipo e das variantes de resistência antiviral. As amostras de soro/plasma são da primeira avaliação de adesão ao tratamento.

Para os demais pacientes com HBV-DNA indetectável no momento da inscrição para o estudo, foram selecionadas a primeira amostra de soro/plasma disponível nesse banco de amostras, com o intuito de selecionar amostras positivas para a realização do sequenciamento convencional para identificação do genótipo.

\subsubsection{PCR e sequenciamento}

Os genótipos de HBV e variantes de resistência antiviral foram analisados por sequenciamento direto. O DNA foi extraído de $200 \mu \mathrm{L}$ de soro/plasma usando o Qiagen EZ1® Virus Mini Kit v2.0 (Qiagen, Hilden, Alemanha), de acordo com as instruções do fabricante, e eluído em $60 \mu \mathrm{L}$ de água livre de nucleasse (Qiagen, Hilden, Alemanha).

Dessas amostras de DNA, a região do gene da polimerase do HBVDNA foi amplificada por Nested PCR utilizando primers específicos. Resumidamente, os primers, iniciador (forward) na direção 5'-3' (HBV0179FE: 5'- CTA GGA CCC CTG CTC GTG TT -3') e reverso 5'-3' (HBV1286RE: 5'- GCT AGG AGT TCC GCA GTA TGG -3'), foram utilizados na primeira etapa (round) do PCR.

Os primers iniciadores internos: sense, HBVRes311FN (5'- GCT GCA GTC CCC AAC CTC CAA TCA CT3') e antisense, HBVRes1026RN (5'- GGA GCA GCA AAV CCC AAA AGW CC -3') foram usados para o Nested PCR. O Anexo D apresenta o protocolo para programação do Nested PCR.

Os fragmentos pretendidos foram amplificados usando duas vezes 0 PCR MasterMix contendo $10 \mu \mathrm{L}$ de uma mistura para PCR (PerfeCTa SYBR Green FastMix, Low ROX [Quanta BioSciences, Estados Unidos]) com $10 \mu \mathrm{L}$ de DNA extraído (primeiro round) e $3 \mu \mathrm{L}$ do produto do primeiro round de PCR (segundo round). 
Após a amplificação do gene da polimerase, os amplicons (715 pares de bases) foram visualizados por eletroforese em gel de agarose, e purificados através do QIAquick PCR Purification Kit (Qiagen, Hilden, Alemanha), de acordo com as instruções do fabricante. Os produtos de PCR foram quantificados por NanoDrop 2000 spectrophotometer (Thermo Fisher Scientific, Estados Unidos).

Os produtos de PCR foram sequenciados bidireccionalmente, através do método de Sanger, pela GENEWIZ (New Jersey, Estados Unidos) e foram analisados em seguida com o software DeepChek- HBV/HDV v1.4 (ABL SA, Luxemburgo).

\subsection{Procedimento de coleta}

\subsubsection{Aspectos éticos}

O projeto de pesquisa foi submetido à avaliação da Comissão Ética Científica do Departamento de Gastroenterologia do HCFMUSP e da Comissão de Ética para Análise de Projetos de Pesquisa do HCFMUSP (CAPPesq). Sendo assim, em sessão de 27 de outubro de 2010, a CAPPesq aprovou o protocolo de pesquisa número 0581/10, intitulado "Adesão ao tratamento farmacológico com antivirais orais em pacientes portadores de hepatite crônica B" (Anexo E).

Todos os pacientes que preenchiam aos critérios de inclusão e nenhum de exclusão receberam o Termo de Consentimento Livre e Esclarecido (Anexo F), que foi lido, discutido e assinado por eles e pelo investigador principal antes de qualquer procedimento do protocolo. Nesse momento, os pacientes foram orientados sobre o direito de retirar o consentimento a qualquer momento, sem prejuízo algum ao tratamento recebido pelo paciente.

Os questionários respondidos foram preservados em banco de dados eletrônico de propriedade do pesquisador responsável e a identidade do entrevistado foi preservada. 
Posteriormente, o projeto de pesquisa foi submetido à avaliação da CAPPesq em dois outros momentos. Primeiramente, para a mudança de finalidade da pesquisa - doutorado (Anexo G), e em seguida, com a atualização do projeto de pesquisa contemplando as atividades do doutorado sanduíche, realizado no Laboratory of Biochemical Pharmacology da Emory University, em Atlanta (Geórgia), nos Estados Unidos (Anexo H).

\subsubsection{Amostragem}

Couto-Junior ${ }^{(116)}$ desenvolveu um novo método para o cálculo do tamanho de amostra a partir de questionários usados em pesquisa na área da saúde. Porém, ao demonstrar a aplicabilidade em outros questionários com número de itens e categorias semelhantes ao instrumento utilizado nesse estudo (CEAT-HBV), o tamanho de amostra encontrado foi muito superior ao número de pacientes em tratamento para a hepatite B crônica na Unidade (2MG 0404) do Ambulatório do Serviço de Gastroenterologia.

Como qualquer método para cálculo de tamanho de amostra pode produzir tamanhos de amostra tão grandes ou tão pequenos quanto se desejem, optou-se por incluir todos os pacientes que preenchiam aos critérios de inclusão e nenhum de exclusão, sendo utilizada uma amostragem consecutiva (não probabilística) ${ }^{(116,117)}$.

\subsubsection{Entrevista}

As entrevistas foram realizadas por meio da aplicação do questionário, em uma sala reservada para trabalhar sem interrupções, com um tempo máximo de 30 minutos. Os pacientes foram esclarecidos sobre o estudo e convidados a participar, antes da consulta médica agendada para o mesmo dia. Todas as entrevistas foram conduzidas pelo investigador principal, na primeira visita, que utilizou o modelo de entrevista estruturada dirigida. Logo após as entrevistas, todos os questionários foram revisados pelos pesquisadores para garantir o controle de qualidade do preenchimento. 
Nas duas visitas subsequentes, as entrevistas foram realizadas por diferentes farmacêuticos clínicos, seguindo o mesmo protocolo, sob supervisão direta dos investigadores principais.

\subsection{Análise estatística}

Todas as análises estatísticas foram realizada usando o Microsoft Excel 2016 (Microsoft Corporation, Redmond, WA, Estados Unidos) e o SPSS versão 13.0 (IBM Corporation, Armonk, NY, Estados Unidos). Variáveis contínuas foram expressas em média \pm desvio padrão, ou mediana e mínimo/máximo. Variáveis categóricas foram expressas por valor absoluto e frequência; e foram analisadas usando o teste Qui-quadrado e teste exato de Fisher, quando apropriado.

A análise do desfecho primário foi realizada com os dados da população por intenção de tratamento (ITT), que eram todos os pacientes que foram incluídos na primeira avaliação de adesão do estudo. Para minimizar o viés e incluir todos os pacientes na análise de intenção de tratamento, a imputação do paciente em um grupo era necessária em caso de morte, abandono de tratamento ou soroconversão do AgHBs. Para os pacientes que completaram o estudo como planejado, as medidas tomadas na terceira avaliação de adesão foram utilizadas (análise per-protocolo).

Porém, quando o paciente interrompia prematuramente o tratamento antiviral, o desfecho virológico e de adesão ao tratamento era mudado para o grupo de pior desfecho (Não adesão e HBV-DNA positiva). Quando o paciente morria, ou apresentava soroconversão do AgHBs, o desfecho virológico e de adesão ao tratamento era mantido no mesmo grupo. Quando o paciente era retirado do estudo devido à perda de seguimento, o desfecho virológico e de adesão ao tratamento era mantido no mesmo grupo (se paciente transferiu o tratamento para outro serviço). Se nenhum contato fosse possível com o paciente, era caracterizado abandono de tratamento e o paciente era mudado para o grupo de pior desfecho. Pacientes que retiraram o consentimento durante o estudo foram excluídos da análise. 
Para avaliar os preditores de falha de tratamento da hepatite B crônica no início do estudo, foram analisadas as seguintes variáveis: presença de variantes de resistência antiviral, adesão pela quantificação plasmática do antiviral e duração do último esquema de tratamento antiviral.

Os conceitos do modelo de Markov foram utilizados para fazer a análise dinâmica dos desfechos virológicos e de adesão ao tratamento a longo prazo. Valores de $p<0,05$ eram considerados estatisticamente significativos.

\subsection{Revisão bibliográfica}

A realização da pesquisa bibliográfica ocorreu nos principais bancos de dados disponíveis eletronicamente, além de livros. Foram utilizados descritores indexados no Medical Subject Headings (MeSH) e no Descritores em Ciências da Saúde (DeCS) para obtenção de resultados mais precisos. Os artigos de maior interesse tiveram suas referências revistas para encontrar publicações não encontradas nos bancos de dados. A formatação e estruturação dos elementos textuais desta tese respeitaram as normas contidas no "Guia de apresentação de dissertações, teses e monografias", que foi publicado pela Faculdade de Medicina da Universidade de São Paulo, em 2011(118). 


\section{RESULTADOS}

\subsection{Amostra do estudo}

No período de dezembro de 2010 a agosto de 2011, foram realizados 876 agendamentos para realização de consulta médica na Unidade (2MG 0404) do Ambulatório do Serviço de Gastroenterologia, com um total de 580 pacientes.

Após a triagem realizada no período de recrutamento, foram selecionados 230 pacientes que apresentavam registro de retirada de algum medicamento para o tratamento da hepatite B crônica na Farmácia Ambulatorial do HCFMUSP.

Dos 230 pacientes com registro de tratamento da hepatite B crônica, 47 foram excluídos por não preencherem aos critérios de inclusão e exclusão do estudo. Sendo assim, 44 pacientes não preenchiam todos os critérios de inclusão: treze se recusaram a assinar o TCLE; dez não estavam mais em tratamento com os antivirais de uso oral no momento de entrada na pesquisa; nove apresentaram registro de tratamento para a infecção crônica do HBV com interferon-alfa ou interferon peguilado, apenas; quatro não foram localizados; três apresentavam registro de tratamento para a infecção crônica do vírus da hepatite $\mathrm{C}$ com interferon-alfa, três evoluíram a óbito e dois possuíam menos de três meses de tratamento. Três pacientes apresentaram algum critério de exclusão, sendo dois com graves distúrbios psiquiátricos e um portador de esclerose múltipla.

Após a aplicação dos critérios de seleção, finalizou-se com 183 pacientes, compondo a casuística ou amostra do estudo (Figura 12). Nesse ponto foi realizada a primeira avaliação de adesão ao tratamento.

Importante salientar que todos os pacientes que não compareceram à consulta médica e que não foram localizados nos contatos telefônicos tiveram seus dados pesquisados no prontuário do hospital e nos registros de 
dispensação da Farmácia Ambulatorial do HCFMUSP. Com isso, verificouse que três pacientes não estavam recebendo droga antiviral para 0 tratamento da hepatite B crônica e um foi transferido para outro Estado, sendo realizado lá o acompanhamento médico e a retirada dos medicamentos.

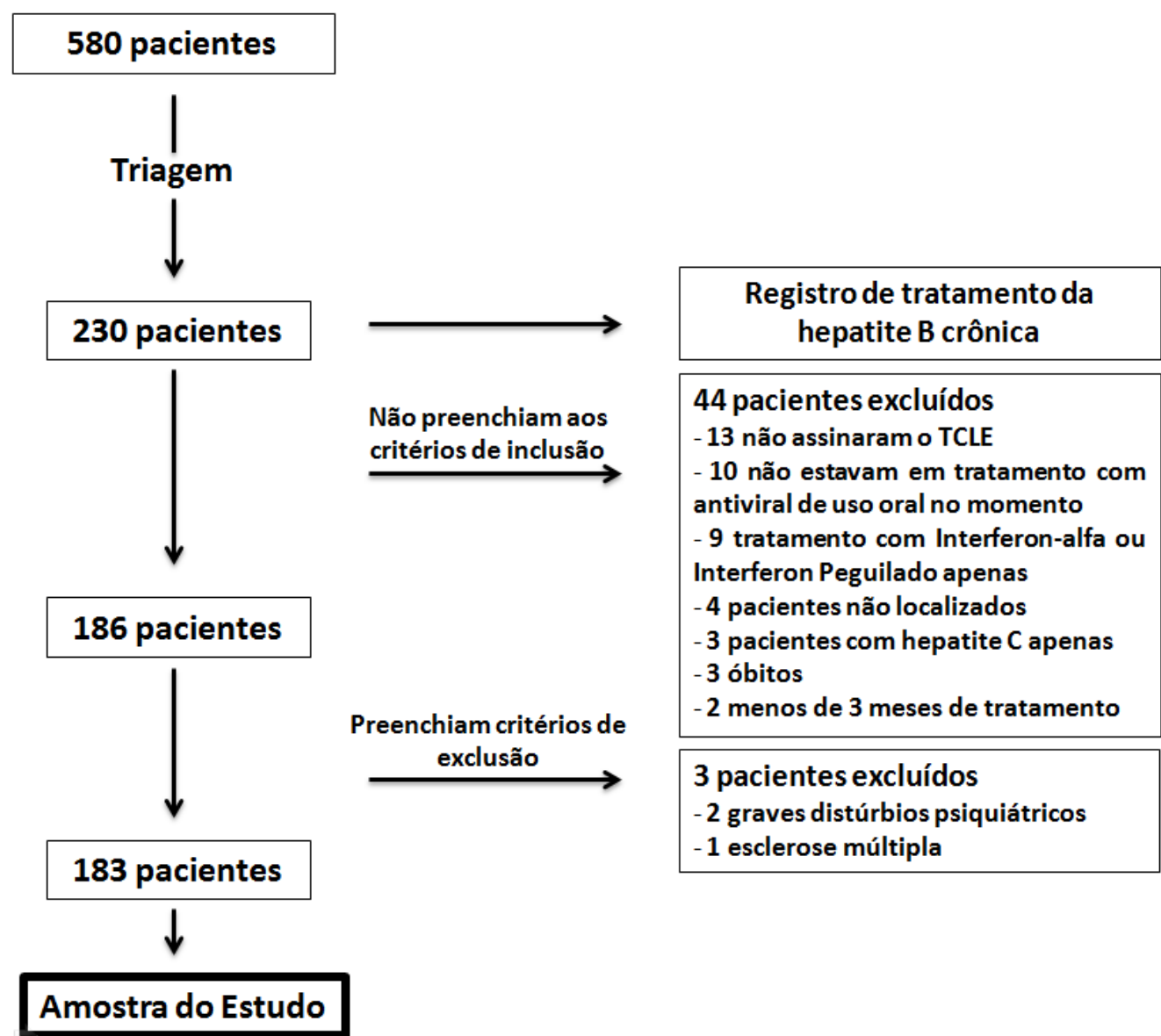

Figura 12. Seleção da Amostra do Estudo

Após a primeira avaliação de adesão ao tratamento, 40/183 pacientes foram excluídos devido a mortes (20), perda de seguimento (16), soroconversão do AgHBs (3), e interrupção do tratamento antiviral (1). A principal causa de morte foi $\mathrm{CHC}$ (11), seguida de choque não classificado (2), choque séptico com foco abdominal (1), insuficiência respiratória (1), acidente vascular cerebral (1), insuficiência renal crônica (1), pneumonia 
bacteriana (1), infarto agudo do miocárdio (1) e suicídio (1). Com relação aos pacientes com perda de seguimento, 12/16 não foram localizados após três tentativas de contato, 3/16 estavam sendo acompanhados em um centro de referência em hepatite $B$ de outra cidade, e 1/16 retirou o consentimento.

Após a segunda avaliação de adesão $(n=143), 8 / 143$ pacientes foram excluídos (4/8 estavam sendo acompanhados em um centro de referência em hepatite $B$ de outra cidade, $1 / 8$ teve perda de seguimento, 1/8 interrompeu o tratamento antiviral, 1/8 morreu por causa desconhecida, e 1/8 retirou o consentimento). Dessa forma, 135 pacientes realizaram a terceira avaliação de adesão (Figura 13).

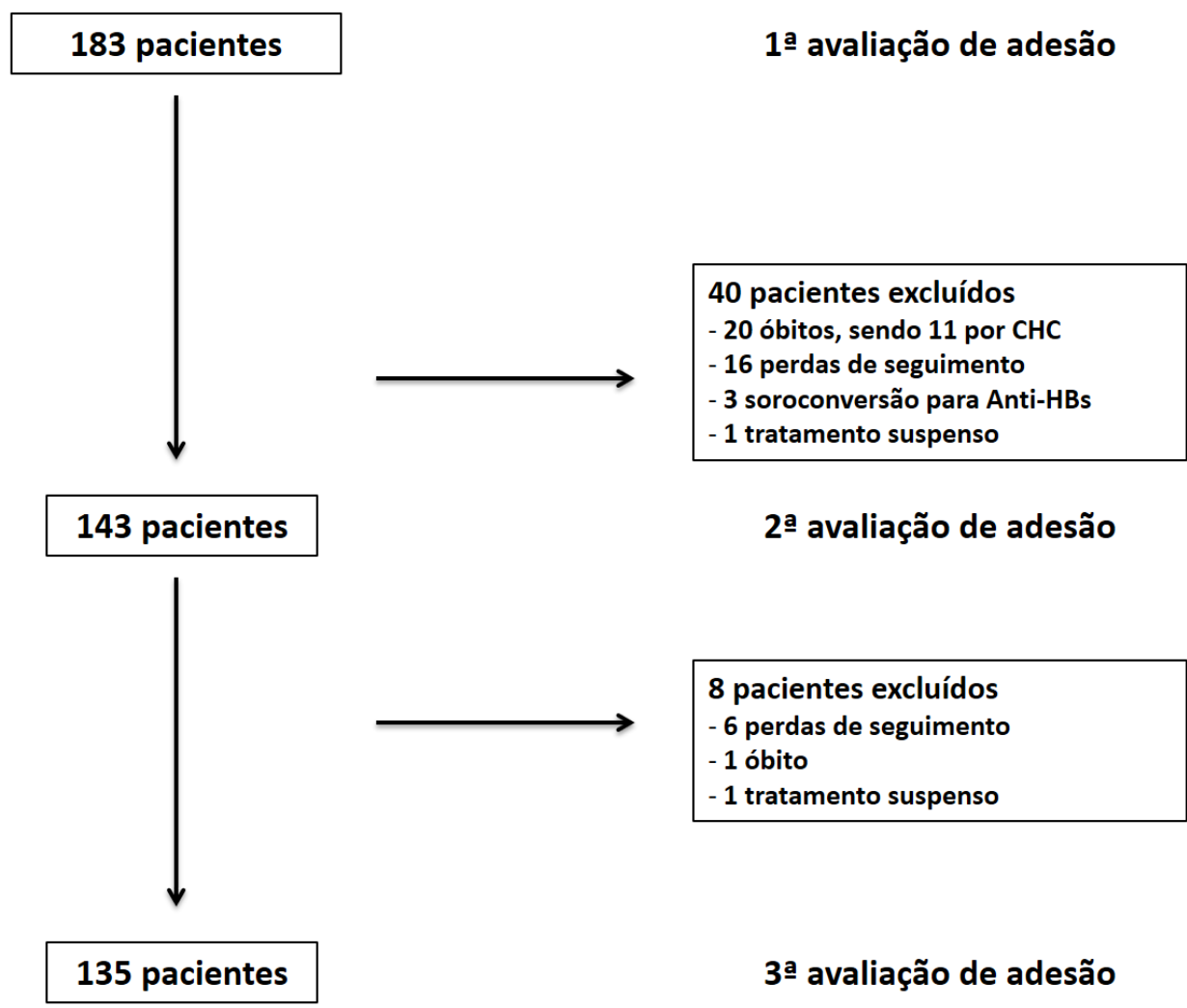

Figura 13. Representação esquemática das três avaliações de adesão ao tratamento e pacientes excluídos ao longo dos 4 anos de seguimento 
Como forma de verificar o status de sobrevida ao final do estudo, foram realizadas tentativas de localização de todos os 13 pacientes com perda de seguimento e não localizados, ao final do 4 ano de seguimento, em diversos bancos de dados da instituição. Com isso, foi observado que dez pacientes não localizados estavam vivos, pois tinham registro recente de consulta ou exames em outros ambulatórios, e três não tiveram informações adicionais encontradas.

\subsection{Caracterização da amostra do estudo}

No período de seleção dos pacientes para o estudo, foram avaliados 183 pacientes da Unidade (2MG 0404) do Ambulatório do Serviço de Gastroenterologia que apresentavam infecção crônica pelo vírus da hepatite $B$, que atendiam aos critérios de inclusão e não apresentavam nenhum de exclusão.

Os dados demográficos e socioeconômicos dos pacientes estão descritos na tabela 3. A maioria dos pacientes (> 95\%) era proveniente do Estado de São Paulo. A mediana de idade foi 54 anos e a população era predominantemente do sexo masculino (68,9\%). Aproximadamente metade $(54,1 \%)$ era da raça branca, $66,1 \%$ estavam casados e $90,2 \%$ dos pacientes referiram serem heterossexuais quando questionada a orientação sexual. Apenas metade dos pacientes $(50,8 \%)$ tinham escolaridade maior que o Ensino Fundamental Completo, aproximadamente $70 \%$ dos pacientes referiram uma renda média familiar anual inferior a $\$ 20,000.00$ USD e mais da metade deles $(55,7 \%)$ não estavam mais trabalhando, seja por estarem aposentados, serem do lar ou desempregados. Vale ressaltar que essa renda média familiar anual, era o total para uma mediana de 3 pessoas por família, mas podendo variar de 1 a 8 indivíduos.

A tabela 4 evidencia que aproximadamente um quarto dos pacientes portadores de hepatite B crônica tinham o genótipo A do HBV; $60 \%$ apresentavam diagnóstico de cirrose e $12 \%$ de carcinoma hepatocelular no início do estudo. A mediana de tempo desde o diagnóstico de hepatite $B$ 
crônica era de 13 anos e mais da metade deles $(54,1 \%)$ desconheciam a forma de transmissão para terem sido infectados pelo HBV.

Apenas $32,3 \%$ dos pacientes tinham realizado um tratamento prévio para hepatite $B$, mas não tiveram resposta satisfatória. Três quartos dos pacientes estavam realizando tratamento antiviral para HBV em monoterapia e os demais, associação de antivirais orais. A mediana de duração do esquema de tratamento antiviral, no início do estudo, era de 58 meses, mas $86,3 \%$ dos pacientes estavam nesse esquema terapêutico há mais de um ano, e metade deles $(49,7 \%)$, estavam no mesmo esquema há mais de cinco anos (Tabela 5).

O tempo de tratamento com antivirais, em meses, pode ser demonstrado na Tabela 6 . Podemos observar que não existe diferença estatisticamente significativa entre o tempo de tratamento com o desfecho virológico (HBV-DNA) e com a adesão ao tratamento. Foi observado também ausência de correlação entre o nível de carga viral de HBV e o tempo de tratamento com antivirais, em meses $(r=-, 055 ; p=0,456)$.

Podemos verificar também na tabela 5 que $20 \%$ dos pacientes referiam dificuldades de realizar o tratamento da hepatite $B, 45,9 \%$ deixaram de tomar o antiviral alguma vez e 53\% apresentaram alguma falha no fornecimento desses medicamentos, no ano anterior ao início do estudo. Porém, podemos ver que a proporção de pacientes com falha devido a não retirada do antiviral na farmácia $(37,7 \%)$ é maior que a falha devido à falta de medicamento em estoque para a dispensação $(27,3 \%)$. Ainda, essas falhas não tiveram associação com o comportamento de adesão dos pacientes no início do estudo $(p>0,05)$.

Esta população estudada apresentava muitas comorbidades, sendo que metade $(49,2 \%)$ dela possuía diagnóstico de pelo menos duas outras doenças crônicas; $20,8 \%$ tomavam cinco ou mais medicamentos concomitantes por dia, que representa $39,4 \%$ desses pacientes em uso de pelo menos cinco formas farmacêuticas (como comprimidos, cápsulas, entre outras) por dia (excluindo os antivirais). Ainda, 5,5\% dos pacientes faziam uso regular de álcool e 11,2\% eram tabagistas (Tabela 4). 
Tabela 3. Características demográficas e socioeconômicas dos pacientes no início do estudo. HCFMUSP, dezembro de 2010 a agosto de $2011(n=183)$

\begin{tabular}{|c|c|}
\hline Variáveis & $n=183$ \\
\hline \multicolumn{2}{|l|}{ Procedência, n (\%) } \\
\hline Cidade de São Paulo & $104(56,8)$ \\
\hline Interior do Estado de São Paulo & $70(38,3)$ \\
\hline Região Sudeste (exceto São Paulo) & $6(3,3)$ \\
\hline Demais regiões & $2(1,1)$ \\
\hline Exterior & $1(0,5)$ \\
\hline Idade $^{\star}$, anos & $54,0(18-83)$ \\
\hline Sexo masculino, n (\%) & $126(68,9)$ \\
\hline \multicolumn{2}{|l|}{ Raça/Cor ${ }^{\mathrm{a}}$, n (\%) } \\
\hline Branca & $99(54,1)$ \\
\hline Preta & $7(3,8)$ \\
\hline Amarela & $37(20,2)$ \\
\hline Parda & $40(21,9)$ \\
\hline \multicolumn{2}{|l|}{ Estado Civil, n (\%) } \\
\hline Solteiro & $39(21,3)$ \\
\hline Casado & $121(66.1)$ \\
\hline Divorciado & $23(12,6)$ \\
\hline \multicolumn{2}{|l|}{ Orientação sexual, n (\%) } \\
\hline Heterossexual & $165(90,2)$ \\
\hline Homossexual & $3(1,6)$ \\
\hline Bissexual & $6(3,3)$ \\
\hline Não informado & $9(4,9)$ \\
\hline \multicolumn{2}{|l|}{ Escolaridade, $n$ (\%) } \\
\hline Analfabeto & $7(3,8)$ \\
\hline Sabe ler e escrever & $4(2,2)$ \\
\hline Ensino Fundamental Incompleto & $62(33,9)$ \\
\hline Ensino Fundamental Completo & $17(9,3)$ \\
\hline Ensino Médio Incompleto & $8(4,4)$ \\
\hline Ensino Médio Completo & $35(19,1)$ \\
\hline Superior Incompleto & $10(5,5)$ \\
\hline Superior Completo & $35(19,1)$ \\
\hline Pós-Graduação & $5(2,7)$ \\
\hline \multicolumn{2}{|l|}{ Ocupação } \\
\hline Aposentado & $68(37,2)$ \\
\hline Trabalhador com Vínculo Empregatício & $49(26,8)$ \\
\hline Trabalhador Autônomo & $32(17,5)$ \\
\hline Do lar & $25(13,6)$ \\
\hline Desempregado & $9(4,9)$ \\
\hline Renda Anual* (USD) & $13,000(1,950-117,000)$ \\
\hline$\leq 10,000, \mathrm{n}(\%)$ & $71(38,8)$ \\
\hline $10,001-20,000, n(\%)$ & $59(32,3)$ \\
\hline $20,001-60,000, n(\%)$ & $44(24,0)$ \\
\hline$>60,001, \mathrm{n}(\%)$ & $9(4,9)$ \\
\hline Número de pessoas / casa & $3,0(1-8)$ \\
\hline
\end{tabular}

*mediana (mínimo - máximo)

aautorreferido, de acordo com prontuário médico. 
Tabela 4. História médica relacionada à hepatite $\mathrm{B}$ crônica no início do estudo. HCFMUSP, dezembro de 2010 a agosto de $2011(n=183)$

\begin{tabular}{|c|c|}
\hline Variáveis & $\mathrm{n}=\mathbf{1 8 3}$ \\
\hline Cirrose $^{\mathrm{a}}, \mathrm{n}(\%)$ & $109(59,6)$ \\
\hline Carcinoma Hepatocelular $^{\mathrm{b}}, \mathrm{n}(\%)$ & $22(12,1)$ \\
\hline \multicolumn{2}{|l|}{ Forma de transmissão, $\mathrm{n}(\%)$} \\
\hline Desconhecido ${ }^{c}$ & $99(54,1)$ \\
\hline Vertical & $47(25,7)$ \\
\hline Transfusão de sangue & $14(7,7)$ \\
\hline Sexual & $10(5,5)$ \\
\hline Hemodiálise & $5(2,7)$ \\
\hline Compartilhamento de seringas e agulhas & $3(1,6)$ \\
\hline Instrumental de barbeiros, manicures e dentistas & $3(1,6)$ \\
\hline Acidente ocupacional & $2(1,1)$ \\
\hline Tempo desde o diagnóstico de HBV ${ }^{\star, d}$ (anos) & $13,0(1-78)$ \\
\hline $\begin{array}{l}\text { HBV-DNA* }{ }^{*} \log _{10} \mathrm{IU} / \mathrm{mL} \\
\text { Genótipos de HBV, n (\%) }\end{array}$ & $1,73(1,07-8,04)$ \\
\hline Genótipo A & $46(25,1)$ \\
\hline Subgenótipo A1 & $28(15,3)$ \\
\hline Subgenótipo A2 & $2(1,1)$ \\
\hline Genótipo C & $22(12,1)$ \\
\hline Genótipo D & $26(14,2)$ \\
\hline Genótipo F & $2(1,1)$ \\
\hline Genótipo desconhecido & $87(47,5)$ \\
\hline Etilismo, n (\%) & $10(5,5)$ \\
\hline Tabagismo ${ }^{f}$, n (\%) & $21(11,5)$ \\
\hline Comorbidades crônicas* & $1(0-8)$ \\
\hline Nenhuma, $\mathrm{n}(\%)$ & $35(19,1)$ \\
\hline 1 doença, $\mathrm{n}(\%)$ & $58(31,7)$ \\
\hline$\geq 2$ doenças, $n(\%)$ & $90(49,2)$ \\
\hline Número de medicamentos concomitantes ${ }^{\star, g} /$ dia & $2,0(0-13)$ \\
\hline Nenhum, n (\%) & $40(21,8)$ \\
\hline 1 - 2 medicamentos, $n(\%)$ & $58(31,7)$ \\
\hline 3 - 4 medicamentos, n (\%) & $47(25,7)$ \\
\hline$\geq 5$ medicamentos, $\mathrm{n}(\%)$ & $38(20,8)$ \\
\hline $\begin{array}{l}\text { Número de unidades de medicamentos } \\
\text { concomitantes / dia }{ }^{*}, \mathrm{~h}\end{array}$ & $3(0-25)$ \\
\hline Nenhum, n (\%) & $40(21,8)$ \\
\hline 1 - 2 unidades, $n(\%)$ & $39(21,3)$ \\
\hline 3 - 4 unidades, n (\%) & $32(17,5)$ \\
\hline$\geq 5$ & $72(39,4)$ \\
\hline
\end{tabular}

*mediana (Mínimo - Máximo).

a Cirrose era diagnosticada por biópsia hepática ou ultrassonografia abdominal.

${ }^{b}$ Qualquer lesão sugestiva de $\mathrm{CHC}$, detectada por ultrassonografia no momento do diagnóstico, confirmada por pelo menos um dos seguintes critérios diagnósticos: histologia positiva, duas técnicas de imagem compatíveis com $\mathrm{CHC}$ (tomografia computadorizada e ressonância magnética com realce arterial e washout), ou um dos resultados de imagem previamente mencionados (qualquer técnica) sugestivos de CHC associado a níveis séricos de alfa-fetoproteína (AFP) > $400 \mathrm{ng} / \mathrm{mL}$ (119). c paciente refere desconhecer como foi infectado pelo HBV. 


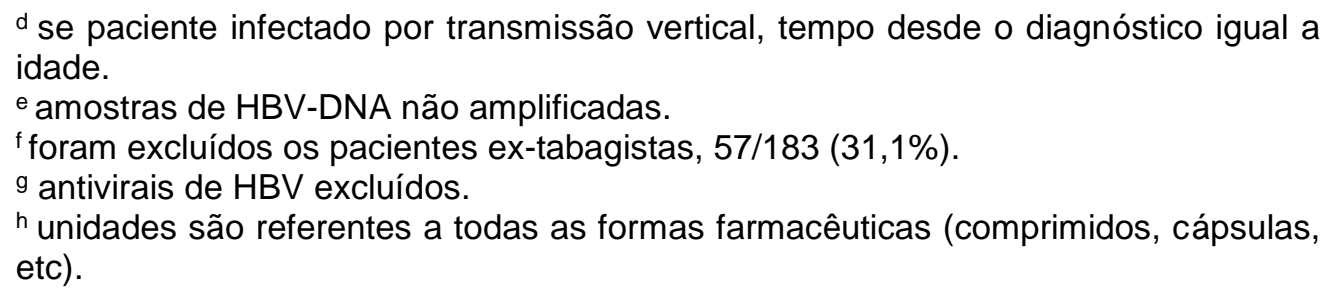

Tabela 5. Informações relacionadas ao tratamento da hepatite B crônica no início do estudo. HCFMUSP, dezembro de 2010 a agosto de $2011(n=183)$

\begin{tabular}{lc}
\hline Variáveis & $\mathbf{n}=\mathbf{1 8 3}$ \\
\hline Tratamento prévio do HBV, $\mathbf{n}(\%)$ & $124(67,7)$ \\
Nenhum & $49(26,7)$ \\
1 regime & $10(5,6)$ \\
$\geq 2$ regimes & $37(20,2)$ \\
Refere dificuldade de realizar o tratamento, $\mathbf{n}(\%)$ & $84(45,9)$ \\
Refere deixar de tomar o antiviral, $\mathbf{n}(\%)$ & $58,0(3-252)$ \\
Tempo de tratamento com antivirais* (meses) & \\
Antivirais em uso no início do estudo ${ }^{*}, \mathbf{n}(\%)$ & $98(53,6)$ \\
3TC & $6(3,3)$ \\
ADV & $20(10,9)$ \\
TDF & $12(6,6)$ \\
ETV & $28(15,3)$ \\
3TC+ADV & $19(10,4)$ \\
3TC+TDF & \\
Número de falhas de fornecimento do antiviral & \\
registrados na ficha de dispensação do paciente & \\
no ano anterior ao início do estudo ${ }^{\mathbf{b}}, \mathbf{n}(\%)$ & $86(47,0)$ \\
0 & $49(26,8)$ \\
1 & $26(14,2)$ \\
2 & $15(8,2)$ \\
3 & $7(3,8)$ \\
4 & \\
Causa da falha de fornecimento, $\mathbf{n}(\%)$ & $47(25,7)$ \\
Não retirada do antiviral pelo paciente & $28(15,3)$ \\
Falta do antiviral na farmácia & $22(12,0)$ \\
Falta e não retirada do antiviral pelo paciente & \\
\hline${ }^{*}$ mediana (Mínimo - Máximo). & \\
a antivirais para HBV usados $\geq 3$ meses. & \\
b dados coletados dos registros eletrônicos de dispensação da farmácia. \\
\end{tabular}


Tabela 6. Distribuição dos pacientes quanto ao tempo de tratamento com antivirais, em meses. HCFMUSP, dezembro de 2010 a agosto de $2011(n=183)$

\begin{tabular}{lcc}
\hline Variável & $\begin{array}{c}\text { Tempo de tratamento em meses } \\
\text { (Média } \pm \text { desvio padrão) }\end{array}$ & $\boldsymbol{p}$ \\
\hline Desfecho Virológico & $64,07 \pm 54,79$ & \\
HBV-DNA detectável & $69,97 \pm 48,34$ & 0,118 \\
HBV-DNA indetectável & & \\
Adesão CEAT-HBV & $73,56 \pm 50,53$ & 0,607 \\
Adesão & $60,03 \pm 50,54$ & \\
Não adesão &
\end{tabular}

\subsection{Desfecho primário}

A tabela 7 mostra que, no início do estudo (2010-11), a frequência de adesão de acordo com o CEAT-HBV era 56,8\% e de acordo com o desfecho virológico era $61,7 \%$. A adesão pelo teste de Morisky apresentou resultados similares.

Tabela 7. Frequência de adesão em função dos desfechos virológicos e de adesão ao tratamento pelo CEAT-HBV e Teste de Morisky, ao longo dos 4 anos de seguimento.

\begin{tabular}{|c|c|c|c|c|c|c|c|c|c|}
\hline \multirow{2}{*}{ Desfechos } & \multicolumn{9}{|c|}{ Frequência de adesão ao tratamento $n$ (\%) } \\
\hline & $2010-11$ & 2013-14 & $p$ & 2013-14 & 2014-15 & $p$ & 2010-11 & 2014-15 & $p$ \\
\hline $\begin{array}{c}\text { Adesão } \\
\text { (CEAT-HBV) - } \\
\text { população } \\
\text { per-protocol }\end{array}$ & $\begin{array}{c}104 / 183 \\
(56,8)\end{array}$ & $\begin{array}{c}101 / 143 \\
(70,6)\end{array}$ & 0,0105 & $\begin{array}{c}101 / 143 \\
(70,6)\end{array}$ & $\begin{array}{c}112 / 135 \\
(83,0)\end{array}$ & 0,0152 & $\begin{array}{c}104 / 183 \\
(56,8)\end{array}$ & $\begin{array}{c}112 / 135 \\
(83,0)\end{array}$ & 0,0001 \\
\hline $\begin{array}{c}\text { Adesão } \\
\text { (CEAT-HBV) - } \\
\text { população por } \\
\text { ITT }\end{array}$ & $\begin{array}{c}104 / 183 \\
(56,8)\end{array}$ & $\begin{array}{c}116 / 182 \\
(63,7)\end{array}$ & 0,1776 & $\begin{array}{c}116 / 182 \\
(63,7)\end{array}$ & $\begin{array}{c}130 / 181 \\
(71,8)\end{array}$ & 0,0993 & $\begin{array}{c}104 / 183 \\
(56,8)\end{array}$ & $\begin{array}{c}130 / 181 \\
(71,8)\end{array}$ & 0,0028 \\
\hline $\begin{array}{c}\text { Adesão (Teste } \\
\text { de Morisky) - } \\
\text { população } \\
\text { per-protocol }\end{array}$ & $\begin{array}{c}98 / 183 \\
(53,5)\end{array}$ & $\begin{array}{c}93 / 143 \\
(65,1)\end{array}$ & 0,0367 & $\begin{array}{c}93 / 143 \\
(65,1)\end{array}$ & $\begin{array}{c}95 / 135 \\
(70,4)\end{array}$ & 0,3420 & $\begin{array}{c}98 / 183 \\
(53,5)\end{array}$ & $\begin{array}{c}95 / 135 \\
(70,4)\end{array}$ & 0,0024 \\
\hline $\begin{array}{c}\text { Virológicos } \\
\text { (HBV-DNA } \\
\text { indetectável) - } \\
\text { população } \\
\text { per-protocol }\end{array}$ & $\begin{array}{c}113 / 183 \\
(61,7)\end{array}$ & $\begin{array}{c}87 / 143 \\
(60,8)\end{array}$ & 0,8671 & $\begin{array}{c}87 / 143 \\
(60,8)\end{array}$ & $\begin{array}{c}94 / 135 \\
(69,6)\end{array}$ & 0,1243 & $\begin{array}{c}113 / 183 \\
(61,7)\end{array}$ & $\begin{array}{c}94 / 135 \\
(69,6)\end{array}$ & 0,1450 \\
\hline $\begin{array}{l}\text { Virológicos } \\
\text { (HBV-DNA } \\
\text { indetectável) - } \\
\text { população por } \\
\text { ITT }\end{array}$ & $\begin{array}{c}113 / 183 \\
(61,7)\end{array}$ & $\begin{array}{c}103 / 182 \\
(56,6)\end{array}$ & 0,3164 & $\begin{array}{c}103 / 182 \\
(56,6)\end{array}$ & $\begin{array}{c}112 / 181 \\
(61,8)\end{array}$ & 0,3056 & $\begin{array}{c}113 / 183 \\
(61,7)\end{array}$ & $\begin{array}{c}112 / 181 \\
(61,8)\end{array}$ & 0,9797 \\
\hline
\end{tabular}


O CEAT-HBV identificou 79/183 (43\%) pacientes com não adesão ao tratamento antiviral e entre esses, 53/79 (67\%) apresentavam maior frequência de HBV-DNA detectável. Porém, 38\% (70/183) tinham HBV-DNA detectável sugerindo falha de resposta ao tratamento. Desfechos de longo prazo nos mostraram que a frequência de adesão, de acordo com o CEATHBV, foi de 70,6\% na segunda avaliação de adesão, baseado na população per-protocol; 63,7\%, baseado na população ITT. Essas frequências de adesão ao tratamento continuaram a aumentar após quatro anos de seguimento, alcançando 83\% ( $p<0,001)$ e 71,8\% (p<0,01) respectivamente. Os desfechos virológicos não apresentaram diferença estatisticamente significativa.

\subsection{Desfechos secundários}

As frequências de migração entre os diferentes grupos, de acordo com os resultados qualitativos do HBV-DNA e avaliação de adesão por CEAT-HBV, podem ser vistos nas figuras 14 (população per-protocol) e 15 (população ITT). Houve um aumento do fluxo de migração de pacientes para o grupo com adesão e HBV-DNA indetectável, representado em verde nessas figuras. Na população per-protocol, a frequência de migração do grupo não adesão e HBV-DNA detectável (representado em vermelho) para o grupo verde apresentou um aumento estatisticamente significativo $(p<0,001)$ ao longo da segunda e terceira avaliação de adesão, com melhores resultados após a terceira avaliação de adesão devido ao fluxo aumentado de migração de pacientes dos grupos representados em amarelo para o grupo verde $(p<0,001)$ (Tabela 8). A população ITT mostrou resultados similares e ocorreu uma manutenção estatisticamente significativa ao longo do tempo de pacientes nos grupos representados em verde e vermelho (Tabela 9). 
$2010-2011(n=183)$

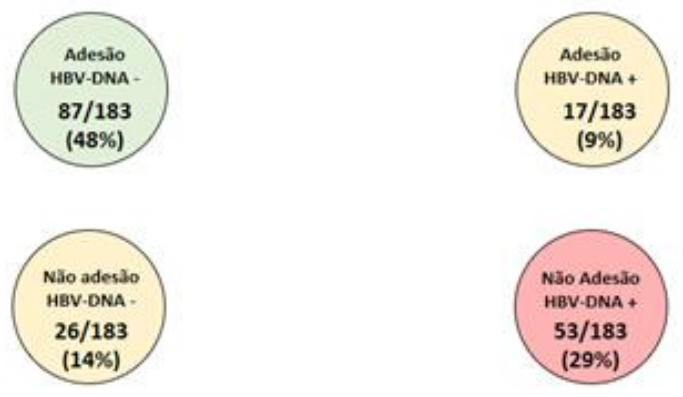

$2013-2014(n=143)$

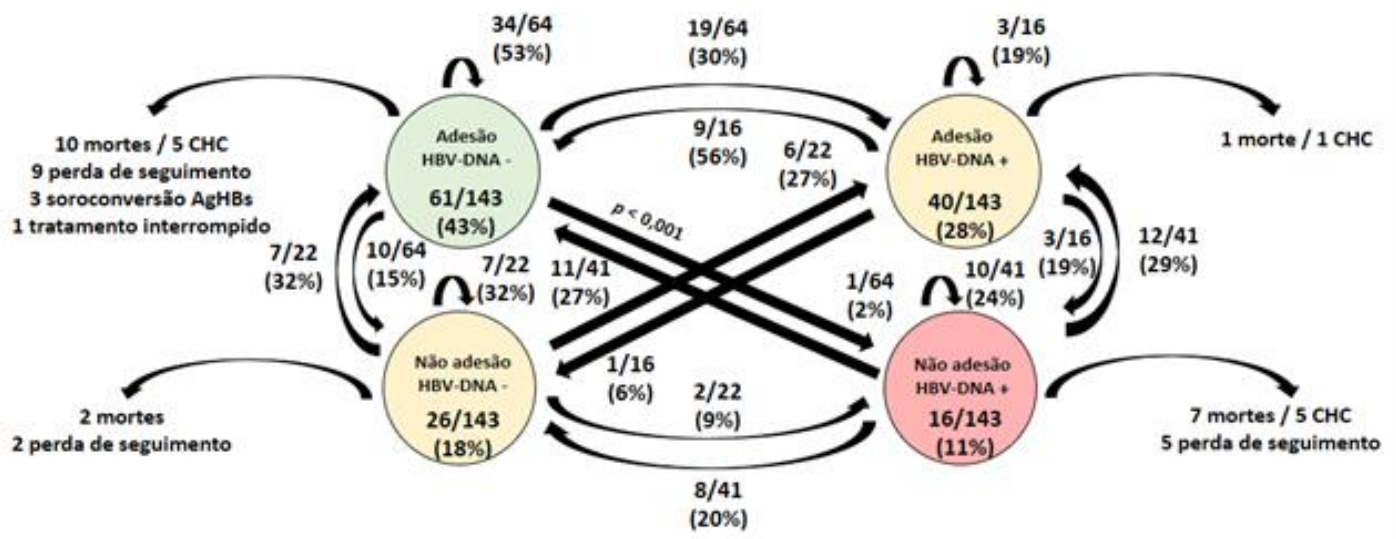

$2014-2015(n=135)$

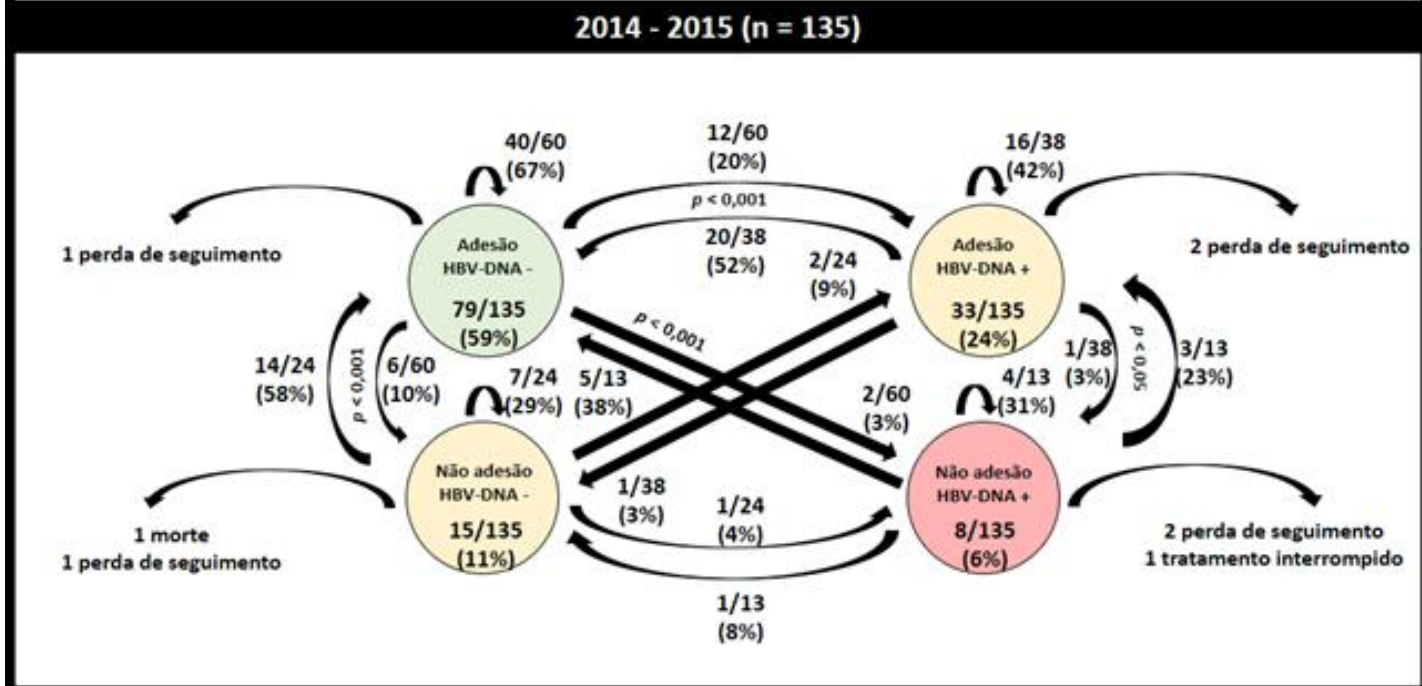

Figura 14. Análise dinâmica dos desfechos virológicos e de adesão ao tratamento na população per-protocol. As cores apresentam os desfechos em ordem progressiva: vermelho (pior), amarelo (intermediário) e verde (melhor). 
Tabela 8. Frequência de migração entre os grupos distribuídos por desfechos virológicos e de adesão ao tratamento antiviral ao longo do tempo, de acordo com a população per-protocol. HCFMUSP, dezembro de 2010 a março de 2015

\begin{tabular}{|c|c|c|c|c|c|}
\hline \multirow{2}{*}{ Desfechos } & \multicolumn{5}{|c|}{ Frequência de migração - n (\%) } \\
\hline & 2013-14 & $p$ & 2013-14 & 2014-15 & $p$ \\
\hline $\begin{array}{c}\text { Mantém adesão e } \\
\text { HBV-DNA (-) }\end{array}$ & $34 / 64$ (53\%) & - & \multicolumn{2}{|c|}{$40 / 60(67 \%)$} & 0,1760 \\
\hline $\begin{array}{l}\text { Mantém adesão e } \\
\text { HBV-DNA (+) }\end{array}$ & $3 / 16(19 \%)$ & - & \multicolumn{2}{|c|}{$16 / 38(42 \%)$} & 0,1276 \\
\hline $\begin{array}{c}\text { Mantém não adesão e } \\
\text { HBV-DNA (-) }\end{array}$ & 7/22 (32\%) & - & \multicolumn{2}{|c|}{$7 / 24(29 \%)$} & 1,0000 \\
\hline $\begin{array}{c}\text { Mantém não adesão e } \\
\text { HBV-DNA (+) }\end{array}$ & $10 / 41(24 \%)$ & - & \multicolumn{2}{|c|}{$4 / 13(31 \%)$} & 0,7216 \\
\hline $\begin{array}{c}\text { Migração entre adesão } \\
\text { com HBV-DNA (-/+) }\end{array}$ & $\begin{array}{c}19 / 64(30 \%) / \\
9 / 16(56 \%)\end{array}$ & 0,0764 & \multicolumn{2}{|c|}{$\begin{array}{l}10 / 60(20 \%) / \\
20 / 38(52 \%)\end{array}$} & 0,0003 \\
\hline $\begin{array}{c}\text { Migração entre adesão } \\
\text { e HBV-DNA (-) com } \\
\text { não adesão e HBV } \\
\text { DNA (+) }\end{array}$ & $\begin{array}{l}1 / 64(2 \%) / \\
11 / 41(27 \%)\end{array}$ & 0,0001 & \multicolumn{2}{|c|}{$\begin{array}{l}2 / 60(3 \%) / \\
5 / 13(38 \%)\end{array}$} & 0,0015 \\
\hline $\begin{array}{c}\text { Migração entre } \\
\text { HBV-DNA (-) com } \\
\text { adesão/não adesão }\end{array}$ & $\begin{array}{c}10 / 64(15 \%) / \\
7 / 22(22 \%)\end{array}$ & 0,1242 & \multicolumn{2}{|c|}{$\begin{array}{l}6 / 60(10 \%) / \\
14 / 24(58 \%)\end{array}$} & 0,0001 \\
\hline $\begin{array}{l}\text { Migração entre não } \\
\text { adesão com HBV-DNA } \\
(-/+)\end{array}$ & $\begin{array}{l}2 / 22(9 \%) / \\
8 / 41(20 \%)\end{array}$ & 0,4718 & \multicolumn{2}{|c|}{$\begin{array}{l}1 / 24(4 \%) / \\
1 / 13(8 \%)\end{array}$} & 1,0000 \\
\hline $\begin{array}{c}\text { Migração entre } \\
\text { HBV-DNA (+) com } \\
\text { adesão/não adesão }\end{array}$ & $\begin{array}{l}3 / 16(19 \%) / \\
12 / 41(29 \%)\end{array}$ & 0,5173 & \multicolumn{2}{|c|}{$\begin{array}{l}1 / 38(3 \%) / \\
3 / 13(23 \%)\end{array}$} & 0,0464 \\
\hline
\end{tabular}

Houve uma substituição do esquema terapêutico de antivirais, presente no início do estudo, que foi notado a partir da segunda avaliação de adesão (Figura 16), como representado a seguir: 54/143 (37,8\%) dos pacientes com $3 T C+T D F$, seguido de 44/143 (30,7\%) com 3TC, 16/143 (11,2\%) com $3 T C+A D V, 15 / 143$ (10,5\%) com TDF, 8/143 (5,6\%) com ETV, 5/143 (3,5\%) com ADV e 1/143 (0,7\%) com ADV+ETV. Na terceira avaliação de adesão, era representado por 56/135 (41,5\%) dos pacientes com 3TC+TDF, 39/135 $(28,9 \%)$ com 3 TC, $15 / 135$ (11,1\%) com TDF, $12 / 135$ (8,9\%) com 3TC+ADV, 
7/135 (5,2\%) com ETV, 5/135 (3,7\%) com ADV e 1/135 (0,7\%) com ADV+ETV), de acordo com a população per-protocol.

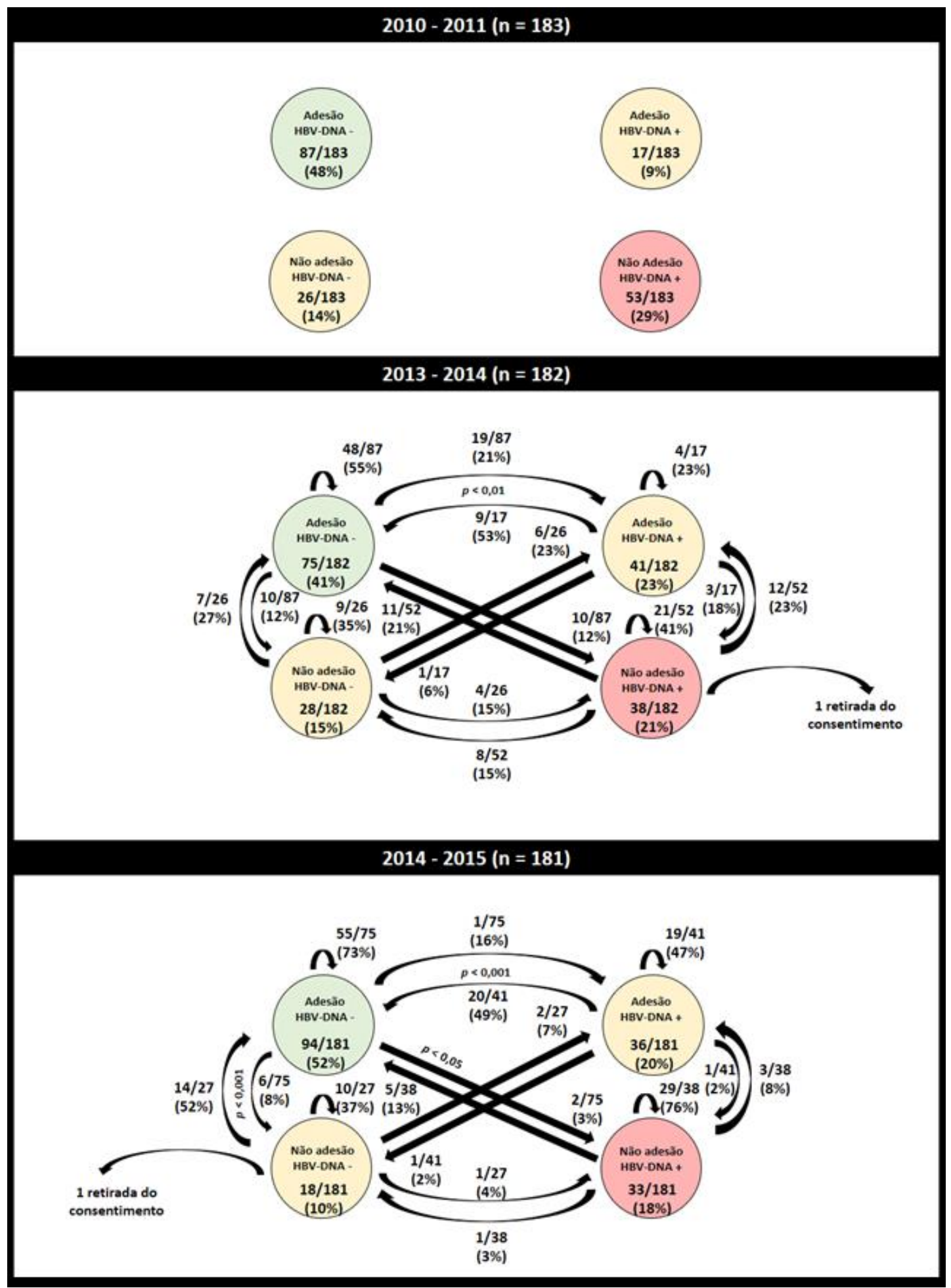

Figura 15. Análise dinâmica dos desfechos virológicos e de adesão ao tratamento na população ITT. As cores apresentam os desfechos em ordem progressiva: vermelho (pior), amarelo (intermediário) e verde (melhor). 
Tabela 9. Frequência de migração entre os grupos distribuídos por desfechos virológicos e de adesão ao tratamento antiviral ao longo do tempo, de acordo com a população por ITT. HCFMUSP, dezembro de 2010 a março de 2015

\begin{tabular}{|c|c|c|c|c|c|}
\hline \multirow{2}{*}{ Desfechos } & \multicolumn{5}{|c|}{ Frequência de migração - n (\%) } \\
\hline & 2013-14 & $p$ & 2013-14 & 2014-15 & $p$ \\
\hline $\begin{array}{c}\text { Mantém adesão e } \\
\text { HBV-DNA (-) }\end{array}$ & 48/87 (55\%) & - & \multicolumn{2}{|c|}{$55 / 75(73 \%)$} & 0,0256 \\
\hline $\begin{array}{l}\text { Mantém adesão e } \\
\text { HBV-DNA (+) }\end{array}$ & $4 / 17(23 \%)$ & - & \multicolumn{2}{|c|}{$19 / 41(47 \%)$} & 0,1442 \\
\hline $\begin{array}{c}\text { Mantém não adesão e } \\
\text { HBV-DNA (-) }\end{array}$ & $9 / 26(35 \%)$ & - & \multicolumn{2}{|c|}{ 10/27 (37\%) } & 1,0000 \\
\hline $\begin{array}{c}\text { Mantém não adesão e } \\
\text { HBV-DNA (+) }\end{array}$ & $21 / 52$ (41\%) & - & \multicolumn{2}{|c|}{ 29/38 (76\%) } & 0,0011 \\
\hline $\begin{array}{l}\text { Migração entre adesão } \\
\text { com HBV-DNA (-/+) }\end{array}$ & $\begin{array}{c}19 / 87(21 \%) / \\
9 / 17(53 \%)\end{array}$ & 0,0147 & \multicolumn{2}{|c|}{$\begin{array}{l}12 / 75(16 \%) / \\
20 / 41(49 \%)\end{array}$} & 0,0004 \\
\hline $\begin{array}{c}\text { Migração entre adesão } \\
\text { e HBV-DNA (-) com } \\
\text { não adesão e HBV } \\
\text { DNA (+) }\end{array}$ & $\begin{array}{l}10 / 87(12 \%) / \\
11 / 52(21 \%)\end{array}$ & 0,1455 & \multicolumn{2}{|c|}{$\begin{array}{l}2 / 75(3 \%) / \\
5 / 38(13 \%)\end{array}$} & 0,0418 \\
\hline $\begin{array}{c}\text { Migração entre } \\
\text { HBV-DNA (-) com } \\
\text { adesão/não adesão }\end{array}$ & $\begin{array}{c}10 / 87(12 \%) / \\
7 / 26(27 \%)\end{array}$ & 0,0655 & \multicolumn{2}{|c|}{$\begin{array}{l}6 / 75(8 \%) / \\
14 / 27(52 \%)\end{array}$} & 0,0001 \\
\hline $\begin{array}{l}\text { Migração entre não } \\
\text { adesão com HBV-DNA } \\
(-/+)\end{array}$ & $\begin{array}{l}4 / 26(15 \%) / \\
8 / 52(15 \%)\end{array}$ & 1,0000 & \multicolumn{2}{|c|}{$\begin{array}{l}1 / 27(4 \%) / \\
1 / 38(3 \%)\end{array}$} & 1,0000 \\
\hline $\begin{array}{c}\text { Migração entre } \\
\text { HBV-DNA (+) com } \\
\text { adesão/não adesão }\end{array}$ & $\begin{array}{l}3 / 17(18 \%) / \\
12 / 52(23 \%)\end{array}$ & 0,7464 & \multicolumn{2}{|c|}{$\begin{array}{l}1 / 41(2 \%) / \\
3 / 38(8 \%)\end{array}$} & 0,3467 \\
\hline
\end{tabular}

As principais razões para exclusões de pacientes foram as mortes (21/183), sendo que 10 das 21 mortes foram causadas por CHC. O genótipo C do HBV apresentou significativa associação com o desenvolvimento de CHC nesta população $(p=0,0460)$.

Na primeira avaliação de adesão, podemos notar que 70 pacientes não apresentavam resposta adequada do tratamento antiviral devido HBV-DNA estar detectável (Figura 17), e cinco pacientes foram excluídos dessas análises devido a indisponibilidade de amostras de soro/plasma de HBV. 


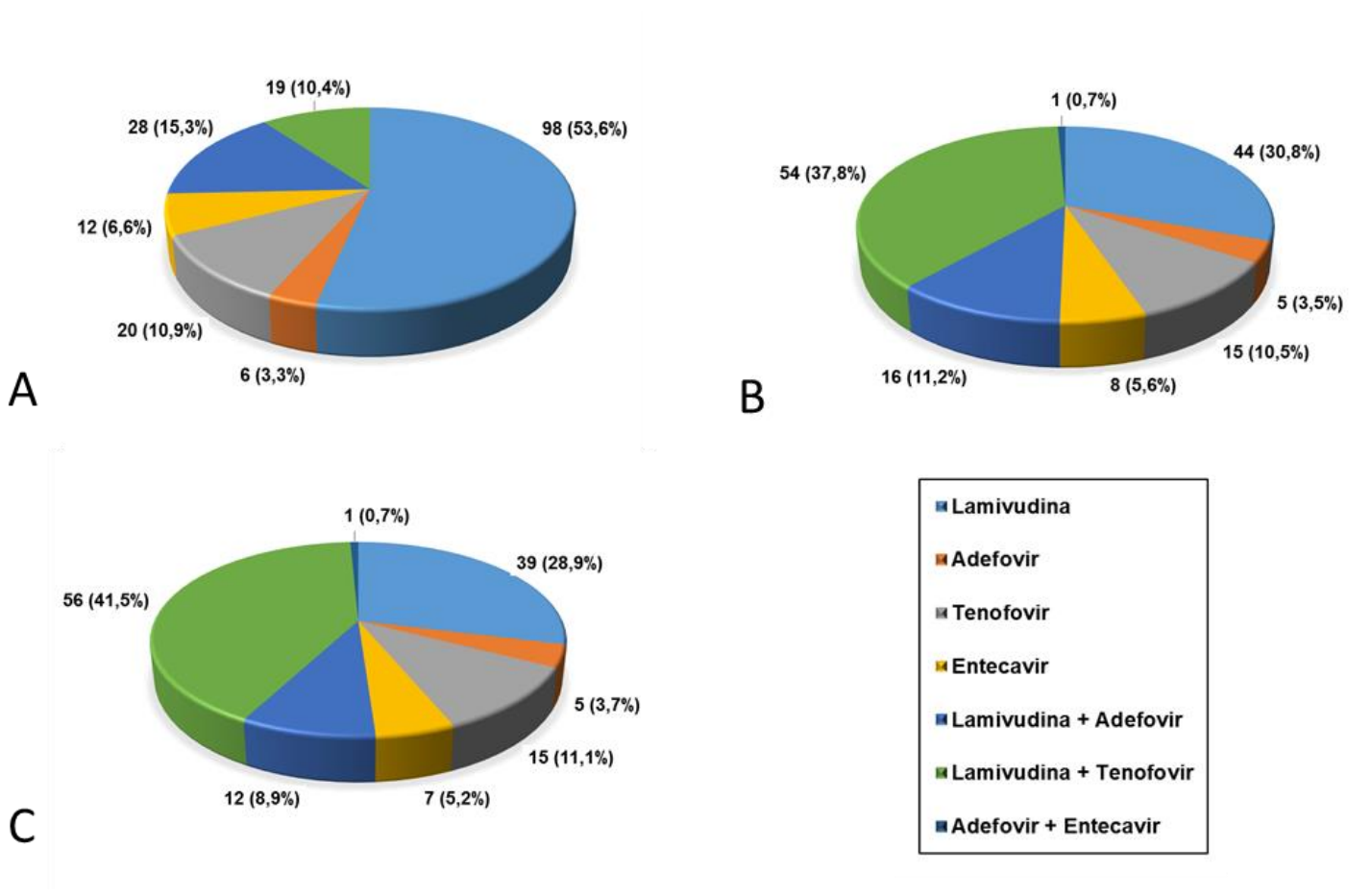

Figura 16. Distribuição dos pacientes quanto as mudanças de antivirais ao longo do tempo. (A) Esquema terapêutico na primeira avaliação de adesão. HCFMUSP, dezembro de 2010 a agosto de 2011 ( $n=183$ ) (B) Esquema terapêutico na segunda avaliação de adesão. HCFMUSP, novembro de 2013 a maio de 2014 ( $n=$ 143). (C) Esquema terapêutico na terceira avaliação de adesão. HCFMUSP, julho de 2014 a março de $2015(n=135)$

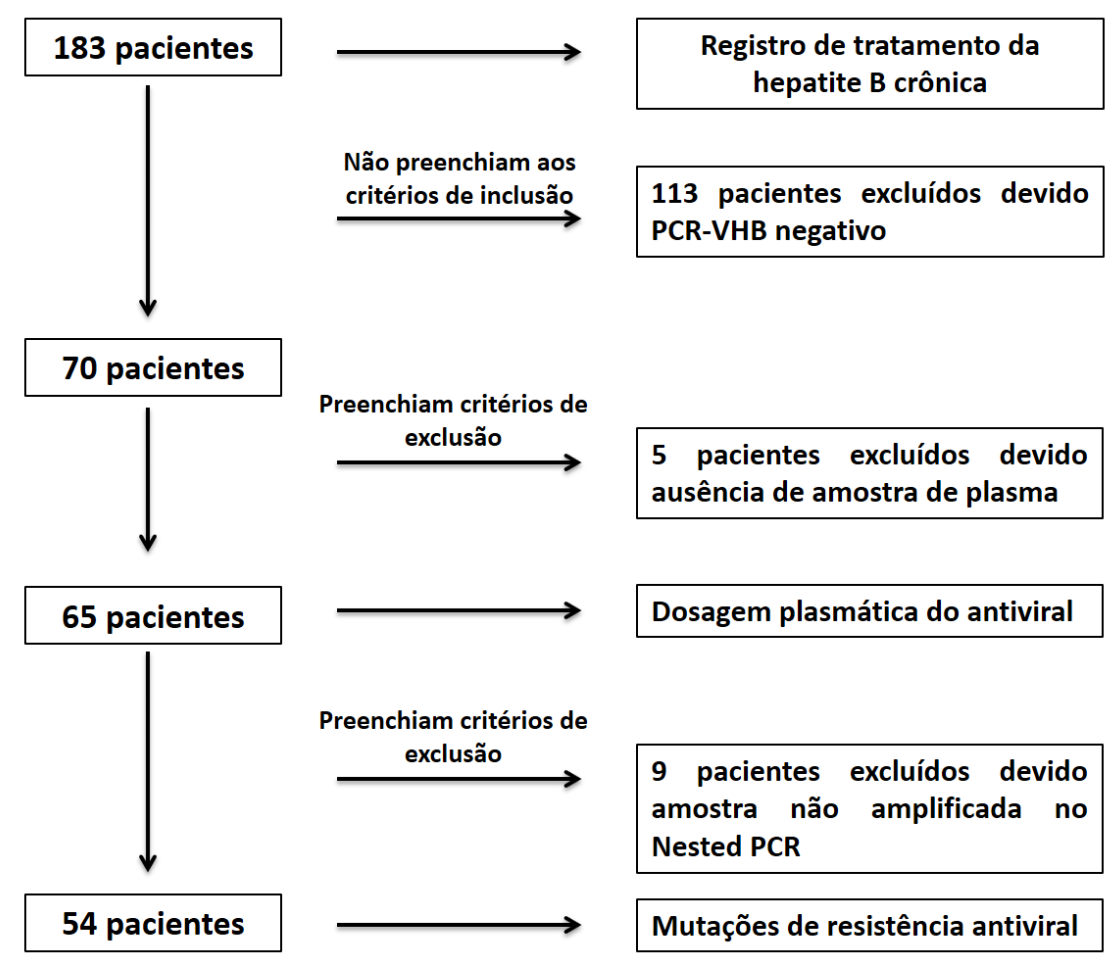

Figura 17. Derivação da população com falha de tratamento no início do estudo 
Apenas 54 amostras de soro/plasma dos pacientes com HBV foram amplificadas usando o Nested PCR (Figura 18).

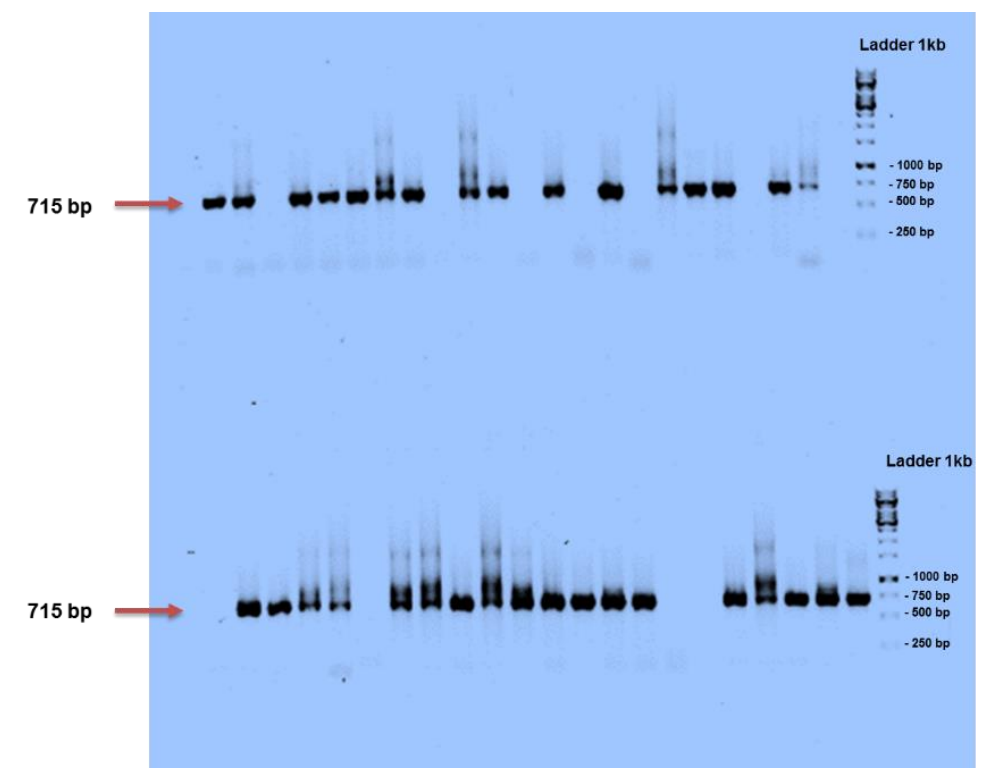

Figura 18. Representação esquemática das amostras de soro/plasma dos pacientes com HBV. Aproximadamente 800 pares de base da região da polimerase do HBV-DNA foram amplificados por Nested PCR e podem ser visualizados por eletroforese em gel de agarose 2\%. HCFMUSP, dezembro de 2010 a agosto de $2011(n=54)$

As mais frequentes variantes de resistência antiviral foram M204l/V (77,7\%), L180M (59,2\%), L80I (14,8\%), V173L (7,41\%) e Q215H (5,5\%), conforme pode ser visto na figura 19A. Quando as variantes de resistência antiviral foram estratificadas de acordo com o esquema de tratamento no início do estudo, essas variantes de HBV estiveram presentes em $39,3 \%$, $31,6 \%$ e $25,5 \%$ dos pacientes em uso de 3TC+ADV, 3TC+TDF e $3 T \mathrm{TC}$ monoterapia, respectivamente, após uma mediana de 58 meses de tratamento antiviral. Um paciente do grupo recebendo TDF em monoterapia apresentou uma variante de resistência antiviral de interesse, mas esse paciente tinha realizado tratamento prévio com 3TC e ETV em monoterapia. No geral, 42/145 (29\%) dos pacientes em uso de 3TC apresentaram variantes de resistência antiviral no início do estudo (Figura 19 B). 


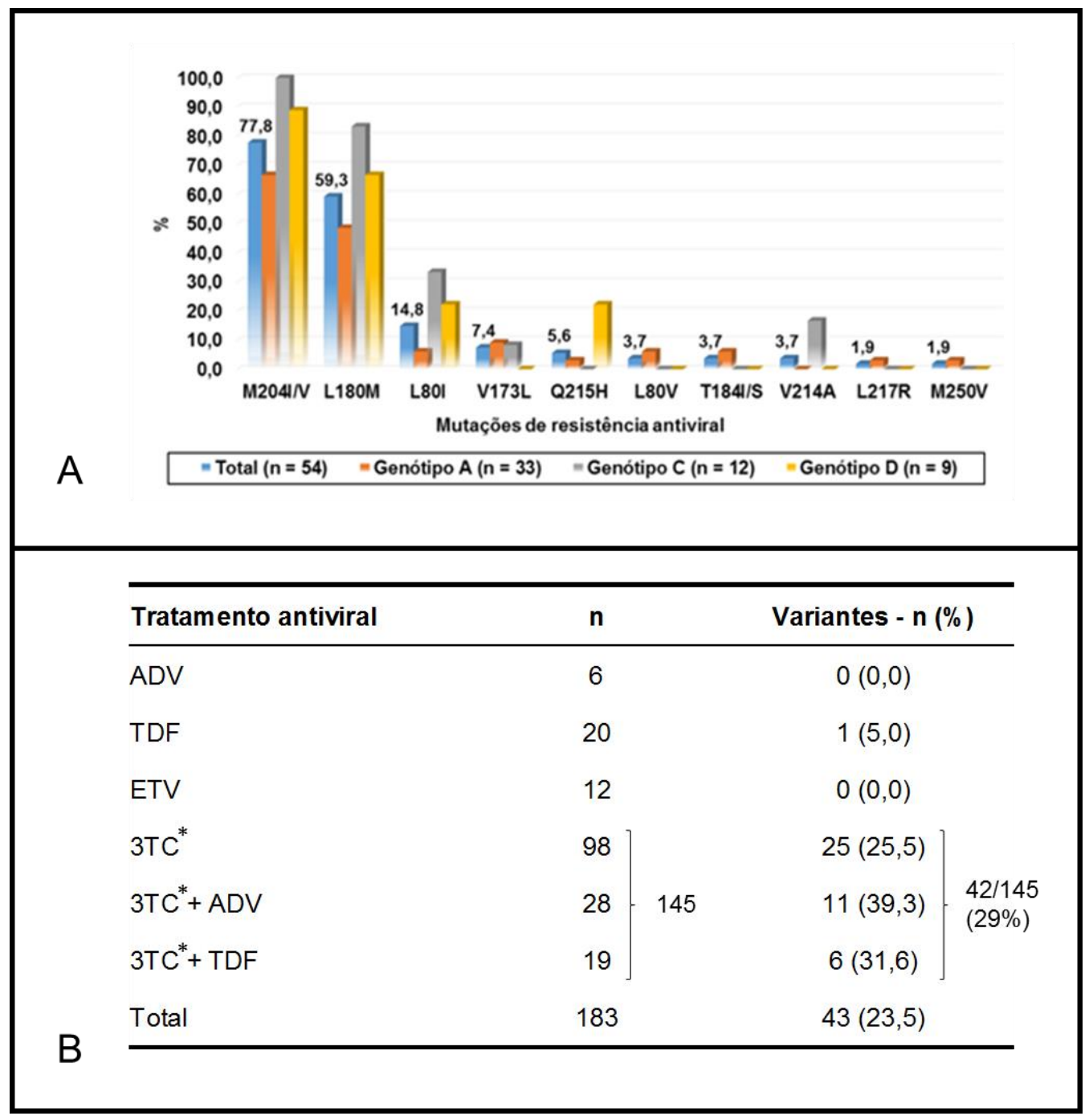

Figura 19. Variantes de resistência antiviral analisadas pelo software DeepChekHBV/HDV v1.4. (A) Frequência das variantes de resistência antiviral de acordo com os genótipos do HBV $(n=54)$ (B) Frequência das variantes de resistência antiviral de acordo com o esquema terapêutico $(n=183)$. ${ }^{*} 3 T C 150 \mathrm{mg}^{(66)}$.

A frequência de adesão por método direto, através na quantificação plasmática dos antivirais (Anexo I), nesse subgrupo de pacientes com HBVDNA detectável no início do estudo, foi 52,3\% (34/65).

Com isso, os principais preditores associados com a falha do tratamento (HBV-DNA detectável) no início do estudo foram presença de variantes de resistência antiviral (38,6\%), seguido de presença de variantes de resistência antiviral e não adesão ao tratamento (22,9\%), não adesão ao tratamento $(12,9 \%)$, duração do tratamento antiviral insuficiente $(10,0 \%)$ e outros fatores não determinados (15,7\%). 


\section{DISCUSSÃO}

Em nosso estudo, a adesão aos antivirais orais em pacientes ambulatoriais portadores de hepatite B crônica, atendidos em um centro terciário de referência, foi baixa no início da pesquisa. Alguns autores demostraram que a média de adesão aos antivirais, reportada, variava entre $81 \%$ a $99 \%$, com $66 \%$ a $92 \%$ dos pacientes apresentando $100 \%$ de adesão ao tratamento(112).

Durante o acompanhamento desta coorte de pacientes, o conhecimento sobre as variantes de resistência antiviral e o comportamento de não adesão ao tratamento da hepatite $\mathrm{B}$, no início do estudo, levaram à necessidade de substituição do esquema terapêutico e à novas intervenções nessa população para promover o aumento da adesão ao tratamento.

O programa de educação aos pacientes portadores de hepatite $B$, pautado nas comunicações relacionadas à adesão ao tratamento antiviral, com o uso da cartilha "Juntos contra a Hepatite B" (Anexo A), no segundo e terceiro atendimentos para avaliação de adesão, foi a chave para a melhora da frequência de adesão e aumento da migração do fluxo de pacientes para o grupo com adesão e HBV-DNA indetectável(113).

No mundo, vários pesquisadores ${ }^{(120-128)}$ apresentaram experiências bem-sucedidas através de trabalhos que tiveram a atuação do farmacêutico clínico, assim como nesse estudo, como no monitoramento de antimicrobianos, na avaliação de adesão ao tratamento, no manejo de 
reações adversas de medicamentos, entre outras atividades. O impacto da atuação do farmacêutico clínico, na melhora da adesão ao tratamento de pacientes portadores de doenças crônicas, tem sido demonstrado em vários ensaios clínicos randomizados ${ }^{(125,129-134)}$. Uma revisão sistemática recente demonstrou que as intervenções realizadas por farmacêuticos para a melhora da adesão ao tratamento foram, estatisticamente, mais efetivas do que as realizadas por médicos e enfermeiros ${ }^{(125)}$.

Existem muitas barreiras apresentadas pelos gestores da saúde para a ampliação dessa prática profissional no Brasil, muitas vezes restrita aos ambientes de ensino e pesquisa, devido à resistência em disponibilizar recursos financeiros para a contratação de profissionais para essas atividades, assim como pela dificuldade de demonstrar benefícios imediatos. Além disso, mesmo com os esforços das entidades regulamentadoras pela valorização profissional do farmacêutico, os avanços têm sido ínfimos e o reconhecimento profissional para essa prática está longe de ser alcançado.

Os desfechos virológicos isoladamente, não foram indicativos de melhora, estatisticamente significativa, ao longo do tempo. O fluxo dinâmico de pacientes entre os grupos, a presença de variantes de resistência antiviral, a não adesão e a duração de tratamento insuficiente podem explicar esse ponto.

No Brasil, até 2009, a primeira linha de tratamento para pacientes portadores de hepatite B crônica era apenas a lamivudina 150 mg, uma vez ao dia, em monoterapia(65, 66). Entretanto, muitos pacientes, em todo o mundo, têm desenvolvido resistência antiviral a partir do uso generalizado de 
antivirais menos potentes, como a lamivudina (na dose de $100 \mathrm{mg} / \mathrm{dia}$ ) ou adefovir, que tem uma baixa barreira genética de resistência ${ }^{(108,109)}$. A resistência à lamivudina (100 mg / dia) se desenvolve em aproximadamente $20 \%$ dos pacientes, após 1 ano, e em $70 \%$ dos pacientes, após 5 anos de tratamento $(50,135)$. O seu uso por longos períodos pode selecionar variantes tirosina-metionina-aspartato-aspartato (YMDD) da DNA polimerase do $\mathrm{HBV}^{(136)}$.

Nosso estudo apresentou apenas $29 \%$ de variantes de resistência antiviral à lamivudina, no subgrupo tratado com esse medicamento após uma mediana de tempo de tratamento de 58 meses. Essa maior dosagem (150 mg / dia) tem sido pouco estudada até o momento e estudos clínicos, com maior número de pacientes, devem ser encorajados.

Outros países, como a China e os Estados Unidos, demonstraram que o custo com a terapia antiviral foi uma barreira significativa para a melhora do cuidado dos pacientes com hepatite B crônica, correlacionando esse dado com a não adesão(105,137,138). Este fato não foi uma limitação para o nosso estudo porque o governo brasileiro garante acesso gratuito ao tratamento antiviral a todos os pacientes portadores de hepatite B crônica.

No início desse estudo, a frequência de adesão foi de 56,8\%, 53,5\% e 61,7\% de acordo com o CEAT-HBV, Teste de Morisky e desfecho virológico, respectivamente $(p=0,1430)$. Não enfatizamos os resultados do teste de Morisky nas outras avaliações porque o CEAT-HBV é um questionário validado para hepatite B crônica, além de ser um instrumento específico com maior sensibilidade e especificidade $(88,89,103)$. 
Muitos fatores podem explicar a baixa adesão aos antivirais, observada neste estudo. O estigma do tratamento e o impacto psicológico da doença sob os pacientes podem ser diferentes em comparação com aqueles que vivem com HIV e alguns tipos de câncer. Outras razões para a baixa adesão aos antivirais poderiam estar relacionados ao fato de que a maioria da população estudada apresentou baixa escolaridade, baixa renda familiar anual e outras comorbidades crônicas ${ }^{(106)}$. Além disso, mais da metade dos pacientes apresentou cirrose compensada e 12,1\% tinha $\mathrm{CHC}$ no início do estudo. Uma terceira explicação possível para a baixa taxa de adesão é que nossos pacientes foram provenientes de um centro terciário que é referência nacional no transplante de fígado e $\mathrm{CHC}$. Muitos pacientes estavam identificados com polifarmácia e experimentavam períodos de falha de fornecimento do antiviral na farmácia e perda do acompanhamento na consulta médica(139, 140).

Um fato interessante está relacionado às mortes por $\mathrm{CHC}$ : no início do estudo, $12,1 \%$ dos pacientes tinham $\mathrm{CHC}$, mas não nos estágios finais de doença hepática. Após dois anos do início do estudo, aproximadamente metade desses pacientes tinha morrido. É importante enfatizar que cinco mortes causadas por CHC ocorreram no grupo com adesão e HBV-DNA indetectável.

Os estudos pivotais avaliam os desfechos de eficácia e segurança de um ano e/ou por um período estendido de 2 anos. Esses resultados não podem ser extrapolados para a prática clínica devido aos desafios como a adesão persistente e o acesso ao antiviral, muitas vezes com alto custo ${ }^{(137}$, 
141). Dessa forma, os estudos observacionais pós-comercialização são necessários para demonstrar a evidência de efetividade em vida real.

Nossos pacientes apresentaram uma mediana de 58 meses de duração do tratamento com antivirais, no início do estudo, e a pesquisa de variantes de resistência antiviral e genotipagem do HBV não é rotina na prática clínica. Embora muitos estudos ${ }^{(142-144)}$ mostrem que o tratamento por tempo indeterminado com tenofovir e entecavir esteja associado com a redução da incidência de $\mathrm{CHC}$, as evidências de longo prazo, na vida real, podem ser afetadas pela baixa adesão e resistência antiviral ${ }^{(145,146)}$.

As intervenções farmacêuticas em pacientes ambulatoriais com 0 auxílio de cartilhas de orientação sobre adesão podem melhorar a resposta aos antivirais, e consequentemente, diminuir cuidados de saúde e custos desnecessários. Porém, esse benefício requer constantes intervenções junto ao paciente considerando que esse efeito pode se perder com o término ou interrupção das intervenções ${ }^{(130)}$.

Esse estudo possui várias limitações. A primeira diz respeito à pesquisa das variantes de resistência e à quantificação plasmática dos antivirais estudados apenas durante a primeira avaliação de adesão. Em segundo lugar, os medicamentos antivirais no Brasil não são encontrados facilmente para compra, embora a população do estudo tinha acesso gratuito ao tratamento antiviral, diferentemente de outras pesquisas ${ }^{(106,137)}$. A terceira limitação refere-se aos pacientes serem provenientes de um centro de referência terciário com doenças mais avançadas. Por último, constatamos que os regimes de tratamento com antivirais eram muito 
heterogêneos. Porém, apresentamos resultados de adesão de longo prazo que podem ser extrapolados para outras populações de pacientes. Por fim, a pesquisa das variantes de resistência antiviral e a quantificação plasmática dos antivirais, em uma série histórica, podem confirmar esses resultados.

Percebemos que em um modelo dinâmico de vida real, o escape viral é comum na prática clínica e está relacionado a variantes de resistência, a não adesão e outras causas ainda desconhecidas. Nossos dados destacam a importância do monitoramento da adesão durante todas as visitas médicas nos pacientes portadores de hepatite B crônica em tratamento antiviral. A compreensão da real causa de escape virológico é prudente, uma vez que a avaliação da adesão pode evitar a substituição desnecessária da terapia. Além disso, programas de educação do paciente relacionados a adesão ao tratamento podem melhorar a efetividade do tratamento da hepatite $B$ crônica na prática clínica. 


\section{CONCLUSÕES}

I. As frequências de adesão ao tratamento antiviral aumentaram após quatro anos de seguimento, alcançando 83\% ( $p<0,001$; população per-protocol) e 71,8\% ( $p<0,01$; população ITT). Os desfechos virológicos não apresentaram diferença estatisticamente significativa.

II. Houve um aumento do fluxo de migração de pacientes para o grupo com adesão e HBV-DNA indetectável, sendo um aumento estatisticamente significativo $(p<0,001)$ na população perprotocol, com melhores resultados após a terceira avaliação de adesão. A população ITT mostrou resultados similares e ocorreu uma manutenção estatisticamente significativa ao longo do tempo de pacientes do grupo com adesão e HBV-DNA indetectável.

III. Os principais preditores associados com a falha do tratamento foram presença de variantes de resistência antiviral (38,6\%), seguido de presença de variantes de resistência antiviral e não adesão ao tratamento $(22,9 \%)$, não adesão ao tratamento (12,9\%), duração do tratamento antiviral insuficiente $(10,0 \%)$ e outros fatores não determinados (15,7\%). 


\section{ANEXOS}

7.1 Anexo A - Cartilha "Juntos contra a Hepatite B"

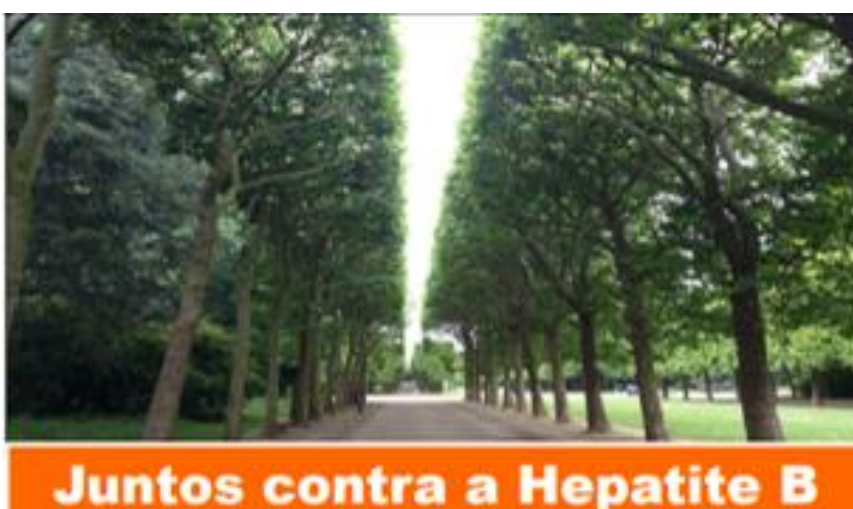

A CURA TAMBÉM DEPENDE DE VOCÊ

Aprenda mais sobre o seu tratamento

(ver exemplar original anexado à tese) 


\subsection{Anexo B - CEAT-HBV - "Questionário para avaliação da adesão ao tratamento antiviral em pacientes portadores de hepatite B crônica"}

\begin{tabular}{|c|c|c|c|c|c|}
\hline Durante a última semana & Sempre & $\begin{array}{c}\text { Mais da metade } \\
\text { das vezes }\end{array}$ & $\begin{array}{c}\text { Aproximadamente a } \\
\text { metade das vezes }\end{array}$ & $\begin{array}{l}\text { Alguma } \\
\text { vez }\end{array}$ & $\begin{array}{c}\text { Nenhuma } \\
\text { vez }\end{array}$ \\
\hline $\begin{array}{l}\text { 1. Deixou de tomar sua } \\
\text { medicação alguma vez? }\end{array}$ & & & & & \\
\hline $\begin{array}{l}\text { 2. Se alguma vez sentiu-se } \\
\text { melhor, deixou de tomar sua } \\
\text { medicação? }\end{array}$ & & & & & \\
\hline $\begin{array}{l}\text { 3. Se alguma vez depois de } \\
\text { tomar sua medicação sentiu-se } \\
\text { pior, deixou de tomá-la? }\end{array}$ & & & & & \\
\hline $\begin{array}{l}\text { 4. Se alguma vez se sentiu triste } \\
\text { ou deprimido, deixou de tomar } \\
\text { sua medicação? }\end{array}$ & & & & & \\
\hline
\end{tabular}

5. Lembra-se que remédios está tomando nesse momento?

(escrever os nomes)

6. Como é a relação que mantém com o seu médico?

\begin{tabular}{|c|c|c|c|c|}
\hline Ruim & Um pouco ruim & Regular & Pode melhorar & Boa \\
\hline
\end{tabular}

7. Quanto você se esforça para seguir com o tratamento?

8. Quanta informação você tem sobre os medicamentos que toma para a Hepatite $B$ ?

9. Quanto benefício pode lhe trazer o uso destes medicamentos?

10. Considera que sua saúde melhorou desde que começou a tomar os medicamentos para a Hepatite $B$ ?

11. Até que ponto sente-se capaz de seguir com o tratamento?

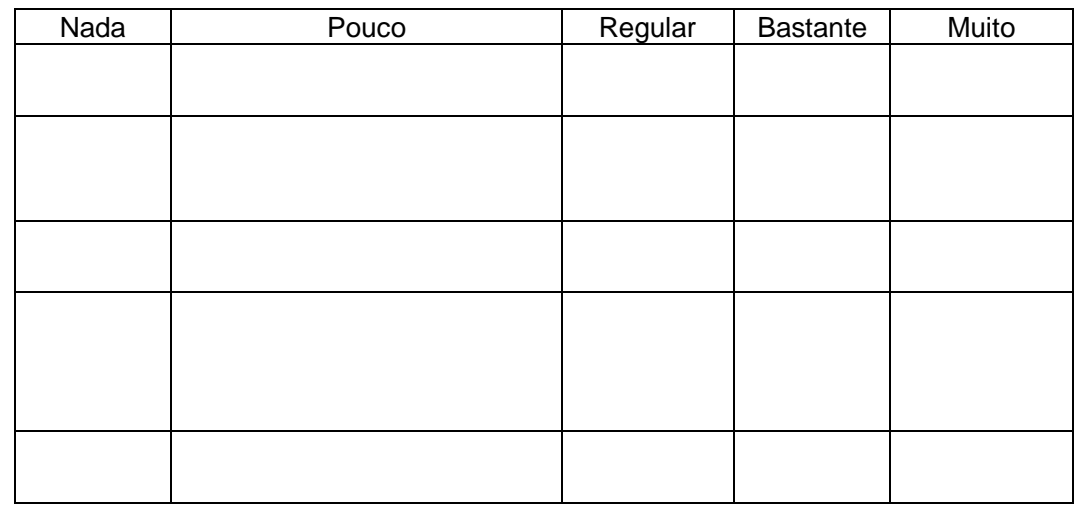

\begin{tabular}{|c|c|c|c|c|c|}
\hline \multirow[b]{2}{*}{$\begin{array}{l}\text { 12. Normalmente está acostumado a tomar a } \\
\text { medicação na hora certa? }\end{array}$} & $\begin{array}{l}\text { Não, } \\
\text { nunca }\end{array}$ & $\begin{array}{l}\text { Sim, } \\
\text { alguma vez }\end{array}$ & $\begin{array}{l}\text { Sim, aproximada- } \\
\text { mente a metade } \\
\text { das vezes }\end{array}$ & $\begin{array}{l}\text { Sim, } \\
\text { muitas } \\
\text { vezes }\end{array}$ & $\begin{array}{l}\text { Sim, } \\
\text { sempre }\end{array}$ \\
\hline & & & & & \\
\hline $\begin{array}{l}\text { 13. Quando os resultados dos exames são bons, } \\
\text { seu médico costuma utilizá-los para lhe dar ânimo } \\
\text { e motivação para seguir com o tratamento? }\end{array}$ & & & & & \\
\hline
\end{tabular}

14. Como sente-se em geral com o tratamento desde que começou a tomar seus remédios?

\begin{tabular}{|l|r|r|r|r}
\hline Muito insatisfeito & Insatisfeito & Indiferente & Satisfeito & Muito satisfeito \\
\hline
\end{tabular}

15. Como avalia a intensidade dos efeitos colaterais relacionados com o uso dos medicamentos para a Hepatite B?

\begin{tabular}{|l|l|l|l|l|} 
Muito intensos & Intensos & Medianamente intensos & Pouco intensos & Nada intensos
\end{tabular}

16. Quanto tempo acredita que perde ocupando-se em tomar seus remédios?

\begin{tabular}{|l|c|c|c|c} 
Muito tempo & Bastante tempo & Regular & Pouco tempo & Nada de tempo \\
\hline
\end{tabular}

17. Que avaliação tem de si mesmo com relação a tomada dos remédios para a Hepatite B?

\begin{tabular}{|c|c|c|c|c|}
\hline Nada cumpridor & Pouco cumpridor & Regular & Bastante cumpridor & Muito cumpridor \\
\hline
\end{tabular}


18. Quanta dificuldade tem para tomar a medicação?

\begin{tabular}{|l|l|l|l|l|} 
Muita dificuldade & Bastante dificuldade & Regular & Pouca dificuldade & Nenhuma dificuldade \\
\hline
\end{tabular}

19. Desde que está em tratamento alguma vez deixou de tomar sua medicação um dia completo, ou mais de um? [Se responde afirmativamente, Quantos dias aproximadamente?]

20. Utiliza alguma estratégia para lembrar-se de tomar a medicação?

Qual?

\begin{tabular}{|l|l|}
\hline Sim & Não \\
\hline & \\
& \\
\hline & \\
& \\
\hline
\end{tabular}

O "Questionário para avaliação da adesão ao tratamento antiviral em pacientes portadores de hepatite B crônica" (CEAT-HBV) se trata de uma versão do CEAT-VIH para uso em pacientes portadores de hepatite B crônica. CEAT-VIH ${ }^{\odot}$ está protegido por leis internacionais de copyright, com todos os direitos reservados a Eduardo Remor. Não use sem permissão. Para obter informações sobre, ou permissão para usar o CEAT-VIH ${ }^{\circ}$, ou qualquer de suas versões, por favor, entre em contato pelo email (ceat.vih@gmail.com). 


\subsection{Anexo C - Teste de Morisky}

1. Você alguma vez se esquece de tomar seu remédio? 2. Você, às vezes, é descuidado quanto ao horário de tomar seu remédio?

3. Quando você se sente melhor, às vezes, você para de tomar seu remédio?

4. Às vezes, se você se sente pior quando toma o remédio, você para de tomá-lo?

\begin{tabular}{|l|l|}
\hline Sim & Não \\
\hline & \\
\hline & \\
\hline & \\
\hline & \\
\hline & \\
\hline
\end{tabular}


7.4 Anexo D - Protocolo de Nested PCR para amplificação do HBV-DNA

\begin{tabular}{|c|c|c|c|}
\hline \multicolumn{4}{|c|}{ Primeiro Round } \\
\hline Componentes & Volume & [] Final & $\begin{array}{l}\text { Volume X número de } \\
\text { amostras }=\text { total }\end{array}$ \\
\hline Primer HBV0179FE $(10 \mu \mathrm{M})$ & $1 \mu \mathrm{l}$ & $\sim 0,5 \mu \mathrm{M}$ & $1 \mu l^{*}$ \\
\hline Primer HBV1286RE $(10 \mu \mathrm{M})$ & $1 \mu l$ & $\sim 0,5 \mu \mathrm{M}$ & $1 \mu l^{*}$ \\
\hline $\begin{array}{l}\text { PerfeCTa }{ }^{\circledR} \text { SYBR } \AA \text { Green } \\
\text { FastMix } ® \text {, Low ROX }{ }^{\top M}\end{array}$ & $10 \mu \mathrm{l}$ & 1,0 unit & $10 \mu 1^{*}=$ \\
\hline Template de DNA & $10 \mu \mathrm{l}$ & - & $20 \mu \mathrm{l}$ \\
\hline \multicolumn{4}{|c|}{ Segundo Round } \\
\hline Componentes & Volume & [] Final & $\begin{array}{l}\text { Volume } \mathrm{X} \text { número de } \\
\text { amostras = total }\end{array}$ \\
\hline $\begin{array}{l}\text { Primer HBVRes311FN (10 } \\
\mu \mathrm{M})\end{array}$ & $1 \mu \mathrm{l}$ & $0,4 \mu \mathrm{M}$ & $1 \mu l^{*}$ \\
\hline $\begin{array}{l}\text { Primer HBVRes1026RN (10 } \\
\mu \mathrm{M})\end{array}$ & $1 \mu \mathrm{l}$ & $0,4 \mu \mathrm{M}$ & $1 \mu l^{*}$ \\
\hline $\begin{array}{l}\text { PerfeCTa } \AA \text { SYBR } \AA \text { Green } \\
\text { FastMix } \AA \text {, Low ROX }{ }^{\mathrm{TM}}\end{array}$ & $10 \mu \mathrm{l}$ & 1,0 unit & $0,1 \mu \mathrm{l}^{*}$ \\
\hline Template de DNA & $3 \mu \mathrm{l}$ & & $20 \mu \mathrm{l}$ \\
\hline
\end{tabular}

Realizar o PCR conforme abaixo:

\begin{tabular}{|c|l|l|}
\hline \multicolumn{3}{|c|}{ Primeiro Round } \\
\hline 1. Desnaturar & $94^{\circ} \mathrm{C}$ & $5 \mathrm{~min}$ \\
\hline 2. Desnaturar & $94^{\circ} \mathrm{C}$ & $45 \mathrm{seg}$ \\
\hline 3. Anelar & $55^{\circ} \mathrm{C}$ & $20 \mathrm{seg}$ \\
\hline 4. Extender & $72^{\circ} \mathrm{C}$ & $1 \mathrm{~min} 15 \mathrm{seg}$ \\
\hline 5. & $72^{\circ} \mathrm{C}$ & $7 \mathrm{~min}$ \\
\hline 6. & $4^{\circ} \mathrm{C}$ & manter \\
\hline Repetir as etapas $2-4,40$ ciclos \\
\hline
\end{tabular}

\begin{tabular}{|c|l|l|}
\hline \multicolumn{3}{|c|}{ Segundo Round } \\
\hline 1. Desnaturar & $95^{\circ} \mathrm{C}$ & $5 \mathrm{~min}$ \\
\hline 2. Desnaturar & $95^{\circ} \mathrm{C}$ & $30 \mathrm{seg}$ \\
\hline 3. Anelar & $58^{\circ} \mathrm{C}$ & $15 \mathrm{seg}$ \\
\hline 4. Extender & $72^{\circ} \mathrm{C}$ & $1 \mathrm{~min} 15 \mathrm{seg}$ \\
\hline 5. & $72^{\circ} \mathrm{C}$ & $7 \mathrm{~min}$ \\
\hline 6. & $4^{\circ} \mathrm{C}$ & manter \\
\hline Repetir as etapas $2-4,40$ ciclos \\
\hline
\end{tabular}




\subsection{Anexo E - Aprovação do protocolo de pesquisa}
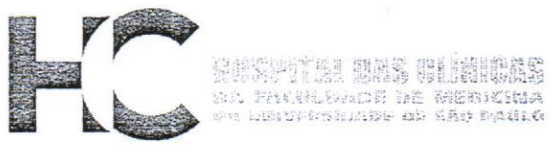

\section{APROVAÇÃO}

A Comissão de Ética para Análise de Projetos de Pesquisa CAPPesq da Diretoria Clínica do Hospital das Clínicas e da Faculdade de Medicina da Universidade de São Paulo, em sessão de 27/10/2010, APROVOU O Protocolo de Pesquisa n 0581/10, intitulado: "ADESĀO AO TRATAMENTO FARMACOLÓGICO COM ANTIVIRAIS ORAIS EM PACIENTES PORTADORES DE HEPATITE CRÔNICA B" apresentado pelo Departamento de GASTROENTEROLOGIA, inclusive o Termo de Consentimento Livre e Esclarecido.

Cabe ao pesquisador elaborar e apresentar à CAPPesq, os relatórios parciais e final sobre a pesquisa (Resolução do Conselho Nacional de Saúde n 196, de 10/10/1996, inciso IX.2, letra "c").

Pesquisador (a) Responsável: Suzane Kioko Ono-Nita

Pesquisador (a) Executante: Rodrigo Martins Abreu

CAPPesq, 29 de Outubro de 2010

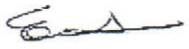

Prof. Dr. Eduardo Massad Presidente da Comissão de Ética para Análise de Projetos de Pesquisa 
7.6 Anexo F - Termo de Consentimento Livre e Esclarecido

HOSPITAL DAS CLÍNICAS DA FACULDADE DE MEDICINA DA

UNIVERSIDADE DE SÃO PAULO - HCFMUSP

TERMO DE CONSENTIMENTO LIVRE E ESCLARECIDO

DADOS DE IDENTIFICAÇÃO DO SUJEITO DA PESQUISA OU RESPONSÁVEL LEGAL

1. NOME:

DOCUMENTO DE IDENTIDADE No: SEXO: $M \square F \square$

DATA NASCIMENTO: .........................

ENDEREÇO:

BAIRRO:

CEP:.

CIDADE:

№

APTO

2. RESPONSÁVEL LEGAL:

NATUREZA (grau de parentesco, tutor, curador etc.):

DOCUMENTO DE IDENTIDADE N : SEXO: $M \square F \square$

DATA NASCIMENTO: .........................

ENDEREÇO:

TELEFONE: DDD

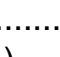

BAIRRO:

CEP:

CIDADE:

№

APTO

TELEFONE: DDD (...................

\section{DADOS SOBRE A PESQUISA}

1. TÍTULO DO PROTOCOLO DE PESQUISA

"Adesão ao tratamento farmacológico com antivirais orais em pacientes portadores de hepatite crônica B"

2. PESQUISADORES: Suzane Kioko Ono-Nita, Rodrigo Martins Abreu.

CARGO/FUNÇÃO: Prof. Doutor.

INSCRIÇÃO CONSELHO REGIONAL № 68.066

UNIDADE DO HCFMUSP: Disciplina de Gastroenterologia

3. AVALIAÇÃO DO RISCO DA PESQUISA:

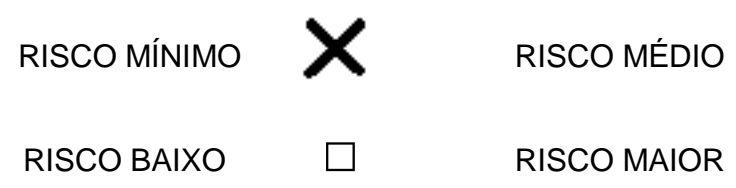

4. DURAÇÃO DA PESQUISA: 3 anos. 


\title{
HOSPITAL DAS CLÍNICAS DA FACULDADE DE MEDICINA DA UNIVERSIDADE DE SÃO PAULO - HCFMUSP
}

\begin{abstract}
Essas informações estão sendo fornecidas para sua participação voluntária neste estudo, que visa avaliar o uso correto dos antivirais orais para o tratamento dos pacientes portadores de hepatite crônica B, com o objetivo de evitar o aumento do número de medicamentos prescritos. Se você concordar em participar voluntariamente, será solicitado que responda a um breve questionário, que avaliará como você está tomando os seus medicamentos. Somente no final do estudo poderemos concluir a presença de algum benefício.

Em qualquer etapa do estudo, você terá acesso aos profissionais responsáveis pela pesquisa para esclarecimento de eventuais dúvidas. O principal investigador é a Dra Suzane Kioko Ono-Nita que pode ser encontrada no endereço Av. Dr. Enéas de Carvalho Aguiar, 255 - 9o andar, no telefone 11-3069-7830. Se você tiver alguma consideração ou dúvida sobre a ética da pesquisa, entre em contato com o Comitê de Ética em Pesquisa (CEP) - Rua Ovídio Pires de Campos, 225 - 5o andar - tel: 3069-6442 ramais 16, 17, 18 ou 20, FAX: 3069-6442 ramal 26 - E-mail: cappesq@hcnet.usp.br

É garantida a liberdade da retirada de consentimento a qualquer momento e deixar de participar do estudo, sem qualquer prejuízo à continuidade de seu tratamento na Instituição. Além disso, garantimos que não sofrerá qualquer discriminação no seu seguimento, sendo acompanhado no ambulatório de Gastroenterologia Clínica do ICHCFMUSP, conforme rotina do serviço.

As informações obtidas serão analisadas em conjunto com outros pacientes, não sendo divulgada a identificação de nenhum paciente. Você tem direito à privacidade. Toda informação obtida neste estudo que possa ser identificada com seu nome, deverá permanecer confidencial. Seu nome não será revelado em quaisquer relatórios ou publicações resultantes deste estudo, sem o seu expresso consentimento. Você tem o direito de ser mantido atualizado sobre os resultados parciais que sejam do conhecimento dos pesquisadores.

Não há despesas pessoais para você em qualquer fase do estudo, incluindo exames e consultas. Também não há compensação financeira relacionada à sua participação. Se existir qualquer despesa adicional, ela será absorvida pelo orçamento da pesquisa.
\end{abstract}

Acredito ter sido suficientemente informado a respeito das informações que li ou que foram lidas para mim, descrevendo o estudo "Adesão ao tratamento farmacológico com antivirais orais em pacientes portadores de hepatite crônica B".

Eu discuti com a Dra Suzane Kioko Ono-Nita sobre a minha decisão em participar nesse estudo. Ficaram claros para mim quais são os propósitos do estudo, os procedimentos a serem realizados, seus desconfortos e riscos, as garantias de confidencialidade e de esclarecimentos permanentes. Ficou claro também que minha participação é isenta de despesas e que tenho garantia do acesso a tratamento hospitalar quando necessário. Concordo voluntariamente em participar deste estudo e poderei retirar o meu consentimento a qualquer momento, antes ou durante o mesmo, sem penalidades ou prejuízo ou perda de qualquer benefício que eu possa ter adquirido, ou no meu atendimento neste Serviço.

ASSINATURA DO PACIENTE / REPRESENTANTE LEGAL

Data / /

ASSINATURA DA TESTEMUNHA

Data / /

(para casos de pacientes menores de 18 anos, analfabetos, semi-analfabetos ou portadores de deficiência auditiva ou visual)

(Somente para o responsável do projeto)

Declaro que obtive de forma apropriada e voluntária o Consentimento Livre e Esclarecido deste paciente ou representante legal para a participação neste estudo. 


\subsection{Anexo G - Aprovação do protocolo de pesquisa com finalidade de doutorado}

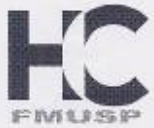

$N^{\circ}$ Protocolo: $0581 / 10$

Título: Avaliação das causas de não adesão ao tratamento antiviral em pacientes portadores de hepatite $B$ crônica

Pesquisador Responsável: Suzane Kioko Ono-Nita

Pesquisador Executante: Rodrigo Martins Abreu

Finalidade Acadêmica: Doutorado

Departamento: GASTROENTEROLOGIA

O Coordenador da Comissāo de Ética para Análise de Projetos de Pesquisa - CAPPesq da Diretoria Clínica do Hospital das Clínicas da Faculdade de Medicina da Universidade de São Paulo, APROVOU / TOMOU CIÉNCIA adreferendum em 26/04/2013, do(s) documento(s) abaixo mencionado(s):

- Carta datada de 25/04/2013 - Mudança de titulo do projeto de "Adesão ao tratamento farmacológico com antivirais orais em pacientes portadores de hepatite crônica B" para "Avaliação das causas de não adesāo ao tratamento antiviral em pacientes portadores de hepatite B crônica" - Mudança de finalidade acadêmica para doutorado do aluno Rodrigo Martins Abreu

A CAPPesq em obediência d̀ Resolução CNS 196/96, solicita ao pesquisador (a) s elaboração de relatório parcial e final.

No caso de relatório parcial é necessário informar o tempo previsto para a conclusão do protocolo e breve resumo dos resultados obtidos.

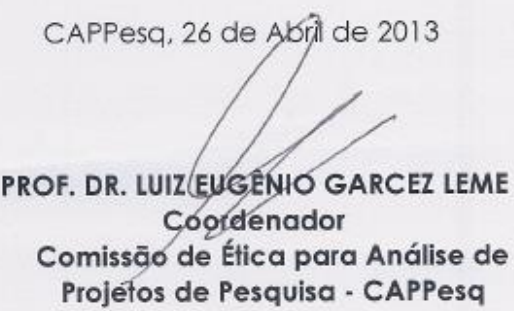

Rua Dr. Ovidio Pires de Campos, 225 - Prédio da Administração - $5^{\circ}$ andar - CEP 05403.010 - Sã̃o Paulo - SP 5511 2661-7585 - 5511 2661-6442 ramais: 16,17, 18 | marcia.carvalho@hc.fm.usp.br 


\subsection{Anexo $\mathrm{H}$ - Aprovação dos documentos relacionados ao doutorado sanduíche}

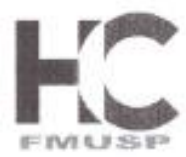

Hospital das Clínicas da FMUSP

Comissão de Ética para Análise de Projetos de Pesquisa

CAPPesq

$N^{\circ}$ Protocolo: 0581/10

Título: Avaliação das causas de não adesão ao tratamento antiviral de pacientes portadores de hepatite B crônica

Pesquisador Responsável: Suzane Kioko Ono-Nita

Pesquisador Executante: Rodrigo Martins Abreu

Disciplina: Gastroenterologia

Departamento: GASTROENTEROLOGIA

A Comissão de Ética para Análise de Projetos de Pesquisa CAPPesq da Diretoria Clínica do Hospital das Clínicas da Faculdade de Medicina da Universidade de São Paulo, APROVOU / TOMOU CIÊNCIA na sessão datada de 03/09/2014, do(s) documento(s) abaixo mencionado(s), conforme parecer anexo.

- Carta datada de 25.08.14 - Projeto de Pesquisa v.3, Termo de Consentimento Livre e Esclarecido 2 v.1; Carta de dispensa de TCLE, Carta convite da Emory University, Aprovação de financiamento pelo CNPQ

Em conformidade com a Resolução CNS n 466/12 - cabe ao pesquisador: a) desenvolver o projeto conforme delineado; b) elaborar e apresentar relatórios parciais e final; c)apresentar dados solicitados pelo CEP, a qualquer momento; d) manter em arquivo sob sua guarda, por 5 anos da pesquisa, contendo fichas individuais e todos os demais documentos recomendados pelo CEP; e) encaminhar os resultados para publicação, com os devidos créditos aos pesquisadores associados e ao pessoal técnico participante do projeto: f) justificar perante ao CEP interrupção do projeto ou a não publicação dos resultados.

\section{CAPPesq, 05 de Setembro de 2014

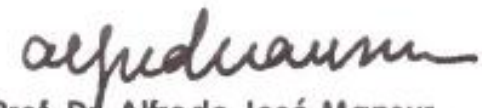 \\ Prof. Dr. Alfredo José Mansur Coordenador \\ Comissão de Ética para Análise de Projetos de Pesquisa - CAPPesq}




\section{Hospital das Clínicas da FMUSP}

Comissão de Ética para Análise de Projetos de Pesquisa CAPPesq

\section{PARECER}

\begin{tabular}{|l|l|}
\hline PROTOCOLO DE PESQUISA N2: 0581/10 & Data sessão: 03/09/2014 \\
\hline
\end{tabular}

TíTULO DA PESQUISA: Avaliação das causas de não adesã̃o ao tratamento antiviral de pacientes portadores de hepatite $B$ crônica

PESQUISADOR (A) RESPONSÁVEL: Suzane kioko Ono-Nita

PESQUISADOR (A) EXECUTANTE: Rodrigo Martins Abreu

DEPARTAMENTO: Gastroenterologia

\section{CONSIDERAÇÕES DO RELATOR APROVADAS PELO PLENÁRIO:}

Documentos apresentados:

$\checkmark$ Solicitaçăo de dispensa de novo TCLE para utilização das amostras do protocolo de pesquisa no 244/04 - já aprovado por já existir uma TCLE prévia e muitos pacientes já evoluirem à óbito;

$\checkmark$ Carta da CNPq - modalidade: Doutourado Sanduiche no Exterior noi Exterior - consentimento de bolsa;

$\checkmark$ Emenda do projeto - indicando como será feita a detecção através da análise de ultrasequenciamento do virus - exterior; Interveção farmacêutica para melhora da adesão, pelo serviço de envio de mensagem de celular;cronograma atualizado;questionário; TCLE clara e simples:

$\checkmark$ Salientamos que é de responsabilidade do pesquisador providenciar a documentação e a forma de envio do material biológico ao exterior, dentro das normas sanitárias vigentes.

CONCLUSÃO: Solicitação aprovada.

\begin{tabular}{|l|l|l|}
\hline ENVIAR Á CONEP & SIM ( ) & NÃO (X) \\
\hline
\end{tabular}

aypdrawnen

Prof. Dr. Alfredo José Mansur

Coordenador

Comissão de Ética para Análise de Projetos de Pesquisa-CAPPesq 
7.9 Anexo I - Quantificação plasmática dos antivirais por CL-MS/MS

\begin{tabular}{|c|c|c|c|c|c|c|c|}
\hline $\begin{array}{l}\text { Paciente } \\
\quad \text { ID }\end{array}$ & $\begin{array}{l}\text { Tratamento } \\
\text { antiviral }\end{array}$ & $\begin{array}{l}\text { Dose total } \\
\text { diária (mg) }\end{array}$ & $\begin{array}{c}3 \mathrm{TC} \\
(\mathrm{ng} / \mathrm{mL})\end{array}$ & $\begin{array}{c}\mathrm{TDF} \\
(\mathrm{ng} / \mathrm{mL})\end{array}$ & $\underset{(\mathrm{ng} / \mathrm{mL})}{\mathrm{ADV}}$ & $\underset{(\mathrm{ng} / \mathrm{mL})}{\mathrm{ETV}}$ & $\begin{array}{l}\text { Adesão (1) } \\
\quad \text { Não } \\
\text { adesão (0) }\end{array}$ \\
\hline 1 & 3TC & 150 & 5,7 & - & - & - & 0 \\
\hline 2 & $3 T C+A D V$ & $100+10$ & 200,0 & - & 7,4 & - & 1 \\
\hline 5 & $3 T C+T D F$ & $100+300$ & 326,0 & 82,2 & - & - & 1 \\
\hline 6 & $3 T C+$ TDF & $100+300$ & 136,0 & *** & - & - & 0 \\
\hline 9 & 3TC & 150 & 30,1 & - & - & - & 1 \\
\hline 10 & $3 T C+T D F$ & $100+300$ & 30,6 & $* * *$ & - & - & 0 \\
\hline 11 & 3TC & 150 & 15,2 & - & - & - & 0 \\
\hline 12 & $3 T C+A D V$ & $100+10$ & 10,8 & - & $\star * *$ & - & 0 \\
\hline 15 & $3 T C+A D V$ & $100+10$ & 53,5 & - & 5,7 & - & 1 \\
\hline 17 & 3TC & 150 & 22,8 & - & - & - & 1 \\
\hline 18 & 3TC & 150 & 13,1 & - & - & - & 0 \\
\hline 19 & TDF & 300 & - & 0,1 & - & - & 0 \\
\hline 22 & 3TC & 150 & $* * *$ & - & - & - & 0 \\
\hline 30 & $3 T C+T D F$ & $100+300$ & 68,3 & $* * *$ & - & - & 0 \\
\hline 32 & 3TC & 150 & 177,0 & - & - & - & 1 \\
\hline 35 & 3TC & 150 & 75,5 & - & - & - & 1 \\
\hline 36 & $3 T C+T D F$ & $100+300$ & 59,6 & $* \star *$ & - & - & 0 \\
\hline 39 & $3 T C+T D F$ & $100+300$ & 72,7 & $* \star *$ & - & - & 0 \\
\hline 43 & 3TC & 150 & 195,0 & - & - & - & 1 \\
\hline 44 & 3TC & 150 & 40,2 & - & - & - & 1 \\
\hline 50 & 3TC & 150 & 7,6 & - & - & - & 0 \\
\hline 51 & $3 T C+A D V$ & $100+10$ & 15,3 & - & $* * *$ & - & 0 \\
\hline 52 & ETV & 0.5 & - & - & - & $\star * *$ & 0 \\
\hline 57 & ETV & 0.5 & - & - & - & *** & 0 \\
\hline 59 & 3TC & 100 & 229,0 & - & - & - & 1 \\
\hline 60 & $3 T C+A D V$ & $100+10$ & 151,0 & - & 16,7 & - & 1 \\
\hline 61 & 3TC & 150 & 43,2 & - & - & - & 1 \\
\hline 63 & $3 T C+T D F$ & $100+300$ & $* * *$ & $* * *$ & - & - & 0 \\
\hline 67 & $3 T C+T D F$ & $100+300$ & 76,6 & $* * *$ & - & - & 0 \\
\hline 69 & 3TC & 150 & 24,2 & - & - & - & 1 \\
\hline 73 & $3 T C+T D F$ & $100+300$ & 217,0 & *** & - & - & 0 \\
\hline
\end{tabular}




\begin{tabular}{|c|c|c|c|c|c|c|c|}
\hline $\begin{array}{l}\text { Paciente } \\
\text { ID }\end{array}$ & $\begin{array}{c}\text { Tratamento } \\
\text { antiviral }\end{array}$ & $\begin{array}{l}\text { Dose total } \\
\text { diária }(\mathrm{mg})\end{array}$ & $\begin{array}{c}3 \mathrm{TC} \\
(\mathrm{ng} / \mathrm{mL})\end{array}$ & $\begin{array}{c}\mathrm{TDF} \\
(\mathrm{ng} / \mathrm{mL})\end{array}$ & $\begin{array}{c}\mathrm{ADV} \\
(\mathrm{ng} / \mathrm{mL})\end{array}$ & $\begin{array}{c}\text { ETV } \\
\text { (ng/mL) }\end{array}$ & $\begin{array}{l}\text { Adesão (1) } \\
\quad \text { Nâo } \\
\text { adesâo (0)* }\end{array}$ \\
\hline 79 & $3 T C+A D V$ & $100+10$ & 194,0 & - & 14,7 & - & 1 \\
\hline 85 & TDF & 300 & - & 35,9 & - & - & 0 \\
\hline 86 & $3 T C+T D F$ & $100+300$ & $* * *$ & $* * *$ & - & - & 0 \\
\hline 88 & $3 T C+A D V$ & $100+10$ & 11,7 & - & 2,5 & - & 0 \\
\hline 89 & $3 T C+T D F$ & $100+300$ & 177,0 & 92,1 & - & - & 1 \\
\hline 91 & TDF & 300 & - & 21,6 & - & - & 0 \\
\hline 92 & 3TC & 150 & 162,0 & - & - & - & 1 \\
\hline 97 & TDF & 300 & - & 184,0 & - & - & 1 \\
\hline 98 & 3TC & 150 & 58,9 & - & - & - & 1 \\
\hline 100 & 3TC & 150 & 145,0 & - & - & - & 1 \\
\hline 102 & 3TC & 150 & 184,0 & - & - & - & 1 \\
\hline 107 & 3TC & 150 & 304,0 & - & - & - & 1 \\
\hline 109 & $3 T C+A D V$ & $100+10$ & 201,0 & - & 17,4 & - & 1 \\
\hline 113 & 3TC & 150 & 23,0 & - & - & - & 1 \\
\hline 117 & TDF & 300 & - & 26,4 & - & - & 0 \\
\hline 118 & 3TC & 150 & 272,0 & - & - & - & 1 \\
\hline 122 & 3TC & 150 & 293,0 & - & - & - & 1 \\
\hline 124 & 3TC & 150 & 132,0 & - & - & - & 1 \\
\hline 125 & $3 T C+$ TDF & $100+300$ & 155,0 & 25,2 & - & - & 0 \\
\hline 126 & $3 T C+T D F$ & $100+300$ & 683,0 & $\star * *$ & - & - & 0 \\
\hline 129 & 3TC & 150 & 84,2 & - & - & - & 1 \\
\hline 130 & 3TC & 150 & 0,8 & - & - & - & 0 \\
\hline 136 & $3 T C+A D V$ & $100+10$ & 15,5 & - & $* * *$ & - & 0 \\
\hline 141 & $3 T C+A D V$ & $100+10$ & 149,0 & - & 17,9 & - & 1 \\
\hline 143 & 3TC & 150 & 108,0 & - & - & - & 1 \\
\hline 146 & 3TC & 150 & 447,0 & - & - & - & 1 \\
\hline 153 & 3TC & 150 & 147,0 & - & - & - & 1 \\
\hline 154 & ETV & 0.5 & - & - & - & *** & 0 \\
\hline 159 & $3 T C+A D V$ & $100+10$ & $* * *$ & - & 0,4 & - & 0 \\
\hline 170 & 3TC & 150 & 278,0 & - & - & - & 1 \\
\hline 174 & $3 T C+A D V$ & $100+10$ & 70,4 & - & 7,7 & - & 1 \\
\hline 179 & TDF & 300 & - & *** & - & - & 0 \\
\hline 180 & TDF & 300 & - & 148,0 & - & - & 1 \\
\hline 182 & ETV & 0.5 & - & - & - & *** & 0 \\
\hline
\end{tabular}

${ }^{*}$ método direto. ${ }^{* *}$ concentração esperada no soro/plasma humano: $3 T C(20-1100 \mathrm{ng} / \mathrm{mL})^{(147)}$; TDF $(64,4-326,0 \mathrm{ng} / \mathrm{mL})^{(148)} ; \mathrm{ADV}(<16,4 \mathrm{ng} / \mathrm{mL})^{(149)} ; \mathrm{ETV}(0,3-4,2 \mathrm{ng} / \mathrm{mL})^{(150)}$. ${ }^{* \star *}{ }^{\text {indetectável. }}$ 


\section{REFERÊNCIAS}

1. Purcell $\mathrm{RH}$. The discovery of the hepatitis viruses. Gastroenterology. 1993;104(4):955-63.

2. Lee WM. Hepatitis $B$ virus infection. $N$ Engl $J$ Med. 1997;337(24):1733-45.

3. Senior JR, London WT, Sutnick AI. The Australia antigen and role of the late Philadelphia General Hospital in reducing post-transfusion hepatitis and sequelae. Hepatology. 2011;54(3):753-6.

4. Blumberg BS, Alter HJ, Visnich S. A "new" antigen in leukemia sera. JAMA. 1965;191:541-6.

5. Lau JY, Wright TL. Molecular virology and pathogenesis of hepatitis B. Lancet. 1993;342(8883):1335-40.

6. Magnius LO, Espmark JA. New specificities in Australia antigen positive sera distinct from the Le Bouvier determinants. J Immunol. 1972;109(5):1017-21.

7. Perkins JA. Hepatitis B virus [on-line]. 2002. Disponível em: http://people.rit.edu/japfaa/index.html.

8. Locarnini S, Hatzakis A, Chen DS, Lok A. Strategies to control hepatitis B: Public policy, epidemiology, vaccine and drugs. J Hepatol. 2015;62(1 Suppl):S76-86.

9. Ito K, Yotsuyanagi $\mathrm{H}$, Sugiyama M, Yatsuhashi $\mathrm{H}$, Karino $\mathrm{Y}$, Takikawa $Y$, et al. Geographic distribution and characteristics of genotype A hepatitis $B$ virus infection in acute and chronic hepatitis $B$ patients in Japan. $J$ Gastroenterol Hepatol. 2016;31(1):180-9.

10. Matsuura K, Tanaka Y, Hige S, Yamada G, Murawaki Y, Komatsu M, et al. Distribution of hepatitis $B$ virus genotypes among patients with chronic infection in Japan shifting toward an increase of genotype A. J Clin Microbiol. 2009;47(5):1476-83.

11. Alvarado-Mora MV, Pinho JR. Distribution of HBV genotypes in Latin America. Antivir Ther. 2013;18(3 Pt B):459-65.

12. Schaefer S. Hepatitis B virus: significance of genotypes. J Viral Hepat. 2005;12(2):111-24.

13. Ding $\mathrm{X}, \mathrm{Gu} \mathrm{H}$, Zhong $\mathrm{ZH}$, Zilong $\mathrm{X}$, Tran HT, Iwaki $\mathrm{Y}$, et al. Molecular epidemiology of hepatitis viruses and genotypic distribution of hepatitis $B$ and C viruses in Harbin, China. Jpn J Infect Dis. 2003;56(1):19-22.

14. Sablon E, Shapiro F. Advances in Molecular Diagnosis of HBV Infection and Drug Resistance. Int J Med Sci. 2005;2(1):8-16. 
15. Ahmed CS, Wang ZH, Bin Z, Chen JJ, Kamal M, Hou JL. Hepatitis B virus genotypes, subgenotypes, precore, and basal core promoter mutations in the two largest provinces of Pakistan. J Gastroenterol Hepatol. 2009;24(4):569-73.

16. Stuyver LJ, Locarnini SA, Lok A, Richman DD, Carman WF, Dienstag $\mathrm{JL}$, et al. Nomenclature for antiviral-resistant human hepatitis B virus mutations in the polymerase region. Hepatology. 2001;33(3):751-7.

17. Lacey L. Review of economic benefits of treating chronic hepatitis B with lamivudine. J Gastroenterol Hepatol. 2004;19 Suppl:S10-2.

18. Kane M. Global programme for control of hepatitis B infection. Vaccine. 1995;13 Suppl 1:S47-9.

19. Ferreira MS. Diagnosis and treatment of hepatitis B. Rev Soc Bras Med Trop. 2000;33(4):389-400.

20. World Health Organization. Guidelines for the prevention, care and treatment of persons with chronic hepatitis B infection. Geneva: World Health Organization; 2015.

21. Chang MH, Chen CJ, Lai MS, Hsu HM, Wu TC, Kong MS, et al. Universal hepatitis $B$ vaccination in Taiwan and the incidence of hepatocellular carcinoma in children. Taiwan Childhood Hepatoma Study Group. N Engl J Med. 1997;336(26):1855-9.

22. Castelo A, Pessôa MG, Barreto TC, Alves MR, Araújo DV. Cost estimates of chronic hepatitis $B$ virus for the Brazilian unified health system in 2005. Rev Assoc Med Bras. 2007;53(6):486-91.

23. Shepard CW, Simard EP, Finelli L, Fiore AE, Bell BP. Hepatitis B virus infection: epidemiology and vaccination. Epidemiol Rev. 2006;28:112-25.

24. Mazzur S, Nath N, Fang C, Bastiaans MJ, Molinaris JL, Balcaser M, et al. Distribution of hepatitis virus (HBV) markers in blood donors of 13 countries of the Western hemisphere: proceedings of the Red Cross Latin American Workshop on Hepatitis B. Bol Oficina Sanit Panam. 1980;89(3):239-48.

25. Martelli CM, de Andrade AL, Cardoso D das D, Sousa LC, Almeida e Silva S, de Sousa MA, et al. Seroprevalence and risk factors for hepatitis $B$ virus infection by AgHBs and anti-HBs markers in prisoners and prime blood donors. Rev Saude Publica. 1990;24(4):270-6.

26. Schweitzer A, Horn J, Mikolajczyk RT, Krause G, Ott JJ. Estimations of worldwide prevalence of chronic hepatitis $B$ virus infection: a systematic review of data published between 1965 and 2013. Lancet. 2015.

27. El-Serag HB. Epidemiology of viral hepatitis and hepatocellular carcinoma. Gastroenterology. 2012;142(6):1264-73.e1.

28. Zhu HL, Li X, Li J, Zhang ZH. Genetic variation of occult hepatitis B virus infection. World J Gastroenterol. 2016;22(13):3531-46. 
29. Hollinger FB. Hepatitis $B$ virus infection and transfusion medicine: science and the occult. Transfusion. 2008;48(5):1001-26.

30. Núñez $M$, Ríos $P$, Pérez-Olmeda $M$, Soriano $V$. Lack of 'occult' hepatitis B virus infection in HIV-infected patients. AIDS. 2002;16(15):2099101.

31. Gutiérrez-García ML, Fernandez-Rodriguez CM, Lledo-Navarro JL, Buhigas-Garcia I. Prevalence of occult hepatitis B virus infection. World J Gastroenterol. 2011;17(12):1538-42.

32. Pereira LM, Martelli CM, Merchán-Hamann E, Montarroyos UR, Braga MC, Lima ML, et al. Population-based multicentric survey of hepatitis B infection and risk factor differences among three regions in Brazil. Am J Trop Med Hyg. 2009;81(2):240-7.

33. Focaccia R. Tratado de Hepatites Virais. 2 ed. Rio de Janeiro: Atheneu; 2007.

34. Brasil, Ministério da Saúde. Hepatites virais no Brasil. Brasília: Ministério da Saúde; 2012.

35. Silva L. Hepatites agudas e crônicas. 2 ed. São Paulo: Sarvier; 1995.

36. Zaterka S, Eisig JN. Tratado de Gastroenterologia: da Graduação à Pós-Graduação. São Paulo: Atheneu; 2011.

37. Araújo ES, Barone AA, Junior FL, Ferreira JS, Focaccia R. I consensus for the management and treatment of hepatitis $B$ carried out by the Brazilian society of infectious diseases. Braz J Infect Dis. 2007;11(1):2-5.

38. Guirao A, Yuste S, Regueiro B. Epidemiología y manifestaciones clínicas de las hepatitis virales. Enferm Infect Microbiol Clin. 2006;24(4):26476.

39. Veronesi R. Doenças infecciosas e parasitárias. 8 ed. Rio de Janeiro: Guanabara Koogan; 1991.

40. Goldstein ST, Alter MJ, Williams IT, Moyer LA, Judson FN, Mottram K, et al. Incidence and risk factors for acute hepatitis B in the United States, 1982-1998: implications for vaccination programs. $J$ Infect Dis. 2002;185(6):713-9.

41. Alter MJ, Margolis HS. The emergence of hepatitis B as a sexually transmitted disease. Med Clin North Am. 1990;74(6):1529-41.

42. Okada K, Kamiyama I, Inomata M, Imai M, Miyakawa Y. e antigen and anti-e in the serum of asymptomatic carrier mothers as indicators of positive and negative transmission of hepatitis B virus to their infants. $\mathrm{N}$ Engl $\mathrm{J}$ Med. 1976;294(14):746-9.

43. Kwon SY, Lee $\mathrm{CH}$. Epidemiology and prevention of hepatitis $\mathrm{B}$ virus infection. Korean J Hepatol. 2011;17(2):87-95. 
44. Carrilho FJ, Ono-Nita SK, Cardoso RA, Cancado EL, Pinho JR, Alves $V A$, et al. A prospective study of hepatitis $B$ virus markers in patients with chronic HBV infection from Brazilian families of Western and Asian origin. Braz J Med Biol Res. 2005;38(9):1399-408.

45. Ono-Nita SK, Carrilho FJ, Cardoso RA, Nita ME, da Silva LC. Searching for chronic hepatitis $B$ patients in a low prevalence area--role of racial origin. BMC Fam Pract. 2004;5:7.

46. Lok AS, McMahon BJ. Chronic hepatitis B: update 2009. Hepatology. 2009;50(3):661-2.

47. McMahon BJ. The natural history of chronic hepatitis B virus infection. Semin Liver Dis. 2004;24 Suppl 1:17-21.

48. Morikawa K, Shimazaki T, Takeda R, Izumi T, Umumura M, Sakamoto $\mathrm{N}$. Hepatitis B: progress in understanding chronicity, the innate immune response, and cccDNA protection. Ann Transl Med. 2016;4(18):337.

49. Wright TL, Lau JY. Clinical aspects of hepatitis B virus infection. Lancet. 1993;342(8883):1340-4.

50. Lampertico $P$, Agarwal K, Berg $T$, Buti $M$, Janssen HLA, Papatheodoridis G, et al. EASL 2017 Clinical Practice Guidelines on the management of hepatitis B virus infection. J Hepatol. 2017.

51. Fonseca J. História natural da hepatite crônica B. Revista da Sociedade Brasileira de Medicina Tropical. 2007;40(6):672-7.

52. Kim V, Abreu RM, Nakagawa DM, Baldassare RM, Carrilho FJ, Ono SK. Pegylated interferon alfa for chronic hepatitis B: systematic review and meta-analysis. J Viral Hepat. 2015.

53. Lai CL, Chien RN, Leung NW, Chang TT, Guan R, Tai DI, et al. A oneyear trial of lamivudine for chronic hepatitis B. Asia Hepatitis Lamivudine Study Group. N Engl J Med. 1998;339(2):61-8.

54. Lai CL, Shouval D, Lok AS, Chang TT, Cheinquer H, Goodman Z, et al. Entecavir versus lamivudine for patients with $\mathrm{HBeAg-negative} \mathrm{chronic}$ hepatitis B. N Engl J Med. 2006;354(10):1011-20.

55. Liaw YF, Gane E, Leung N, Zeuzem S, Wang Y, Lai CL, et al. 2-Year GLOBE trial results: telbivudine Is superior to lamivudine in patients with chronic hepatitis B. Gastroenterology. 2009;136(2):486-95.

56. Gish RG, Lok AS, Chang TT, de Man RA, Gadano A, Sollano J, et al. Entecavir therapy for up to 96 weeks in patients with HBeAg-positive chronic hepatitis B. Gastroenterology. 2007;133(5):1437-44.

57. Hadziyannis SJ, Tassopoulos NC, Heathcote EJ, Chang TT, Kitis G, Rizzetto M, et al. Adefovir dipivoxil for the treatment of hepatitis B e antigennegative chronic hepatitis B. N Engl J Med. 2003;348(9):800-7.

58. Marcellin P, Chang TT, Lim SG, Tong MJ, Sievert W, Shiffman ML, et al. Adefovir dipivoxil for the treatment of hepatitis $B$ e antigen-positive chronic hepatitis B. N Engl J Med. 2003;348(9):808-16. 
59. Dore GJ, Cooper DA, Pozniak AL, DeJesus E, Zhong L, Miller MD, et al. Efficacy of tenofovir disoproxil fumarate in antiretroviral therapy-naive and -experienced patients coinfected with HIV-1 and hepatitis B virus. J Infect Dis. 2004;189(7):1185-92.

60. Perronne C. Antiviral hepatitis and antiretroviral drug interactions. J Hepatol. 2006;44(1 Suppl):S119-25.

61. Reijnders JG, Pas SD, Schutten M, de Man RA, Janssen HL. Entecavir shows limited efficacy in HBeAg-positive hepatitis $B$ patients with a partial virologic response to adefovir therapy. J Hepatol. 2009;50(4):674-83.

62. Tatulli I, Francavilla R, Rizzo GL, Vinciguerra V, lerardi E, Amoruso A, et al. Lamivudine and alpha-interferon in combination long term for precore mutant chronic hepatitis B. J Hepatol. 2001;35(6):805-10.

63. Marcellin P, Gane E, Buti M, Afdhal N, Sievert W, Jacobson IM, et al. Regression of cirrhosis during treatment with tenofovir disoproxil fumarate for chronic hepatitis B: a 5-year open-label follow-up study. Lancet. 2013;381(9865):468-75.

64. Wong GL, Chan HL, Mak CW, Lee SK, Ip ZM, Lam AT, et al. Entecavir treatment reduces hepatic events and deaths in chronic hepatitis $B$ patients with liver cirrhosis. Hepatology. 2013;58(5):1537-47.

65. Brasil, Ministério da Saúde. Protocolo Clínico e Diretrizes Terapêuticas Hepatite Viral Crônica B. Brasília: Ministério da Saúde; 2002.

66. Brasil, Ministério da Saúde. Protocolo clínico e diretrizes terapêuticas para o tratamento da hepatite viral crônica B e coinfecções. Brasília: Ministério da Saúde; 2010.

67. Brasil, Ministério da Saúde. Protocolo clínico e diretrizes terapêuticas para hepatite B e coinfecções. Brasília: Ministério da Saúde; 2017.

68. Kim KH, Kim ND, Seong BL. Discovery and development of anti-HBV agents and their resistance. Molecules. 2010;15(9):5878-908.

69. Martins MA, Carrilho FJ, Alves VAF, Castilho EA, Cerri GG, Wen CL. Clínica Médica: doenças do aparelho digestivo, nutrição e doenças nutricionais. Barueri: Manole; 2009.

70. Hongthanakorn C, Chotiyaputta W, Oberhelman K, Fontana RJ, Marrero JA, Licari T, et al. Virological breakthrough and resistance in patients with chronic hepatitis $B$ receiving nucleos(t)ide analogues in clinical practice. Hepatology. 2011;53(6):1854-63.

71. Berg T, Marcellin P, Zoulim F, Moller B, Trinh H, Chan S, et al. Tenofovir is effective alone or with emtricitabine in adefovir-treated patients with chronic-hepatitis B virus infection. Gastroenterology. 2010;139(4):120717.

72. Lee YS, Suh DJ, Lim YS, Jung SW, Kim KM, Lee HC, et al. Increased risk of adefovir resistance in patients with lamivudine-resistant chronic hepatitis $B$ after 48 weeks of adefovir dipivoxil monotherapy. Hepatology. 2006;43(6):1385-91. 
73. Beutels $P$. Economic evaluations of hepatitis $B$ immunization: a global review of recent studies (1994-2000). Health Econ. 2001;10(8):751-74.

74. Boucle S, Bassit L, Ehteshami M, Schinazi RF. Toward Elimination of Hepatitis B Virus Using Novel Drugs, Approaches, and Combined Modalities. Clin Liver Dis. 2016;20(4):737-49.

75. Ono-Nita SK, Kato N, Shiratori Y, Lan KH, Yoshida H, Carrilho FJ, et al. Susceptibility of lamivudine-resistant hepatitis $B$ virus to other reverse transcriptase inhibitors. J Clin Invest. 1999;103(12):1635-40.

76. Ono-Nita SK, Kato N, Shiratori Y, Masaki T, Lan KH, Carrilho FJ, et al. YMDD motif in hepatitis $B$ virus DNA polymerase influences on replication and lamivudine resistance: A study by in vitro full-length viral DNA transfection. Hepatology. 1999;29(3):939-45.

77. Gupta N, Goyal M, Wu CH, Wu GY. The Molecular and Structural Basis of HBV-resistance to Nucleos(t)ide Analogs. J Clin Transl Hepatol. 2014;2(3):202-11.

78. Menéndez-Arias L, Álvarez M, Pacheco B. Nucleoside/nucleotide analog inhibitors of hepatitis $B$ virus polymerase: mechanism of action and resistance. Curr Opin Virol. 2014;8:1-9.

79. World Health Organization. Adherence to long-term therapies: evidence for action. Geneva: World Health Organization; 2003.

80. Hepke KL, Martus MT, Share DA. Costs and utilization associated with pharmaceutical adherence in a diabetic population. Am $\mathrm{J}$ Manag Care. 2004;10(2 Pt 2):144-51.

81. Simpson SH, Eurich DT, Majumdar SR, Padwal RS, Tsuyuki RT, Varney $\mathrm{J}$, et al. A meta-analysis of the association between adherence to drug therapy and mortality. BMJ. 2006;333(7557):15.

82. Haynes RB, Taylor DW, Sackett DL. Compliance in Health Care. Baltimore: The Johns Hopkins University Press; 1979.

83. Robiner WN. Enhancing adherence in clinical research. Contemp Clin Trials. 2005;26(1):59-77.

84. Santa-Helena ET. Adesão ao tratamento farmacológico de pacientes com hipertensão arterial em unidades de saúde da família em Blumenau, SC [tese]. São Paulo: Faculdade de Medicina, Universidade de São Paulo; 2007.

85. Farmer KC. Methods for measuring and monitoring medication regimen adherence in clinical trials and clinical practice. Clin Ther. 1999;21(6):1074-90; discussion 3.

86. Morisky DE, Green LW, Levine DM. Concurrent and predictive validity of a self-reported measure of medication adherence. Med Care. 1986;24(1):67-74.

87. Haynes RB, Taylor DW, Sackett DL, Gibson ES, Bernholz CD, Mukherjee J. Can simple clinical measurements detect patient noncompliance? Hypertension. 1980;2(6):757-64. 
88. Abreu RM, Silva Ferreira C, Ferreira AS, Remor E, Nasser PD, Carrilho FJ, et al. Assessment of Adherence to Prescribed Therapy in Patients with Chronic Hepatitis B. Infect Dis Ther. 2016;5(1):53-64.

89. Abreu RM. Questionnaire validation for adherence antiviral therapy assessment in chronic hepatitis B patients. São Paulo: University of Sao Paulo School of Medicine; 2013.

90. Remor E. Manual del cuestionario para la evaluación de la adhesión al tratamiento antirretroviral (CEAT-VIH). Madrid: Facultad de PsicologíaUniversidad Autónoma de Madrid; 2002.

91. Remor E. Valoración de la adhesión al tratamiento antirretroviral en pacientes $\mathrm{VIH}+$. Psicothema. 2002;14(2):262-7.

92. Remor E. Cuestionario para la evaluación de la adhesión al tratamiento antirretroviral (CEAT-VIH): estudio internacional. Rev Humanitas. 2006;3:80-1.

93. Remor E, Milner-Moskovics J, Preussler G. Brazilian adaptation of the Assessment of Adherence to Antiretroviral Therapy Questionnaire. Rev Saude Publica. 2007;41(5):685-94.

94. Remor E. International psychometric study of the adherence to antiretroviral treatment questionnaire. 22nd Annual Conference of the European Health Psychology Society; UK2008.

95. Reis AC, Lencastre L, Guerra MP, Remor E. Adaptação portuguesa do questionário para a avaliação da adesão ao tratamento anti-retrovíricoVIH (CEAT-VIH). Psicologia, saúde \& doenças. 2009;10(2):175-91.

96. Chang ML, Liaw YF, Hadziyannis SJ. Systematic review: cessation of long-term nucleos(t)ide analogue therapy in patients with hepatitis $B$ e antigen-negative chronic hepatitis B. Aliment Pharmacol Ther. 2015;42(3):243-57.

97. Ono SK, Kato N, Shiratori Y, Kato J, Goto T, Schinazi RF, et al. The polymerase L528M mutation cooperates with nucleotide binding-site mutations, increasing hepatitis $\mathrm{B}$ virus replication and drug resistance. J Clin Invest. 2001;107(4):449-55.

98. Keeffe EB, Dieterich DT, Han SH, Jacobson IM, Martin P, Schiff ER, et al. A treatment algorithm for the management of chronic hepatitis $B$ virus infection in the United States: an update. Clin Gastroenterol Hepatol. 2006;4(8):936-62.

99. Hoofnagle $\mathrm{JH}$. Hepatitis B--preventable and now treatable. N Engl J Med. 2006;354(10):1074-6.

100. Locarnini S, Hatzakis A, Heathcote J, Keeffe EB, Liang TJ, Mutimer D, et al. Management of antiviral resistance in patients with chronic hepatitis $B$. Antivir Ther. 2004;9(5):679-93.

101. Ayoub WS, Keeffe EB. Review article: current antiviral therapy of chronic hepatitis B. Aliment Pharmacol Ther. 2011;34(10):1145-58. 
102. Ha NB, Garcia RT, Trinh HN, Chaung KT, Nguyen HA, Nguyen KK, et al. Medication nonadherence with long-term management of patients with hepatitis $B$ e antigen-negative chronic hepatitis B. Dig Dis Sci. 2011;56(8):2423-31.

103. Hilleret MN, Larrat S, Stanke-Labesque F, Leroy V. Does adherence to hepatitis $B$ antiviral treatment correlate with virological response and risk of breakthrough? J Hepatol. 2011;55(6):1468-9; author reply 9-70.

104. Zoulim F. Hepatitis: Treatment failure in chronic hepatitis B. Nat Rev Gastroenterol Hepatol. $2011 ; 8(7): 366-7$.

105. Chotiyaputta W, Peterson C, Ditah FA, Goodwin D, Lok AS. Persistence and adherence to nucleos(t)ide analogue treatment for chronic hepatitis B. J Hepatol. 2011;54(1):12-8.

106. Chotiyaputta W, Hongthanakorn C, Oberhelman K, Fontana RJ, Licari T, Lok AS. Adherence to nucleos(t)ide analogues for chronic hepatitis B in clinical practice and correlation with virological breakthroughs. J Viral Hepat. 2012;19(3):205-12.

107. Sogni $P$, Carrieri MP, Fontaine $H$, Mallet V, Vallet-Pichard A, Trabut $\mathrm{JB}$, et al. The role of adherence in virological suppression in patients receiving anti-HBV analogues. Antivir Ther. 2012;17(2):395-400.

108. Terrault NA, Bzowej NH, Chang KM, Hwang JP, Jonas MM, Murad $\mathrm{MH}$. AASLD guidelines for treatment of chronic hepatitis B. Hepatology. 2016;63(1):261-83.

109. EASL. EASL clinical practice guidelines: Management of chronic hepatitis B virus infection. J Hepatol. 2012;57(1):167-85.

110. Liaw YF, Kao JH, Piratvisuth T, Chan HL, Chien RN, Liu CJ, et al. Asian-Pacific consensus statement on the management of chronic hepatitis B: a 2012 update. Hepatol Int. 2012;6(3):531-61.

111. Santa Helena ET, Nemes MI, Eluf-Neto J. Development and validation of a multidimensional questionnaire assessing non-adherence to medicines. Rev Saude Publica. 2008;42(4):764-7.

112. Lieveld FI, van Vlerken LG, Siersema PD, van Erpecum KJ. Patient adherence to antiviral treatment for chronic hepatitis $B$ and $C$ : a systematic review. Ann Hepatol. 2013;12(3):380-91.

113. Giang L, Selinger CP, Lee AU. Evaluation of adherence to oral antiviral hepatitis B treatment using structured questionnaires. World $\mathrm{J}$ Hepatol. 2012;4(2):43-9.

114. Brasil, Ministério da Saúde. Portaria oㅡ 2.981 de 26 de novembro de 2009. Brasília: Ministério da Saúde; 2009.

115. Rimawi BH, Johnson E, Rajakumar A, Tao S, Jiang $Y$, Gillespie S, et al. Pharmacokinetics and Placental Transfer of Elvitegravir and Dolutegravir, and Other Antiretrovirals during Pregnancy. Antimicrob Agents Chemother. 2017. 
116. Couto-Junior EB. Abordagem não-paramétrica para cálculo do tamanho da amostra com base em questionários ou escalas de avaliação na área de saúde [tese]. São Paulo: Faculdade de Medicina, Universidade de São Paulo; 2009.

117. Deming W. Some theory of sampling. New York: Dover; 1966.

118. Cunha AC, Freddi MJAL, Crestana MF, Aragão MS, Cardoso SC, Vilhena V. Guia de apresentação de dissertações, teses e monografias. 3 ed. São Paulo: Divisão de Biblioteca e Documentação/ Faculdade de Medicina da Universidade de São Paulo; 2011.

119. Bruix J, Sherman M. Management of hepatocellular carcinoma: an update. Hepatology. 2011;53(3):1020-2.

120. Rosenfeld E, Kinney S, Weiner C, Newall F, Williams A, Cranswick N, et al. Interdisciplinary medication decision making by pharmacists in pediatric hospital settings: An ethnographic study. Res Social Adm Pharm. 2017.

121. Kovačević SV, Miljković B, Ćulafić $M$, Kovačević $M$, Golubović $B$, Jovanović $M$, et al. Evaluation of drug-related problems in older polypharmacy primary care patients. J Eval Clin Pract. 2017.

122. Tahaineh $\mathrm{LM}$, Khasawneh $\mathrm{AH}$. A randomised control trial to evaluate the clinical pharmacist's role in managing iron deficiency anaemia patients. Int J Pharm Pract. 2017.

123. Awad A, Osman N, Altayib S. Medication adherence among cardiac patients in Khartoum State, Sudan: a cross-sectional study. Cardiovasc J Afr. 2017;28:1-7.

124. Langness JA, Nguyen M, Wieland A, Everson GT, Kiser JJ. Optimizing hepatitis $C$ virus treatment through pharmacist interventions: Identification and management of drug-drug interactions. World $J$ Gastroenterol. 2017;23(9):1618-26.

125. Conn VS, Ruppar TM. Medication adherence outcomes of 771 intervention trials: Systematic review and meta-analysis. Prev Med. 2017;99:269-76.

126. Carter KL, Gabrellas AD, Shah S, Garland JM. Improved latent tuberculosis therapy completion rates in refugee patients through use of a clinical pharmacist. Int J Tuberc Lung Dis. 2017;21(4):432-7.

127. Alassaad A, Bertilsson M, Gillespie U, Sundström J, HammarlundUdenaes $M$, Melhus $H$. The effects of pharmacist intervention on emergency department visits in patients 80 years and older: subgroup analyses by number of prescribed drugs and appropriate prescribing. PLoS One. 2014;9(11):e111797.

128. Silveira MP, Guttier MC, Moreira LB, Mirzazadeh A, Page K. Predictors of non-adherence to clinical follow-up among patients participating in a randomized trial of pharmaceutical care intervention in HIV-positive adults in Southern Brazil. AIDS Behav. 2014;18 Suppl 1:S85-8. 
129. Lee JK, Grace KA, Taylor AJ. Effect of a pharmacy care program on medication adherence and persistence, blood pressure, and low-density lipoprotein cholesterol: a randomized controlled trial. JAMA. 2006;296(21):2563-71.

130. Murray MD, Young J, Hoke S, Tu W, Weiner M, Morrow D, et al. Pharmacist intervention to improve medication adherence in heart failure: a randomized trial. Ann Intern Med. 2007;146(10):714-25.

131. Aljumah K, Hassali MA. Impact of pharmacist intervention on adherence and measurable patient outcomes among depressed patients: a randomised controlled study. BMC Psychiatry. 2015;15:219.

132. Zhai $X B$, Tian DD, Liu $X Y$. The role of the clinical pharmacist in reducing mortality in hospitalized cardiac patients: A prospective, nonrandomized controlled trial using propensity score methods. Int J Clin Pharmacol Ther. 2015;53(3):220-9.

133. Wishah RA, Al-Khawaldeh OA, Albsoul AM. Impact of pharmaceutical care interventions on glycemic control and other health-related clinical outcomes in patients with type 2 diabetes: Randomized controlled trial. Diabetes Metab Syndr. 2015;9(4):271-6.

134. Gallagher J, McCarthy S, Byrne S. Economic evaluations of clinical pharmacist interventions on hospital inpatients: a systematic review of recent literature. Int J Clin Pharm. 2014;36(6):1101-14.

135. Lok AS, Lai CL, Leung N, Yao GB, Cui ZY, Schiff ER, et al. Long-term safety of lamivudine treatment in patients with chronic hepatitis $B$. Gastroenterology. 2003;125(6):1714-22.

136. Ma Y, Yuan Y, Ma X, Tang B, Hu X, Feng J, et al. Association between clinical features and YMDD mutations in patients with chronic hepatitis B following lamivudine therapy. Exp Ther Med. 2016;12(2):847-53.

137. Qiu Q, Duan XW, Li Y, Yang LK, Chen Y, Li H, et al. Impact of partial reimbursement on hepatitis $B$ antiviral utilization and adherence. World $\mathrm{J}$ Gastroenterol. 2015;21(32):9588-97.

138. Qiu Q, Li Y, Duan XW, Yang LK, Chen Y, Li H, et al. Impact of a new reimbursement program on hepatitis $B$ antiviral medication cost and utilization in Beijing, China. PLoS One. 2014;9(10):e109652.

139. Cantudo-Cuenca MR, Jiménez-Galán R, Almeida-Gonzalez CV, Morillo-Verdugo R. Concurrent use of comedications reduces adherence to antiretroviral therapy among HIV-infected patients. J Manag Care Spec Pharm. 2014;20(8):844-50.

140. Balkhy HH, El-Saed A, Sanai FM, Alqahtani M, Alonaizi M, Niazy N, et al. Magnitude and causes of loss to follow-up among patients with viral hepatitis at a tertiary care hospital in Saudi Arabia. J Infect Public Health. 2016. 
141. Chien RN, Peng CY, Kao JH, Hu TH, Lin CC, Hu CT, et al. Higher adherence with 3-year entecavir treatment than lamivudine or telbivudine in treatment-naïve Taiwanese patients with chronic hepatitis B. J Gastroenterol Hepatol. 2014;29(1):185-92.

142. Kim WR, Loomba R, Berg T, Aguilar Schall RE, Yee LJ, Dinh PV, et al. Impact of long-term tenofovir disoproxil fumarate on incidence of hepatocellular carcinoma in patients with chronic hepatitis B. Cancer. 2015;121(20):3631-8.

143. Hosaka T, Suzuki F, Kobayashi M, Seko Y, Kawamura Y, Sezaki H, et al. Long-term entecavir treatment reduces hepatocellular carcinoma incidence in patients with hepatitis B virus infection. Hepatology. 2013;58(1):98-107.

144. Papatheodoridis GV, Chan HL, Hansen BE, Janssen HL, Lampertico $P$. Risk of hepatocellular carcinoma in chronic hepatitis $B$ : assessment and modification with current antiviral therapy. J Hepatol. 2015;62(4):956-67.

145. Van Vlerken LG, Arends P, Lieveld FI, Arends JE, Brouwer WP, Siersema PD, et al. Real life adherence of chronic hepatitis $B$ patients to entecavir treatment. Dig Liver Dis. 2015;47(7):577-83.

146. Chi H, Arends P, Reijnders JG, Carey I, Brown A, Fasano M, et al. Flares during long-term entecavir therapy in chronic hepatitis B. J Gastroenterol Hepatol. 2016;31(11):1882-7.

147. Oliveira ES. Epivir: lamivudina [bula de remédio]. Rio de Janeiro: GlaxoSmithKline; 2013.

148. Tesser A. Viread: tenofovir [bula de remédio]. São Paulo: Gilead Sciences; 2009.

149. Oliveira M. Hepsera: adefovir [bula de remédio]. Rio de Janeiro: GlaxoSmithKline; 2007.

150. Souza TA. Baraclude: entecavir [bula de remédio]. São Paulo: BristolMyers Squibb Company; 2011. 